\title{
Hydrogen bonding to hexafluoroisopropanol controls the oxidative strength of hypervalent iodine reagents
}

Ignacio Colomer, ${ }^{\dagger}$ Christopher Batchelor-McAuley, ${ }^{\ddagger}$ Barbara Odell, ${ }^{\dagger}$ Timothy J. Donohoe $*{ }^{\dagger}$ and Richard G. Compton**‡

$†$ Department of Chemistry, Chemistry Research Laboratory, University of Oxford, Mansfield Road, Oxford OX1 3TA, United Kingdom

† Department of Chemistry, Physical and Theoretical Chemistry Laboratory, University of Oxford, South Parks Road, Oxford OX1 3QZ, United Kingdom

E-mail: timothy.donohoe@chem.ox.ac.uk

E-mail: richard.compton@chem.ox.ac.uk 
1. General experimental details $\quad$ S4

1.1. General procedure for the synthesis of alkenes $\quad$ S4

2. Cyclic voltammetry $\quad$ S5

2.1. trans-Anethole oxidation in ACN S6

2.2. trans-Anethole oxidation in HFIP $\quad$ S7

2.3. PIDA reduction in $\mathrm{ACN} \quad \mathrm{S8}$

2.4. PIDA reduction in HFIP $\quad$ S9

2.5. Ferrocene reference potential in HFIP $\quad$ S10

2.6. Voltammetric characterisation of the alkenes in both $\mathrm{ACN}$ and HFIP S10

2.7. Voltammetric characterisation of iodine(III) reagents PIFA and HTIB in both ACN and HFIP $\quad \mathbf{S 1 4}$

3. Mass Spectrometry experimental details $\quad$ S15

3.1. HRMS of PIDA $\quad$ S16

3.2. HRMS of HFIP $\quad$ S17

$\begin{array}{ll}\text { 3.3. HRMS of a 1:1 mixture of HFIP:PIDA } & \text { S17 }\end{array}$

$\begin{array}{lr}\text { 4. NMR experimental details } & \text { S18 }\end{array}$

4.1. ${ }^{1} \mathrm{H}$ and ${ }^{13} \mathrm{C}$ NMR of PIDA $\quad$ S19

4.2. ${ }^{1} \mathrm{H}$ and ${ }^{13} \mathrm{C}$ NMR of HFIP

4.3. ${ }^{1} \mathrm{H},{ }^{13} \mathrm{C}$ NMR, NOESY-2D and nOe of a 1:1 mixture of HFIP:PIDA S22

4.4. Comparison table of ${ }^{1} \mathrm{H}$ and ${ }^{13} \mathrm{C}$ NMR for PIDA

4.5. ${ }^{1} \mathrm{H}$ and ${ }^{13} \mathrm{C}$ NMR of PIFA $\quad$ S25

4.6. ${ }^{1} \mathrm{H},{ }^{13} \mathrm{C}$ NMR, ${ }^{19} \mathrm{~F}$ and HOESY of a 1:1 mixture of HFIP:PIFA S26

4.7. ${ }^{1} \mathrm{H}$ and ${ }^{13} \mathrm{C}$ NMR of HTIB $\quad$ S28

4.8. ${ }^{1} \mathrm{H}$ and ${ }^{13} \mathrm{C}$ NMR of a 1:1 mixture of HFIP:HTIB S29

4.9. ${ }^{1} \mathrm{H}$-DOSY and Diffusion coefficient of PIDA S30

4.10. ${ }^{1} \mathrm{H}$-DOSY and Diffusion coefficient of HFIP S31

4.11. ${ }^{1}$ H-DOSY and Diffusion coefficient of a 1:1 mixture of HFIP:PIDA S32

4.12. ${ }^{1} \mathrm{H}-\mathrm{DOSY}$ and Diffusion coefficient of $i$-PrOH $\quad S 33$

4.13. ${ }^{1} \mathrm{H}-\mathrm{DOSY}$ and Diffusion coefficient of a 1:1 mixture of $i$-PrOH:PIDA S34

4.14. Table 1. Diffusion coefficients of PIDA (2), $i$-PrOH and the 1:1 mixture of PIDA: $i$-PrOH (6) in $\mathrm{CDCl}_{3}$ as measured via DOSY $\quad \mathrm{S34}$

4.15. ${ }^{1}$ H-DOSY and Diffusion coefficient of PIFA S35

4.16. ${ }^{1}$ H-DOSY and Diffusion coefficient of a 1:1 mixture of HFIP:PIFA S36 
4.17. Table 2. Diffusion coefficients of PIFA, HFIP and the 1:1 mixture of PIFA:HFIP in $\mathrm{CDCl}_{3}$ as measured via DOSY S36

4.18. ${ }^{1} \mathrm{H}$-DOSY and Diffusion coefficient of HTIB S37

4.19. ${ }^{1} \mathrm{H}$-DOSY and Diffusion coefficient of a 1:1 mixture of HFIP:HTIB S38

4.20. Table 3. Diffusion coefficients of HTIB, HFIP and the 1:1 mixture of HTIB:HFIP in $\mathrm{CDCl}_{3}$ as measured via DOSY S38

5. References $\quad$ S39 


\section{General experimental details}

PIDA, PIFA, HTIB and DMP obtained from Fluorochem were used directly as supplied. HFIP obtained from Flurochem was distilled over activated 4A MS prior to use. $\mathrm{CDCl}_{3}$ obtained from Sigma-Aldrich was treated with $\mathrm{K}_{2} \mathrm{CO}_{3}$ to neutralize acidic traces, and was stored over activated 4A MS. trans-Anethole (1) and trans- $\beta$-methylstyrene (14) obtained from Sigma-Aldrich, and $E$-asarone (6) obtained from TCI were used directly as supplied.

All voltammetric measurements were recorded using an Autolab PGSTAT30 computercontrolled potentiostat (Metrohm, Utrecht, The Netherlands). Experiments were performed in a Faraday cage using a three-electrode set-up. A platinum mesh was used as the counter electrode and either a glassy carbon macroelectrode (BASi, West Lafayette, IN, USA radius $=1.5 \mathrm{~mm}$ ) or a carbon fibre microelectrode (ALS electrode supplied by IJ Cambria Scientific, UK, radius = 3.5 $\mu \mathrm{m})$ were used as the working electrode. The reference electrode was either a silver wire (Goodfellow, UK) acting as a pseudo reference or alternatively for some studies in HFIP a Ag/ $\mathrm{Ag}^{+}$ reference electrode was fabricated and used. The $\mathrm{Ag} / \mathrm{Ag}^{+}$reference electrode consisted of a pipette with a glass frit filled with $10 \mathrm{mM}$ silver hexfluorophosphate and $0.1 \mathrm{MBu}_{4} \mathrm{NPF}_{6}$ solution in $\mathrm{HFIP}$ into which a clean silver wire was submerged. Due to the sensitivity of $\mathrm{Ag}^{+}$salts to light the reference electrode was remade daily. Renewal of the working electrode surface was achieved by polishing with alumina slurries in the size sequence $1.0 \mu \mathrm{m}, 0.3 \mu \mathrm{m}$ and $0.05 \mu \mathrm{m}$, (Buehler Ltd, USA). The working electrode was dried under a flow of nitrogen prior to use in the electrochemical experiments. Finally the electrochemical cell was thermostated using a water bath to $25.0 \pm 0.3^{\circ} \mathrm{C}$.

\subsection{General procedure for the synthesis of $E$-styrenes.}

Alkenes 7, 8, 9, 10, 11, 12, 13 and 15 were previously synthesized in our lab and complete experimental data, including fully characterization have already been reported. ${ }^{1}$

A solution of triphenylphosphonium halide (1.2 equiv.) in dry solvent $(5.0 \mathrm{~mL} / \mathrm{mmol}$ of THF or $\mathrm{Et}_{2} \mathrm{O}$ ) was placed in a flame-dried round-bottomed flask. The solution was cooled to $0{ }^{\circ} \mathrm{C}$, and the base (1.1 equiv. of $t$-BuOK or 1.2 equiv. of $n$-BuLi or 1.2 equiv. of $\mathrm{NaH}$ ) was added in one portion. After stirring at $0{ }^{\circ} \mathrm{C}$ for $30 \mathrm{~min}$, the aldehyde (1.0 equiv.) was added. The reaction mixture was gradually warmed to room temperature. After $12 \mathrm{~h}$, the reaction was quenched by slow addition of saturated $\mathrm{NH}_{4} \mathrm{Cl}$. The phases were separated, and the aqueous phase was extracted twice with $\mathrm{Et}_{2} \mathrm{O}$. The combined organic layers were washed with brine and dried over $\mathrm{Na}_{2} \mathrm{SO}_{4}$. The solvent was 
evaporated under reduced pressure to give the corresponding styrene, that was purified by chromatography on silica gel using the appropriate mixture of eluents.

For those examples where the styrene was isolated as a $Z: E$ mixture of isomers, isomerization of $Z$ isomer to $E$ was performed as follows.

To a solution of the $Z: E$ mixture of styrene in $\mathrm{CH}_{2} \mathrm{Cl}_{2} \quad(2.0 \mathrm{~mL} / \mathrm{mmol})$ bis(acetonitrile)palladium (II) chloride $(10-60 \mathrm{~mol} \%)$ was added at room temperature. The reaction was monitored by ${ }^{1} \mathrm{H}$ NMR until completion, diluted with diethyl ether and filtered through a short pad of Florisil ${ }^{\mathrm{TM}}$, eluting with diethyl ether. The solvent was evaporated under reduced pressure to give the corresponding $E$-styrene, that was purified by chromatography on silica gel using the appropriate mixture of eluents. ${ }^{2}$

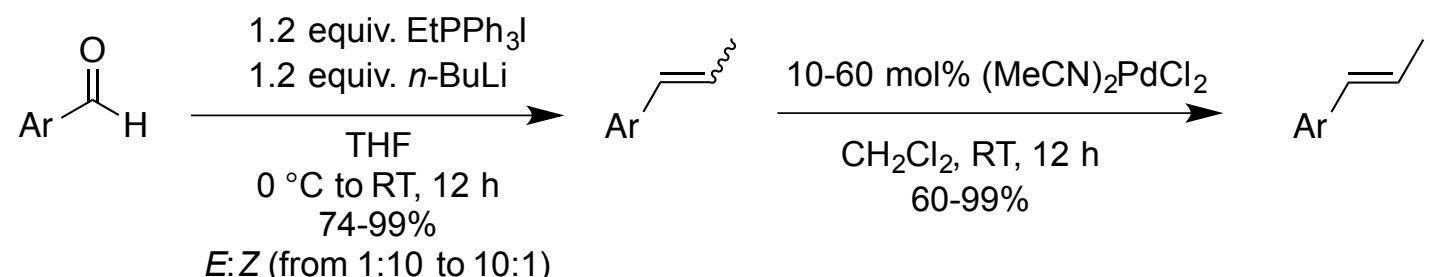

\section{Cyclic voltammetry details}

Voltammetry is a dynamic technique sensitive to both the interfacial electron transfer kinetics and also the prevailing mass-transport to and from the electrochemical interface. Consequently, for a diffusional redox process determining the number of electrons transferred during a voltammetric process requires knowledge of the diffusion coefficient of the reactant. The peak-height $\left(\mathrm{I}_{\mathrm{p}}\right)$ of the voltammetric response of an irreversible multi-electron process at a macroelectrode is parametrically given by the irreversible form of the Randles-Sevcik; ${ }^{3}$

$$
I_{p}=2.99 \times 10^{5} n\left(n^{\prime}+\alpha_{r d s}\right)^{0.5} D^{0.5} A C v^{0.5}
$$

where $\mathrm{n}$ is the total number of electrons transferred, $\mathrm{n}$ ' is the number of electrons transferred prior to the rate determining step, $\alpha_{r d s}$ is the transfer coefficient ${ }^{4}$ associated with the rate determining electron transfer step, D is the diffusion coefficient, A is the geometric area of the electrode, $\mathrm{C}$ is the solution phase concentration of the redox species and $v$ is the voltammetric scan rate. The term $\left(n^{\prime}+\alpha_{r d s}\right)$ can be experimentally measured via a Tafel plot (lnlil vs E). Consequently, experimental use of this equation will yield a value for the product $n D^{0.5}$.

One route by which the individual values of $\mathrm{n}$ and $\mathrm{D}$ can be resolved is by changing the masstransport regime. In this work the steady-state response at an ultramicroelectrode is used to enable $\mathrm{n}$ and $\mathrm{D}$ to be resolved. At high overpotentials the magnitude of faradaic current for the oxidation or 
reduction of a solution phase species is insensitive to the kinetics of the electron transfer process and the steady-state response is given by: ${ }^{3}$

$I_{s S}=4 n F D C r$

where $\mathrm{n}$ is the total number of electrons transferred, $\mathrm{F}$ is the Faraday constant $\left(96485 \mathrm{C} \mathrm{mol}^{-1}\right), \mathrm{D}$ is the diffusion coefficient, $\mathrm{C}$ is the solution phase concentration of the redox species and $\mathrm{r}$ is the radius of the microdisc electrode. Hence, experimental determination of the steady-state Faradaic current yields a value for the product $\mathrm{nD}$. Due to the differing sensitives to the magnitude of the diffusion coefficient, and by assumption that the value of $\mathrm{n}$ is the same under both mass-transport regimes (and is an integer value representing the stoichiometric number of electrons transferred), then the values of $\mathrm{n}$ and $\mathrm{D}$ are experimentally accessible.

In the following the voltammetric experimental details for the oxidation of trans-anethole in both HFIP and ACN at a macro- and micro-disc electrode is reported enabling from in accordance with the above discussion for $\mathrm{n}$ and $\mathrm{D}$ to be determined. The voltammetry for the oxidation of transanethole in ACN and HFIP in the presence of ferrocene is also shown so that the trans-anethole oxidative peak potential may be measured.

\section{1. trans-Anethole Oxidation in $\mathrm{ACN}$}

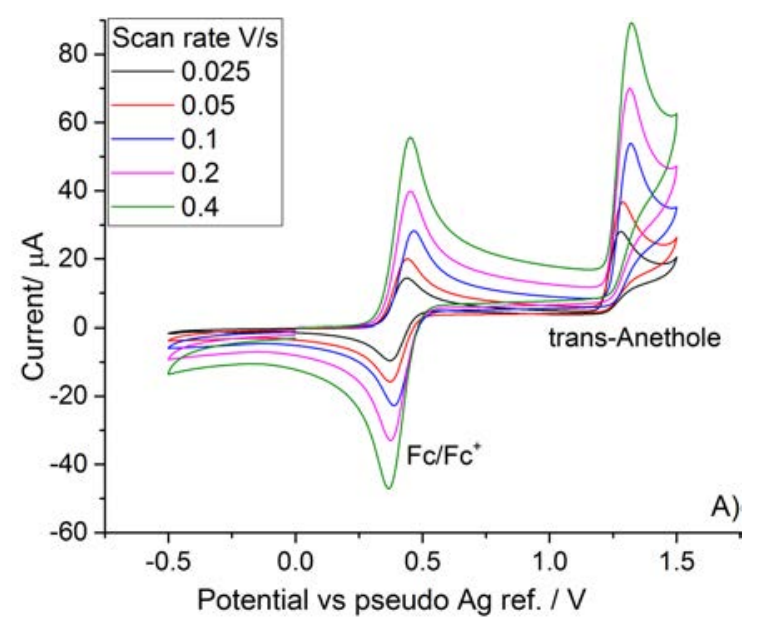

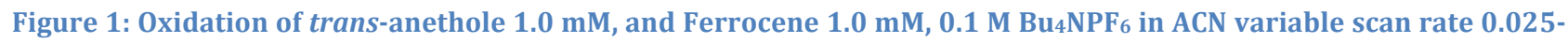
$0.4 \mathrm{~V} / \mathrm{s}$ glassy $\mathrm{C}$ electrode radius $=1.5 \mathrm{~mm}$.

The oxidation of trans-anethole $(1 \mathrm{mM})$ was studied in the presence of $1 \mathrm{mM}$ ferrocene in ACN as a function of scan rate. From the literature the oxidation reaction is known to proceed via a one electron oxidation of the trans-anethole, where the species has a reported diffusion coefficient of $2 \times 10^{-9} \mathrm{~m}^{2} \mathrm{~s}^{-1}$. 


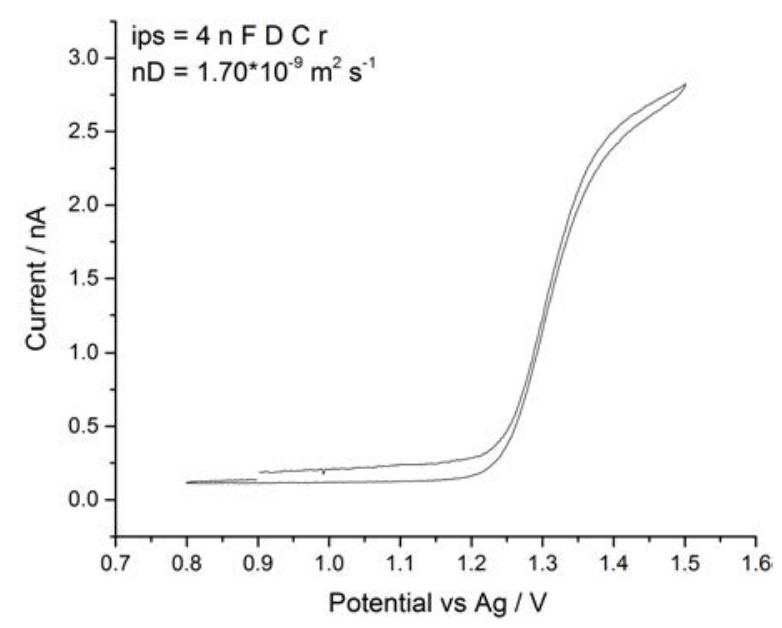

Figure 2: The oxidation of $1 \mathrm{mM}$ trans-anethole in ACN at a carbon fibre microelectrode.

From Tafel analysis the first electron oxidation of the trans-anethole was found to be near reversible with the transfer coefficient measured as $\sim 1$. Given the reported diffusion coefficient of trans-anethole to be $2 \times 10^{-9} \mathrm{~m}^{2} \mathrm{~s}^{-1}$ the steady-state response confirms that the oxidative processes involves the transfer of one-electron.

\section{2. trans-Anethole Oxidation in HFIP}

Figure $1 \mathrm{~A}$ ) of the main text depicts the voltammetric response of trans-anethole at a macro glassy carbon electrode. The figure below depicts the variation of the peak height as a function of scan rate. Tafel analysis yielded a transfer coefficient for the oxidation of trans-anethole on HFIP to be 0.723 , indicating that the electron transfer is likely quasi-reversible.

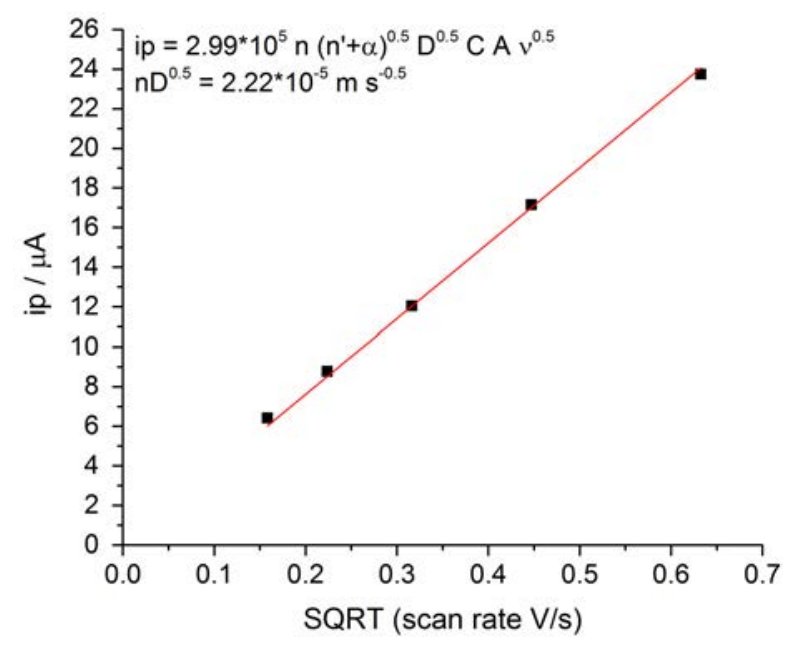

Figure 3: Variation of the measured peak height as a function of scan rate for the oxidation of trans-anethole $1.0 \mathrm{mM}$, $0.1 \mathrm{M} \mathrm{Bu}_{4} \mathrm{NPF}_{6}$ in HFIP at a glassy $\mathrm{C}$ electrode radius $=\mathbf{1 . 5} \mathrm{mm}$. Line of best fit shown in red and the analysis of the gradient is undertaken using the irreversible form of the Randles-Ševčík equation. 
The oxidation of the trans-anethole was also recorded at a carbon fibre microelectrode from comparison of the currents measured under the differing mass-transport regimes it was concluded that the oxidative process involves the transfer of one electron.

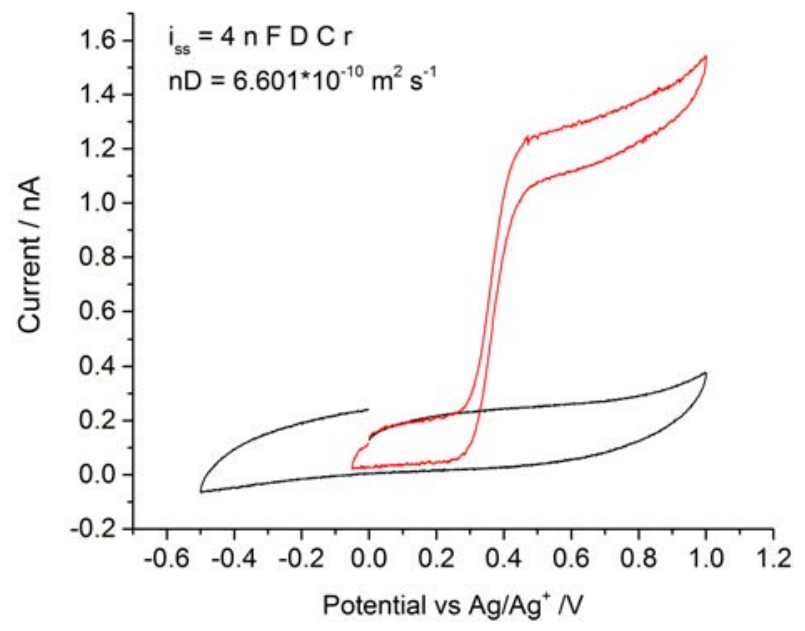

Figure 4: Oxidation of trans-anethole $1.2 \mathrm{mM}, 0.1 \mathrm{M} \mathrm{Bu}_{4} \mathrm{NPF}_{6}$ in $\mathrm{HFIP}$ at $0.025 \mathrm{~V} / \mathrm{s}$ using a micro carbon electrode radius $=3.5 \mu \mathrm{m}$.

\subsection{PIDA reduction in $\mathrm{ACN}$}
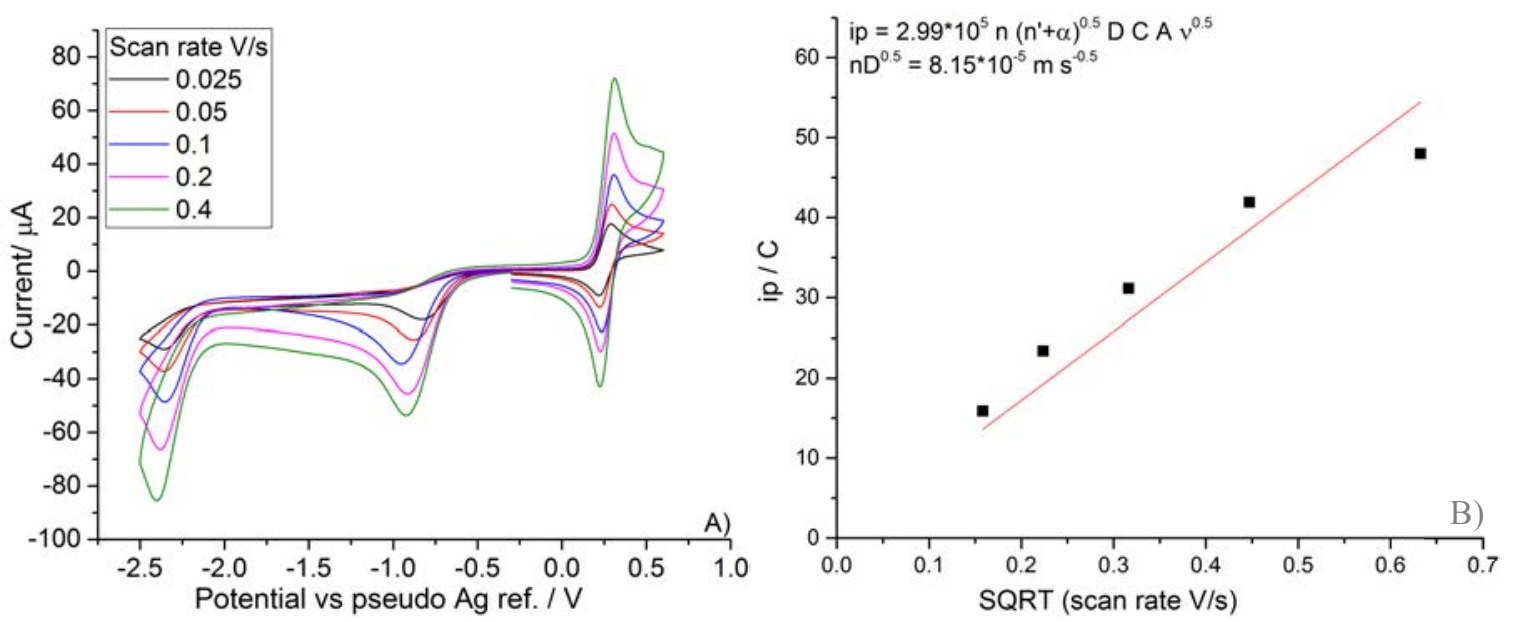

Figure 5: A) Reduction of PIDA 1.0 mM, and Ferrocene $1.0 \mathrm{mM}, 0.1 \mathrm{M} \mathrm{Bu}_{4} \mathrm{NPF}_{6}$ in ACN variable scan rate 0.025-0.4 V/s at a glassy $\mathrm{C}$ electrode radius $=\mathbf{1 . 5} \mathrm{mm}$. B) Variation of the measured peak height as a function of scan rate and the analysis of the gradient using the irreversible form of the Randles-Ševčík

From Tafel analysis the transfer coefficient for the reduction was determined to be 0.25 . 


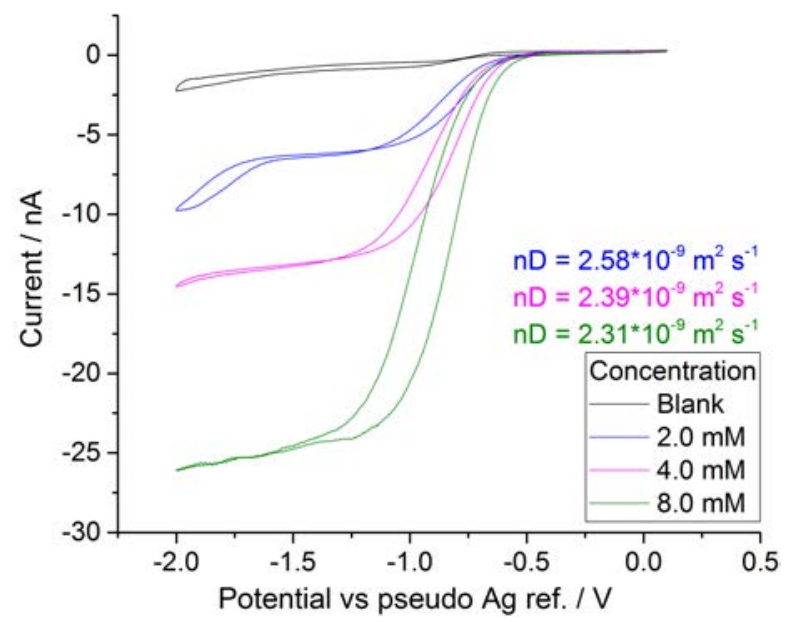

Figure 6: Reduction of PIDA $1 \mathrm{mM}, 0.1 \mathrm{M} \mathrm{Bu} 4 \mathrm{NPF}_{6}$ in ACN at $0.025 \mathrm{~V} / \mathrm{s}$ using a micro carbon electrode radius $=3.5 \mu \mathrm{m}$

By comparison of the results from the macro and micro electrode data it was determined that over the voltammetric timescale the total number of electrons transferred in the first reduction wave is likely to be equal to three.

\subsection{PIDA reduction in HFIP}

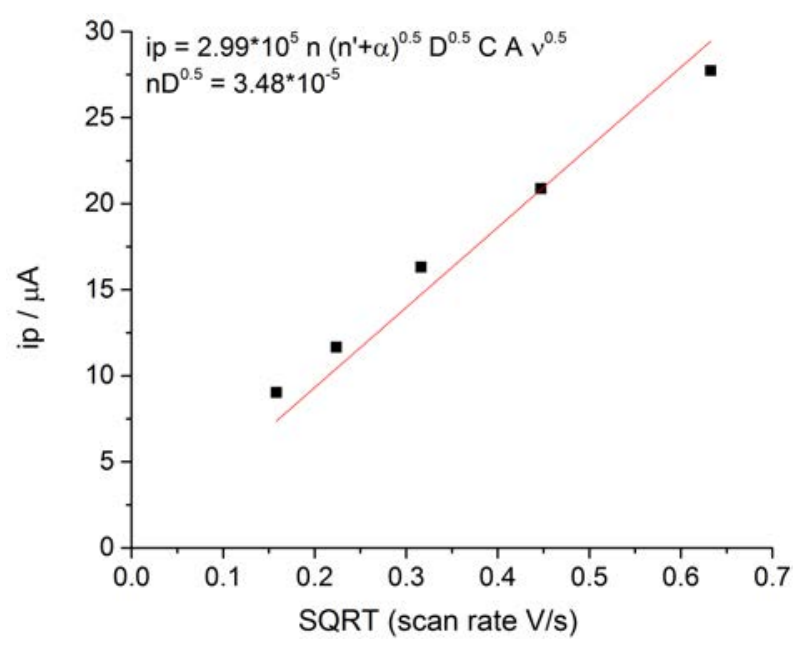

Figure 7: Variation of the measured peak height as a function of scan rate for the reduction of PIDA $1.0 \mathrm{mM}, 0.1 \mathrm{M}$ $\mathrm{Bu}_{4} \mathrm{NPF}_{6}$ in HFIP at a glassy $\mathrm{C}$ electrode radius $=1.5 \mathrm{~mm}$. Line of best fit shown in red and the analysis of the gradient is undertaken using the irreversible form of the Randles-Ševčík equation.

Tafel analysis indicted the transfer coefficient to be 0.4 . 


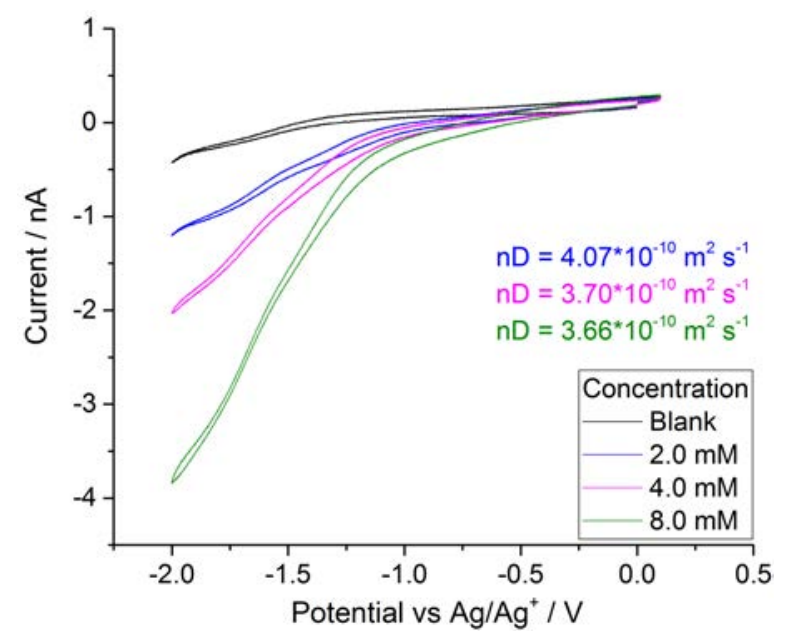

Figure 8: Reduction of PIDA $1 \mathrm{mM}, 0.1 \mathrm{M} \mathrm{Bu}_{4} \mathrm{NPF}_{6}$ in HFIP at $0.025 \mathrm{~V} / \mathrm{s}$ using a micro carbon electrode radius $=3.5$ $\mu \mathrm{m}$

Although the reduction wave for PIDA in HFIP recoded at the microelectrode does not show a clear steady-state region the resulting currents are not inconsistent with the conclusion that a total of three electrons are being transferred to the PIDA over the voltammetric timescale.

\subsection{Ferrocene oxidation measured against $\mathrm{Ag} / \mathrm{Ag}+$ reference}

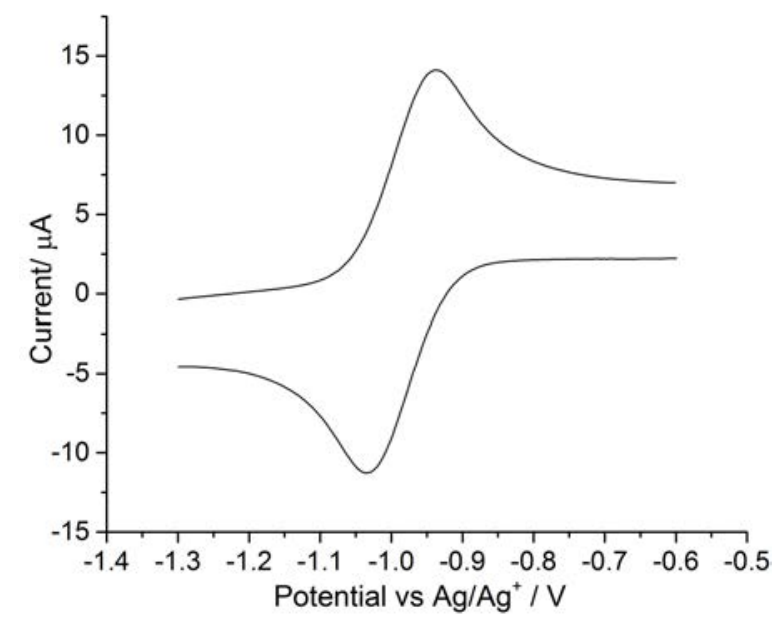

Figure 9: The redox response of $1 \mathrm{mM}$ ferrocene in a $0.1 \mathrm{M} \mathrm{Bu}_{4} \mathrm{NPF}_{6} \mathrm{HFIP}$ at a glassy carbon macro-electrode (radius $=1.5 \mathrm{~mm}$ ) solution as measured against the $\mathrm{Ag} / \mathrm{Ag}^{+}$reference electrode at a scan rate of $0.1 \mathrm{~V} \mathrm{~s}-1$

\subsection{Voltammetric characterisation of the alkenes in both ACN and HFIP}

All voltamemtric results have been recorded at a glassy carbon macroelectrode (radius = $1.5 \mathrm{~mm}$ ). Scan rates used range from $0.025-0.4 \mathrm{~V} \mathrm{~s}^{-1}$. Electrolyte $0.1 \mathrm{M} \mathrm{Bu}_{4} \mathrm{NPF}_{6}$.

a) Measured in ACN b) Measured in HFIP 

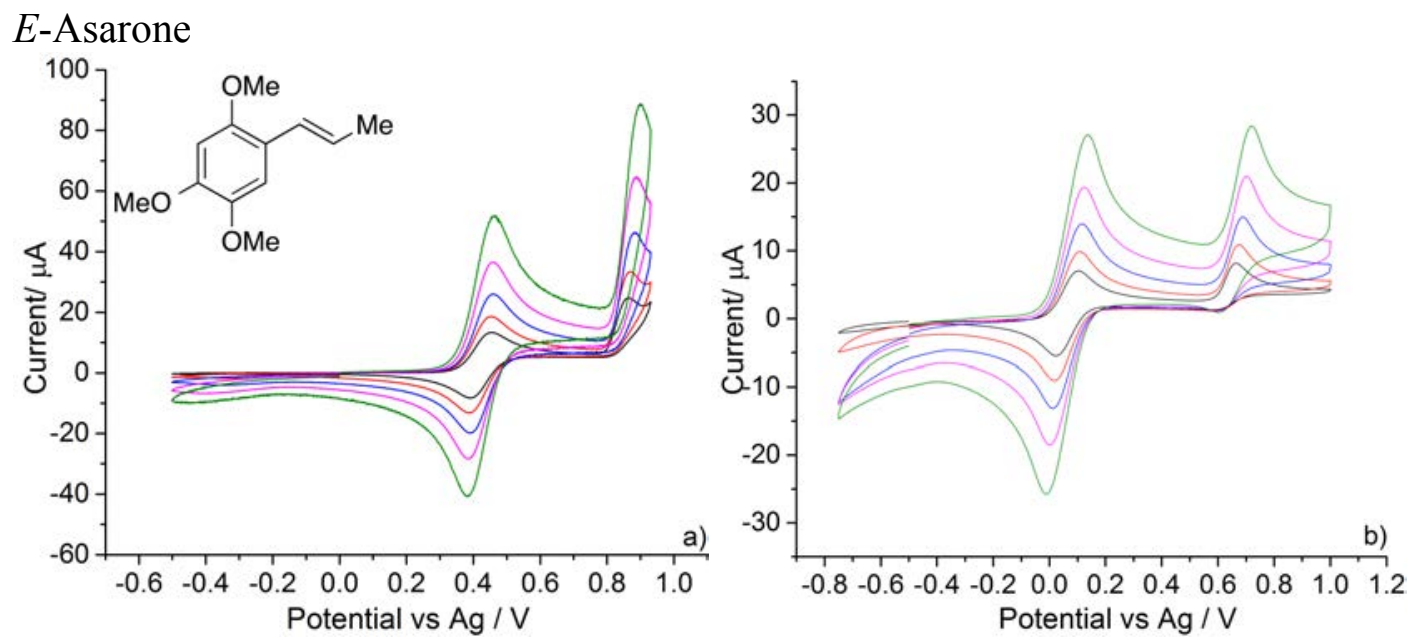

(E)-1-(2-Bromo-4-methoxyphenyl)prop-1-ene
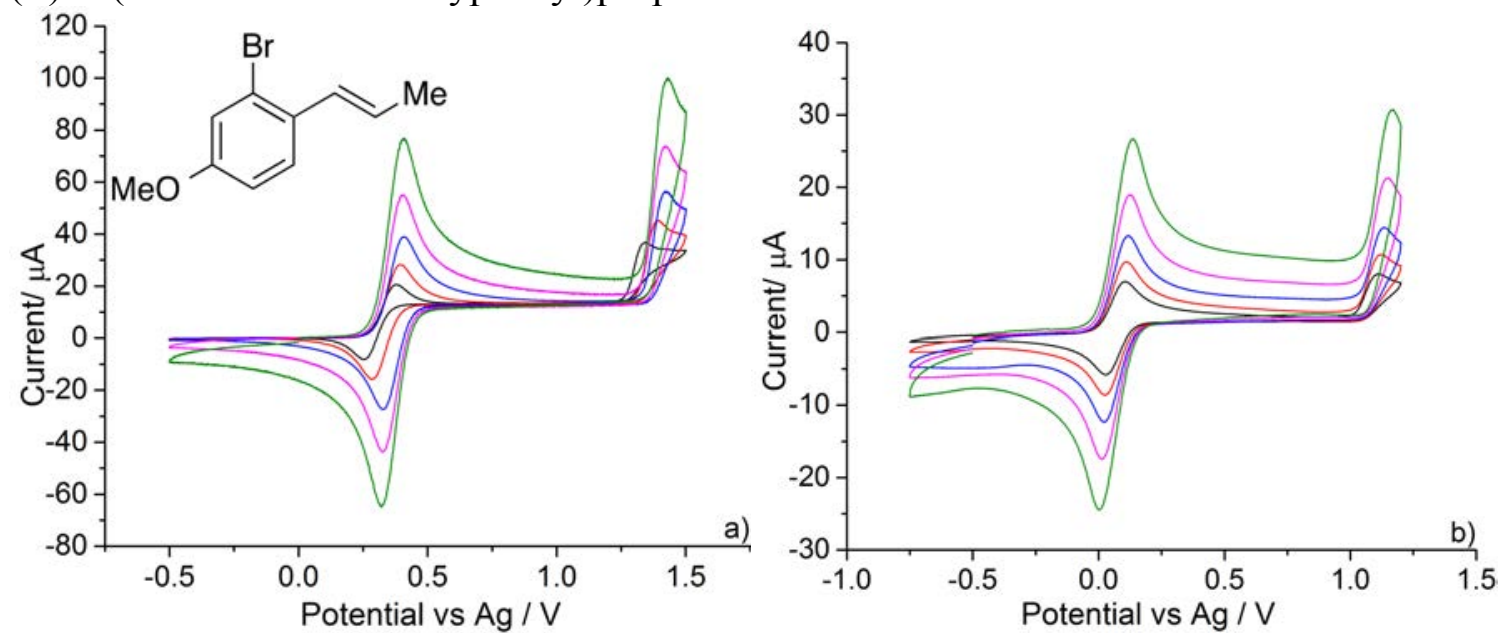

(E)-1-(Naphthalen-1-yl)prop-1-ene
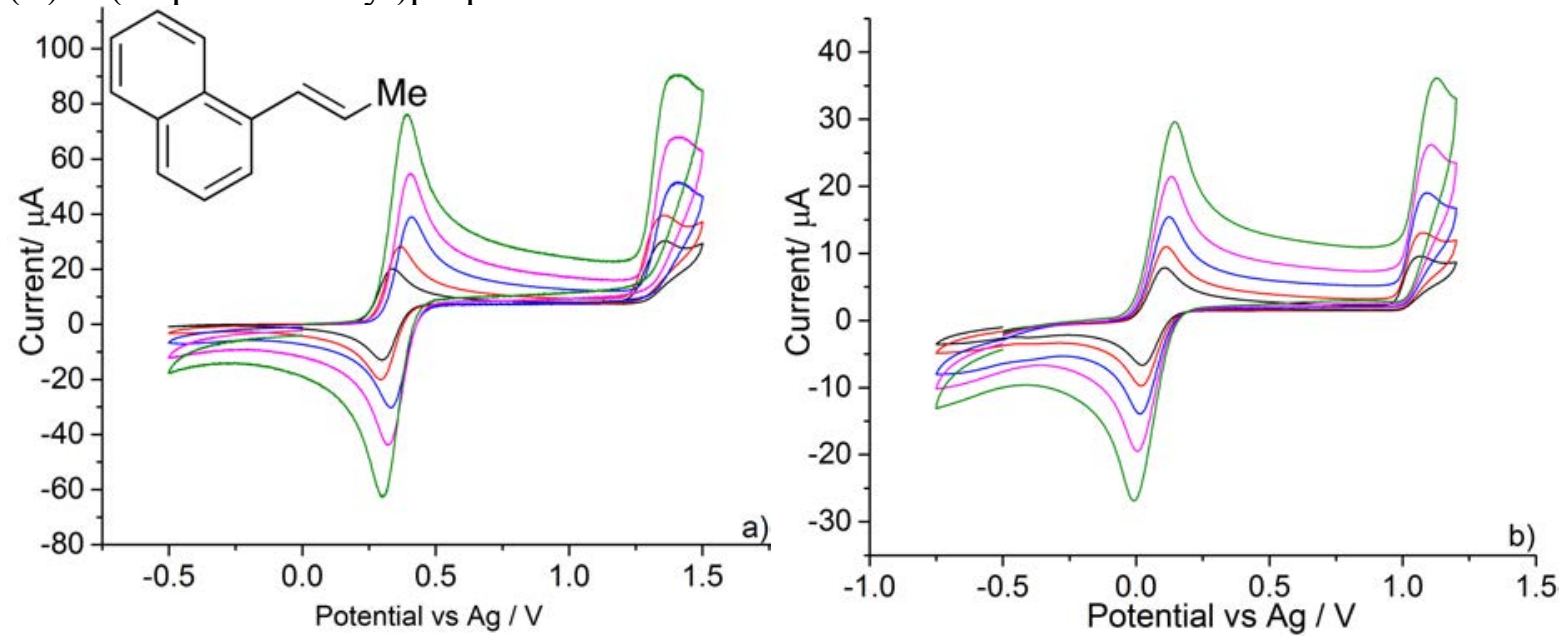
(E)-1-(3,4-Dimethylphenyl)prop-1-ene
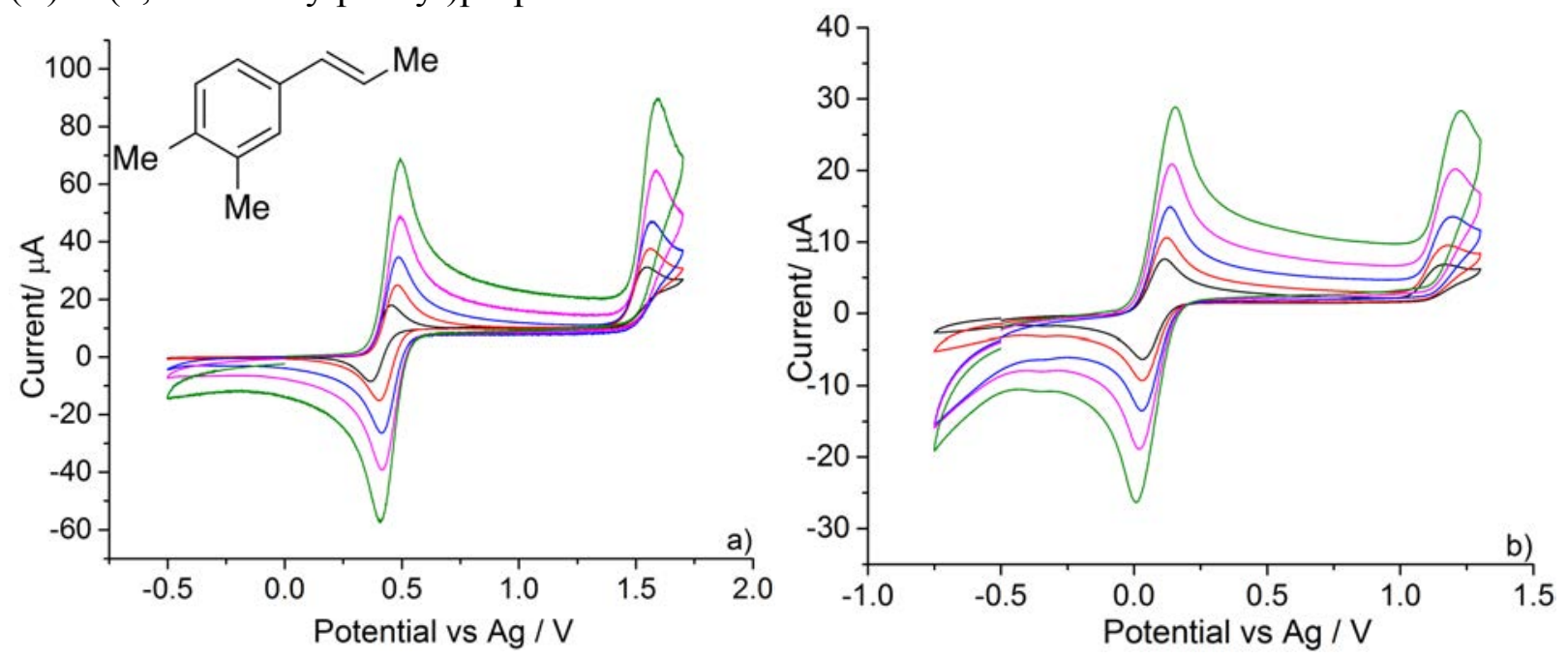

trans- $\beta$-Methylstyrene
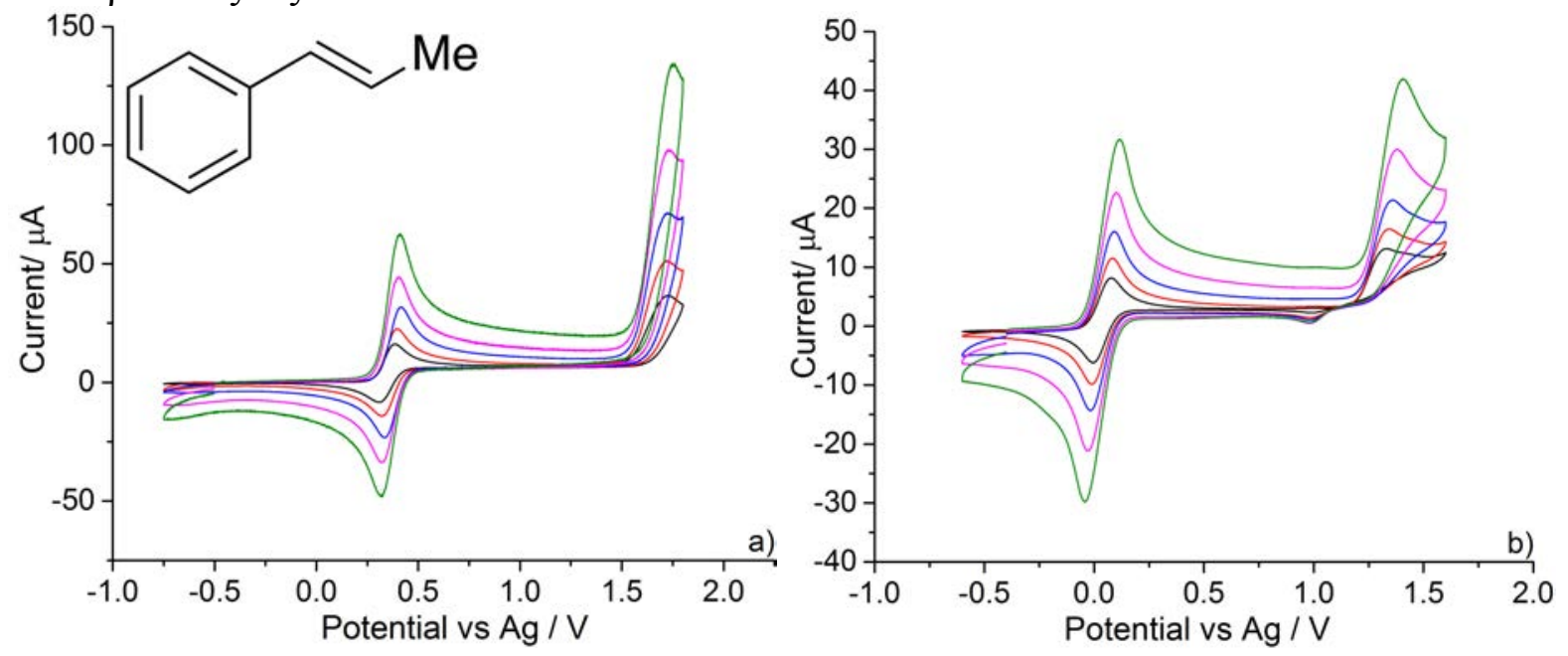

(E)-1-(4-Bromophenyl)prop-1-ene
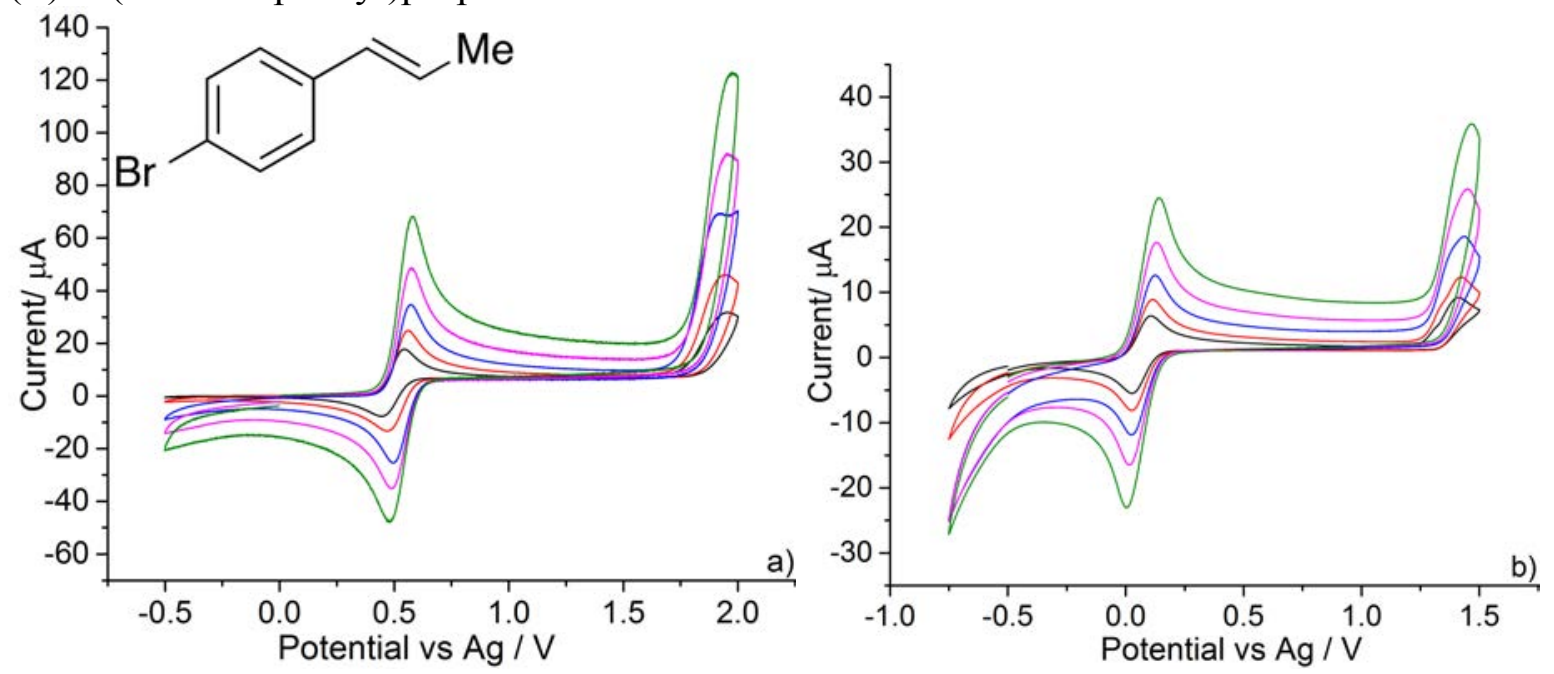
(E)-1-(2-Fluoro-4-methoxyphenyl)prop-1-ene
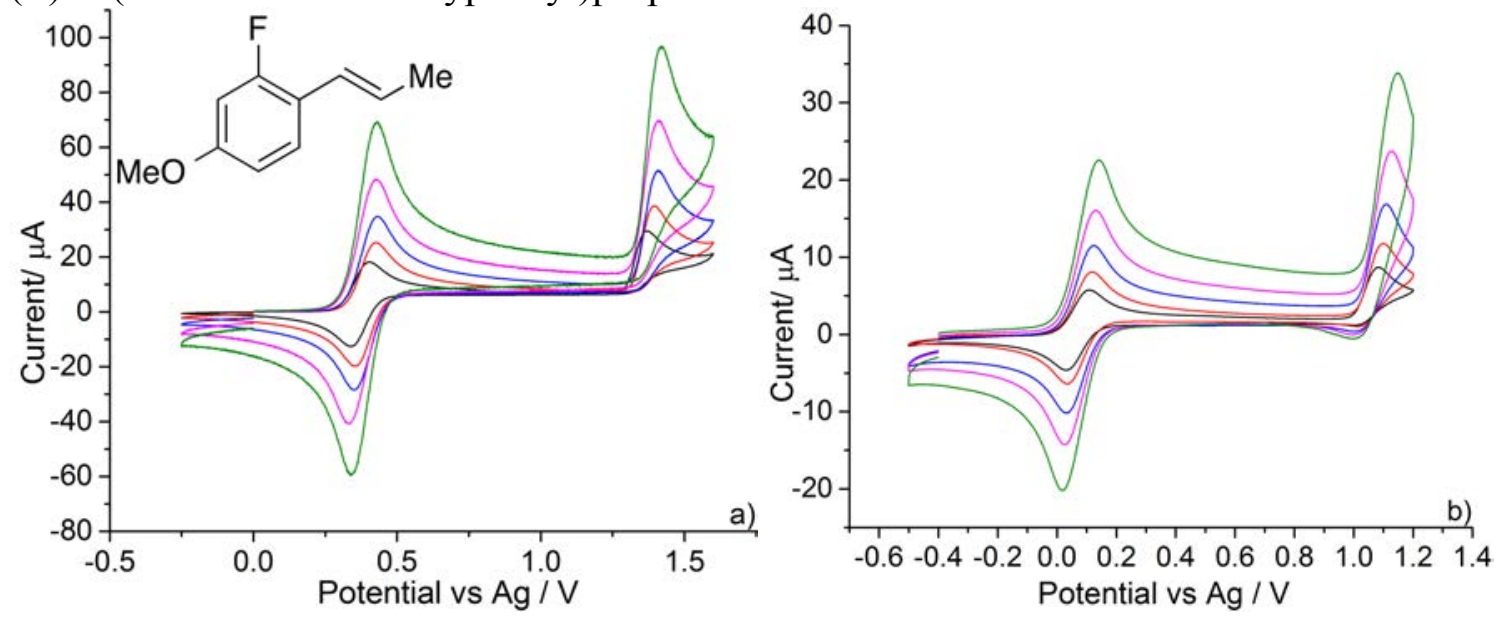

(E)-1-(4-Methoxy-2-methylphenyl)prop-1-ene
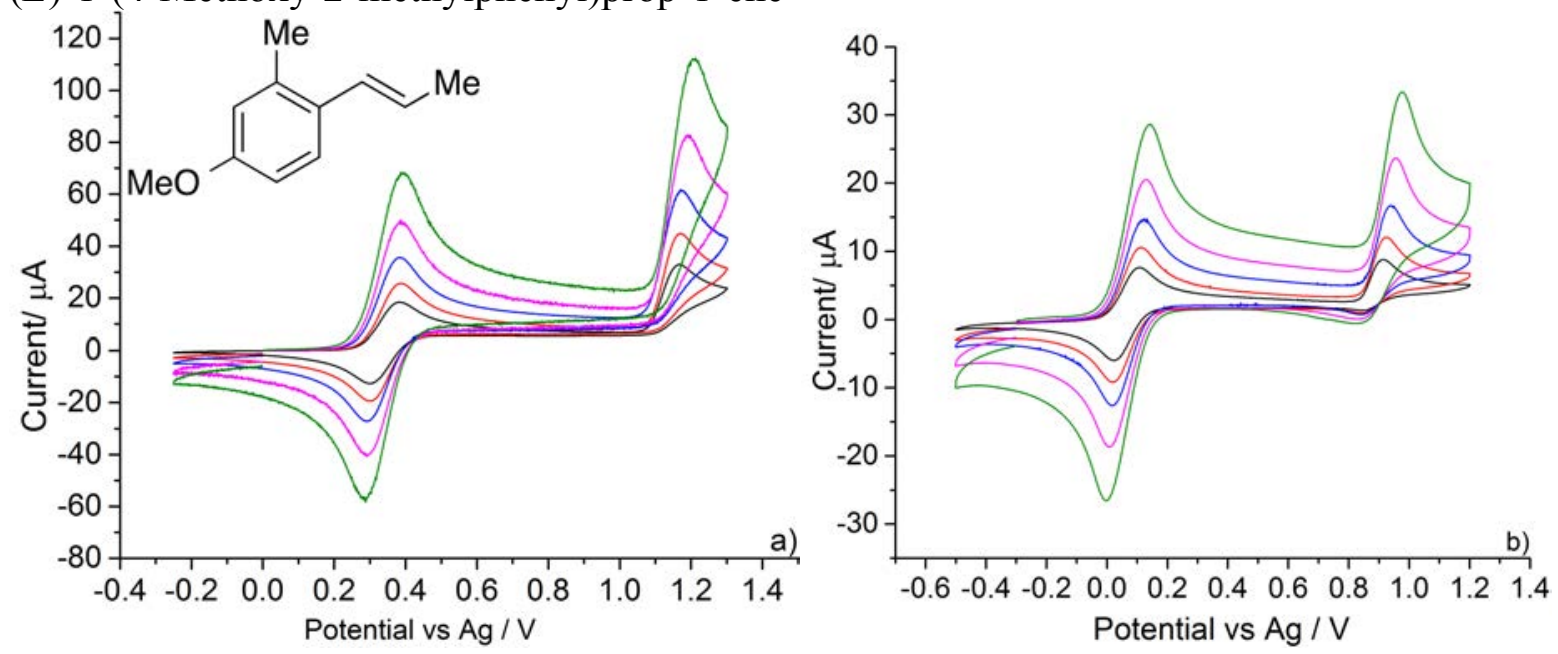

(E)-1-(2,4-Dimethoxyphenyl)prop-1-ene
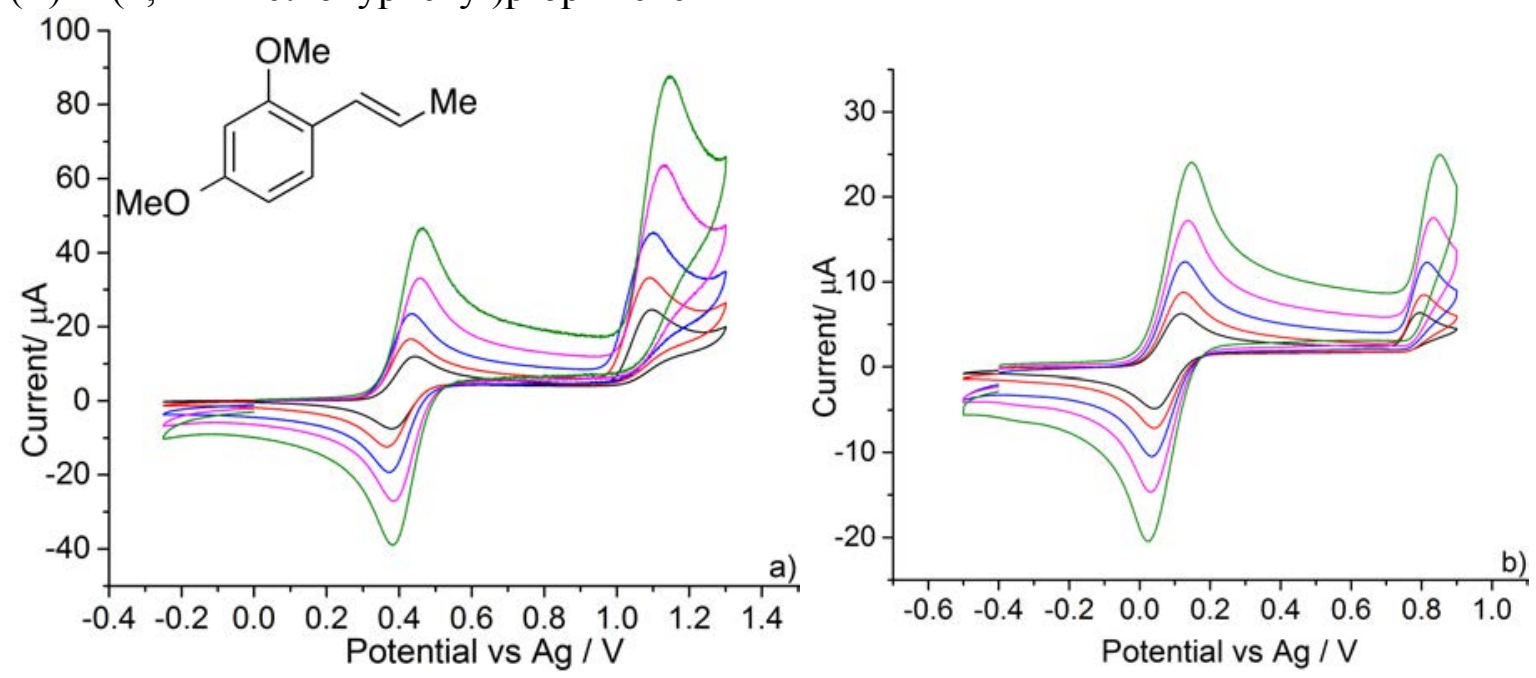
(E)-1-(2-Methoxyphenyl)prop-1-ene
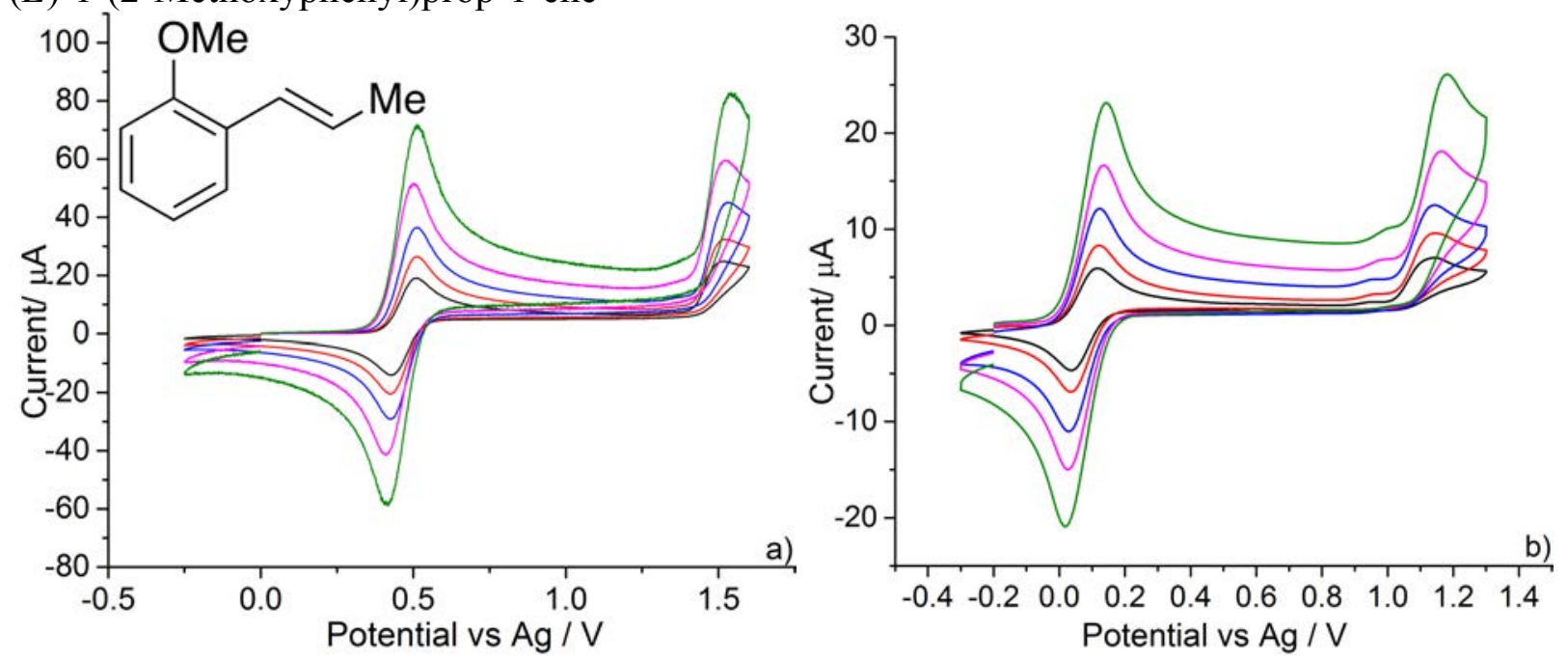

\subsection{Voltammetric characterisation of iodine (III) reagents PIFA and HTIB.}

All voltammetric results have been recorded at a glassy carbon macroelectrode (radius $=1.5 \mathrm{~mm}$ ). Scan rates used range from $0.025-0.4 \mathrm{~V} \mathrm{~s}-1$. Electrolyte $0.1 \mathrm{M} \mathrm{Bu}_{4} \mathrm{NPF}_{6}$.

a) Measured in ACN b) Measured in HFIP.

Due to the reactivity of PIFA and HTIB in ACN, the voltammograms of these species had to be measured using an $\mathrm{Ag} / \mathrm{Ag}+$ reference electrode. The potential of the $\mathrm{Fc} / \mathrm{Fc}+$ redox couple againset the $\mathrm{Ag} / \mathrm{Ag}+$ reference electrode was found to be $+0.086 \mathrm{~V}$, the corresponding voltammetric measurement showing this is depicted below. Note as shown above in the SI section 2.5 , the $\mathrm{Fc} / \mathrm{Fc}^{+}$ redox couple occurs at $-0.988 \mathrm{~V}$ vs $\mathrm{Ag} / \mathrm{Ag}^{+}$in HFIP.

Ferrocene voltammetry in ACN measured against an $\mathrm{Ag} / \mathrm{Ag}+$ reference electrode.

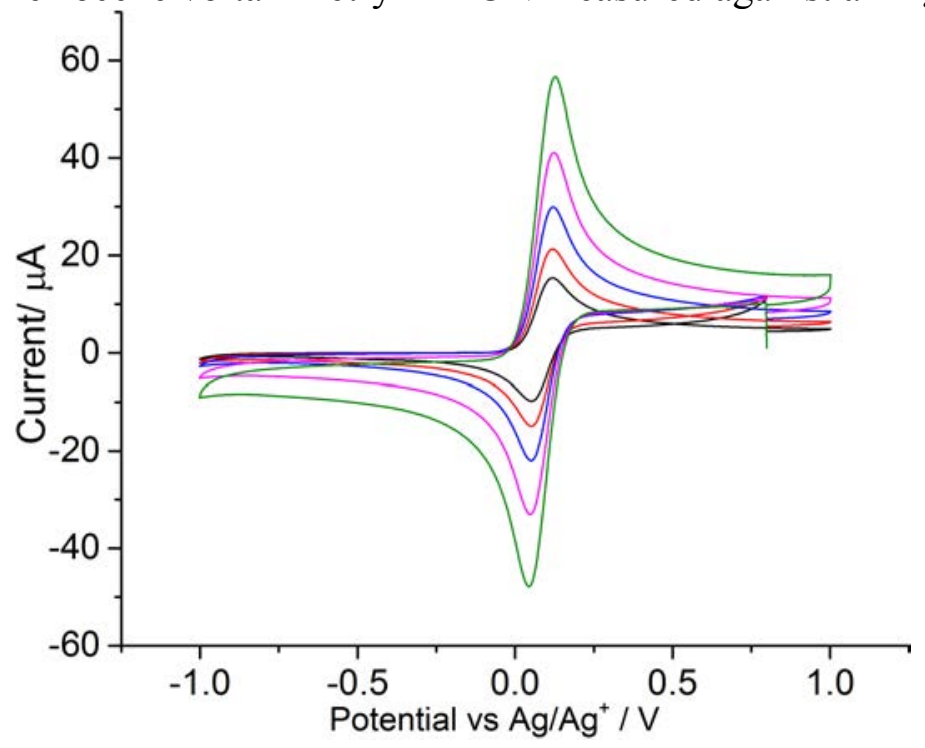



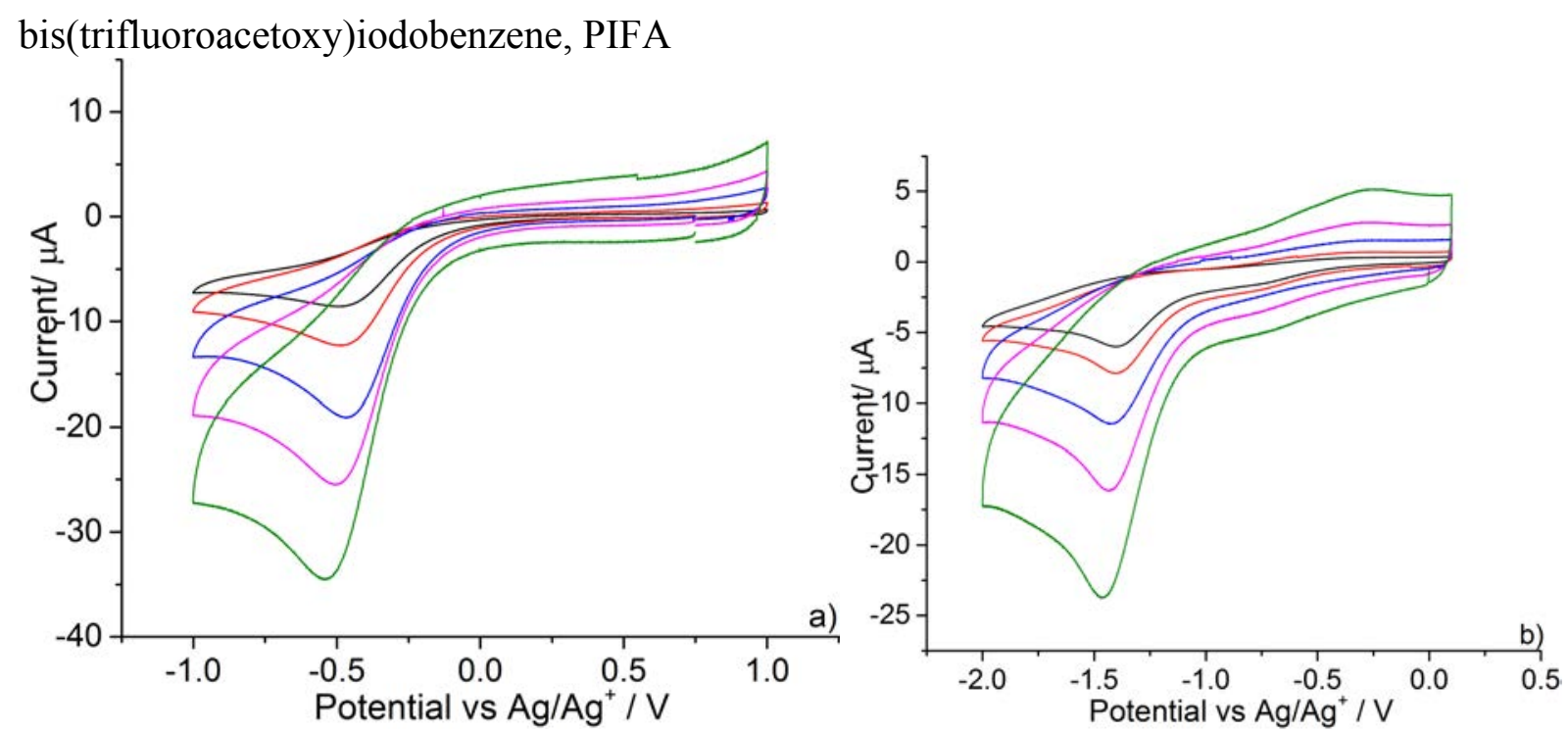

Koser's Reagent

Hydroxy(tosyloxy)iodobenzene (HTIB)
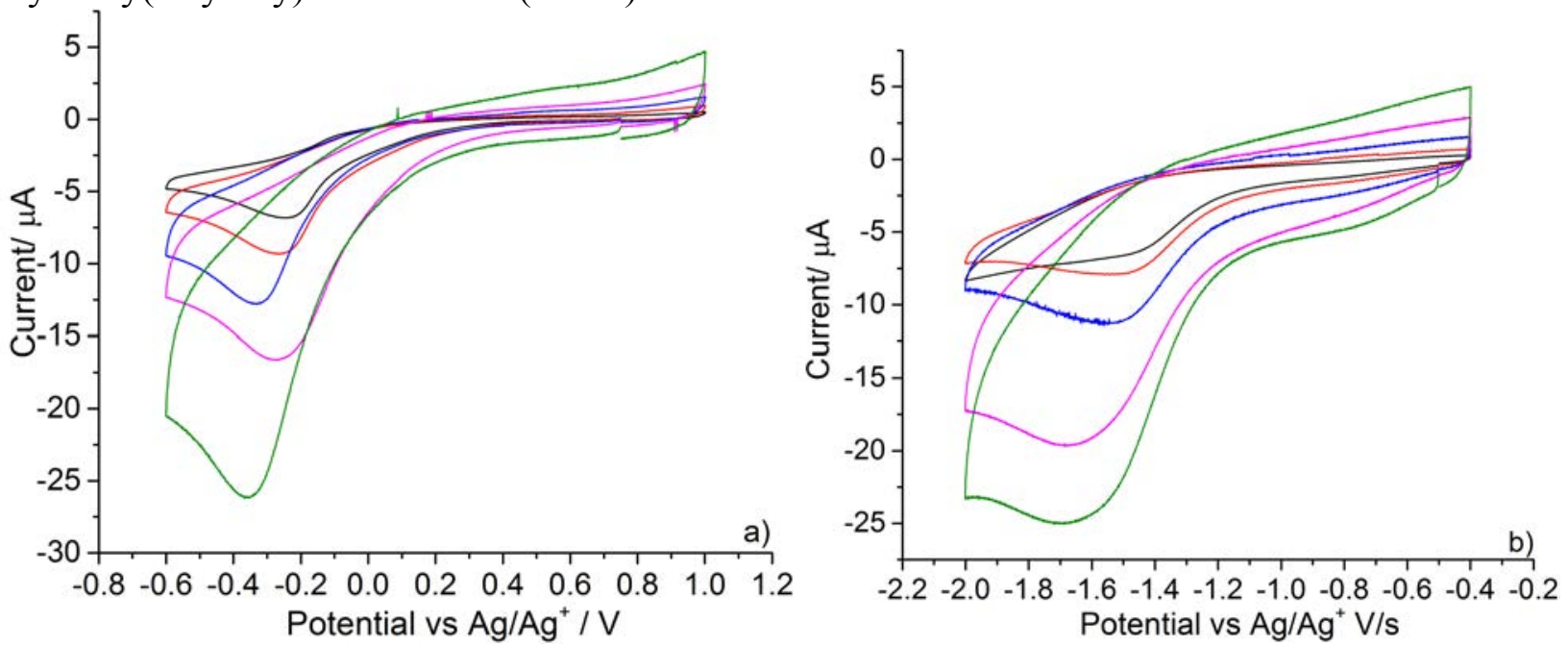

\section{Mass Spectrometry experimental details}

High resolution mass spectra are given to four decimal places under conditions of electrospray ionization (ESI). The experiments were carried on using acetonitrile as solvent because in this solvent any side reaction is known to be slower to avoid any decomposition of the sample. In addition, acetonitrile as a non-nucleophilic molecule does not react by nucleophilic attack on hypervalent iodines. Analyses were performed using a Thermo Exactive mass spectrometer equipped with Waters Acquity liquid chromatography system. Instrument control and data processing were performed using Thermo Xcalibur Software. The system was calibrated on the day of the analysis and its mass accuracy with external calibration (as used for these experiments) is better than $5 \mathrm{ppm}$ for 24 hours following calibration. The mass spec was operated using the heated electrospray (HESI-II) probe and resolution was set to 50,000. Electrospray source conditions were 
adjusted to maximise sensitivity. Acetonitrile was used to transport samples to the mass spectrometer at a flow rate of $0.2 \mathrm{~mL} / \mathrm{min}$.

\subsection{HRMS of PIDA (2)}

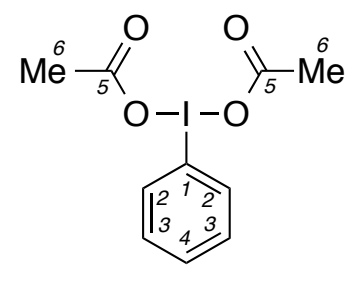

2

HRMS (ESI): The main peaks observed correspond to the following ionized species:

$\left[\mathrm{PhI}(\mathrm{OAc})_{2}+\mathrm{Na}\right]^{+}$calculated for $\mathrm{C}_{10} \mathrm{H}_{11} \mathrm{INaO}_{4}$ requires $m / z$ 344.9600, found $m / z 344.9588$.

$\left[\mathrm{PhI}(\mathrm{OAc})_{2}+\mathrm{K}\right]^{+}$calculated for $\mathrm{C}_{10} \mathrm{H}_{11} \mathrm{IKO}_{4}$ requires $\mathrm{m} / z$ 360.9339, found $\mathrm{m} / \mathrm{z} 360.9325$.

[PhIOAc] ${ }^{+}$calculated for $\mathrm{C}_{8} \mathrm{H}_{8} \mathrm{IO}_{2}$ requires $\mathrm{m} / z$ 262.9554, found $\mathrm{m} / z 262.9559$.

$[\mathrm{PhI}]^{++}$calculated for $\mathrm{C}_{6} \mathrm{H}_{5} \mathrm{I}$ requires $\mathrm{m} / z$ 203.9430, found $\mathrm{m} / \mathrm{z} 203.9428$.

$[\mathrm{Ph}(\mathrm{OAc}) \mathrm{OIPh}]^{+}$calculated for $\mathrm{C}_{14} \mathrm{H}_{13} \mathrm{I}_{2} \mathrm{O}_{3}$ requires $\mathrm{m} / z$ 482.8954, found $\mathrm{m} / z 482.8936$.
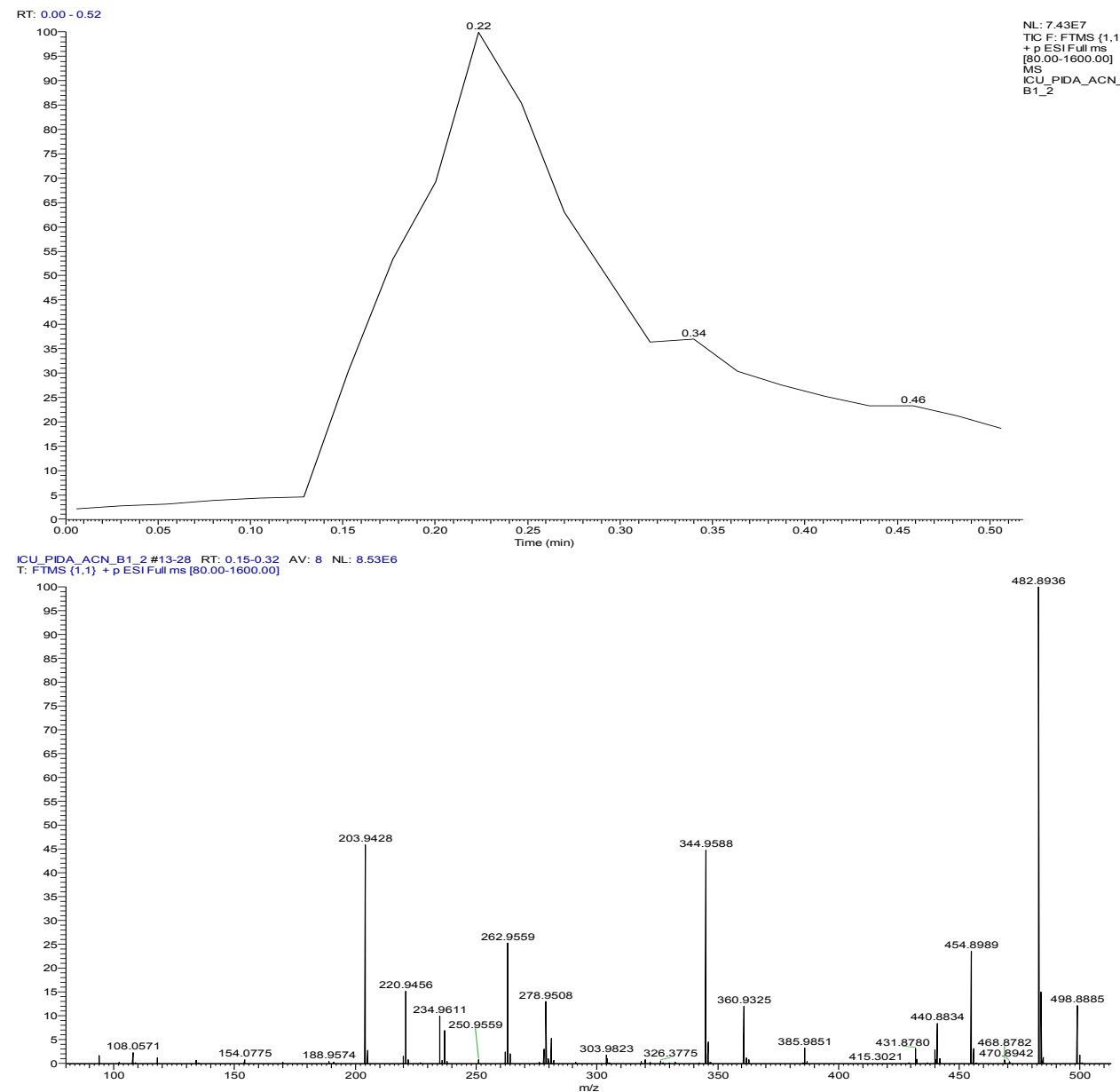


\subsection{HRMS of HFIP (3)}<smiles>OC(C(F)(F)F)[C+](F)(F)[18F]</smiles>

3

HRMS (ESI): The main peaks correspond to the following ionized species:

$\left[\left(\mathrm{CF}_{3}\right)_{2} \mathrm{CHO}^{-}\right.$calculated for $\mathrm{C}_{3} \mathrm{HF}_{6} \mathrm{O}$ requires $\mathrm{m} / z$ 166.9932, found $\mathrm{m} / z 166.9934$.

$[2 \mathrm{M}-\mathrm{H}]^{-}$calculated for $\mathrm{C}_{6} \mathrm{H}_{3} \mathrm{~F}_{12} \mathrm{O}_{2}$ requires $m / z$ 334.9941, found $m / z 334.9943$.

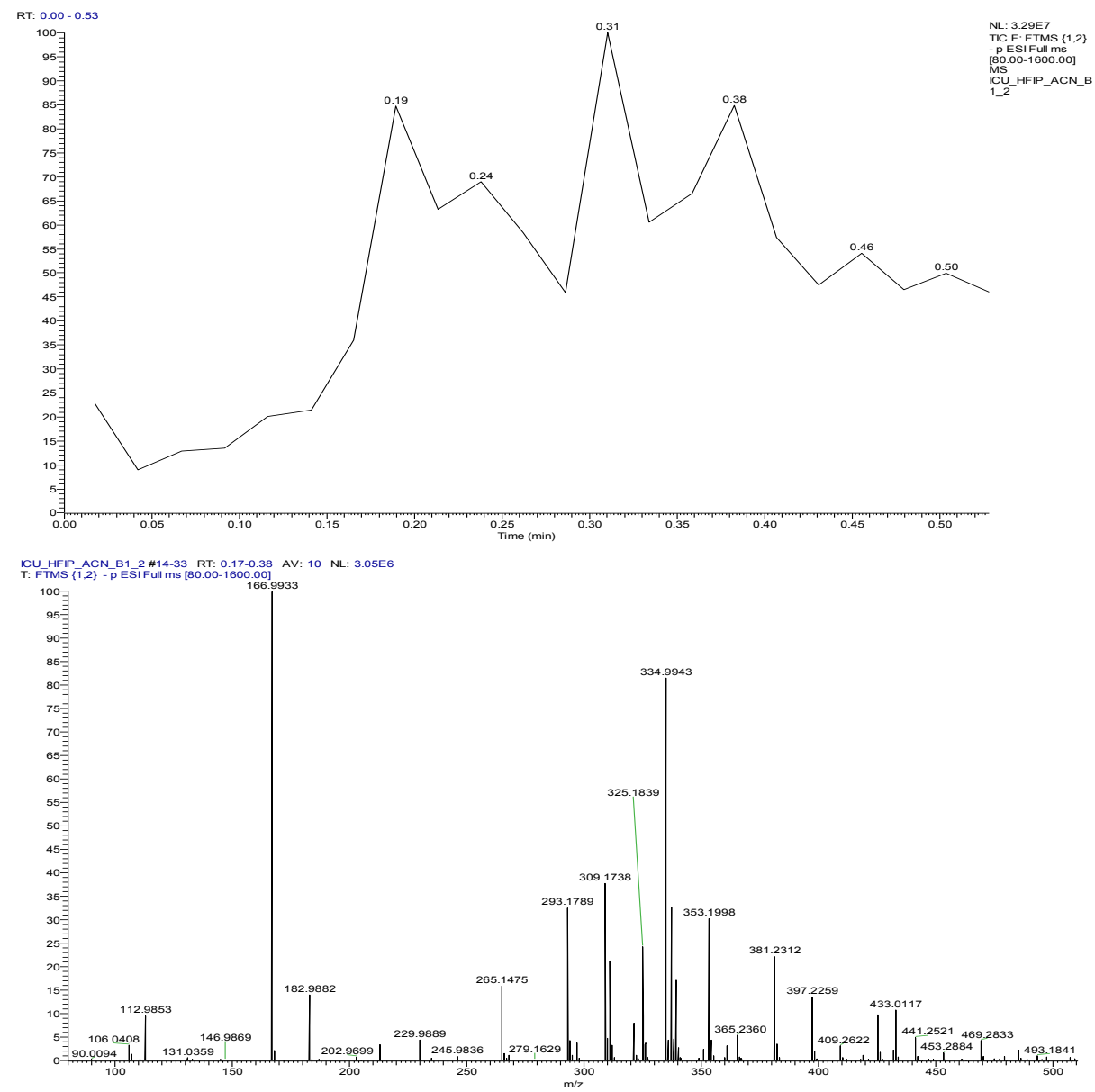

\subsection{HRMS of a 1:1 mixture of HFIP:PIDA (5)}

HRMS (ESI): The main peaks observed are the same as the obtained above for PIDA (2) corresponding to the following ionized species, derived from the ionization of PIDA (2): $\left[\mathrm{PhI}(\mathrm{OAc})_{2}+\mathrm{Na}\right]^{+}$calculated for $\mathrm{C}_{10} \mathrm{H}_{11} \mathrm{INaO}_{4}$ requires $m / z$ 344.9600, found $\mathrm{m} / z$ 344.9587. $\left[\mathrm{PhI}(\mathrm{OAc})_{2}+\mathrm{K}\right]^{+}$calculated for $\mathrm{C}_{10} \mathrm{H}_{11} \mathrm{IKO}_{4}$ requires $\mathrm{m} / z$ 360.9339, found $\mathrm{m} / z 360.9327$. [PhIOAc] $]^{+}$calculated for $\mathrm{C}_{8} \mathrm{H}_{8} \mathrm{IO}_{2}$ requires $m / z$ 262.9554, found $m / z 262.9560$.

$[\mathrm{PhI}]^{++}$calculated for $\mathrm{C}_{6} \mathrm{H}_{5} \mathrm{I}$ requires $\mathrm{m} / z$ 203.9430, found $\mathrm{m} / \mathrm{z} 203.9429$.

$[\mathrm{Ph}(\mathrm{OAc}) \mathrm{OIPh}]^{+}$calculated for $\mathrm{C}_{14} \mathrm{H}_{13} \mathrm{I}_{2} \mathrm{O}_{3}$ requires $\mathrm{m} / z$ 482.8954, found $\mathrm{m} / z 482.8940$. 


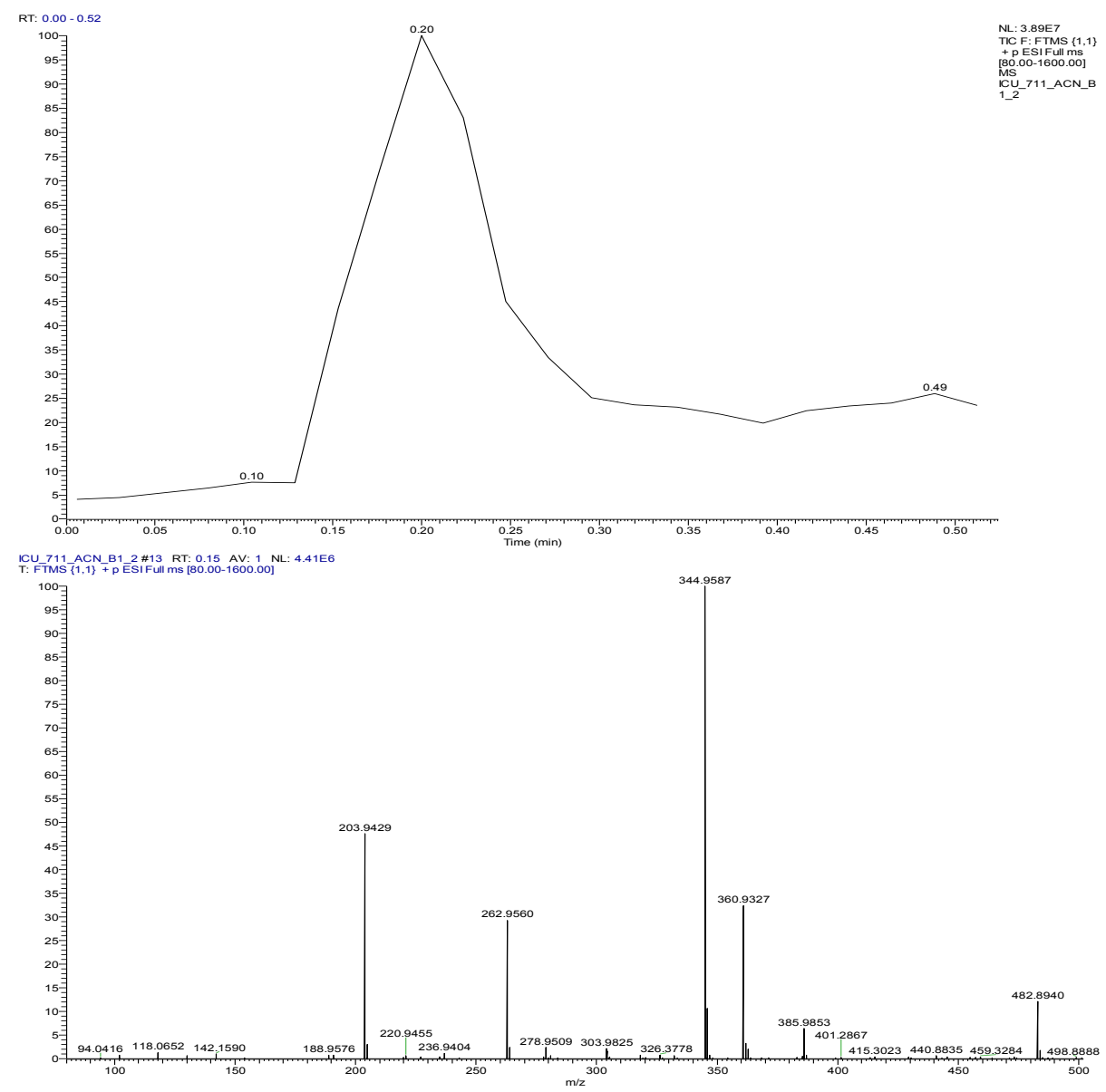

\section{NMR experimental details}

All the NMR experiments were recorded on a Bruker AVIIIHD 400 nanobay or Bruker AVII 500 spectrometer in $\mathrm{CDCl}_{3}$, and referenced to residual solvent peaks. All spectra were acquired in a 5 $\mathrm{mm}$ inverse probehead at $298 \mathrm{~K}$ in $5 \mathrm{~mm}$ tubes. Chemical shifts are quoted in ppm (parts per million) to the nearest $0.01 \mathrm{ppm}$ with signal splitting recorded as singlet (s), doublet (d), triplet (t), quartet (q), quintet (quin), sextet (sex), septet (sept), multiplet (m) and broad singlet (br. s). Coupling constants, $J$, are measured in $\mathrm{Hz}$ to the nearest $0.1 \mathrm{~Hz}$.

2D NOESY spectra were collected using the standard Bruker pulse programs noesyph or noesygpph $\left(90-\mathrm{t}_{1}-90-\tau_{\mathrm{m}}-90\right.$-Acq, without or with a purging bipolar gradient pulse pair $\left(\mathrm{G}_{1}-180\right.$-[$\mathrm{G}_{1}$ ) at the midpoint of the mixing period) with mixing times of $800 \mathrm{~ms}$ at the temperatures and in the solvents stated. For each data set, 8 or 16 transients were acquired for each of 256 increments with $2 \mathrm{~K}$ data points per spectrum, using recovery times of $2 \mathrm{~s}$. Data were processed typically as $1 \mathrm{~K}$ $\mathrm{x} 1 \mathrm{~K}$ data points using shifted squared-sinebell apodisation windows (WDW=QSINE, SSB=2).

DOSY NMR measurements were performed using a Bruker AVII-500 equipped with a TFI probehead at $298^{\circ} \mathrm{K}$ with constant temperature control (air flow $4001 \mathrm{~h}^{-1}$ ) using the 2D sequence 
for diffusion measurement using double stimulated echo for convection compensation and longitudinal eddy current delay, using bipolar gradient pulses for diffusion, and using three spoil gradients (Bruker terminology: dstebpgp35) pulse sequence. Diffusion data were collected using $32 \mathrm{~K}$ data points on well mixed homogeneous samples in de-acidified $\mathrm{CDCl}_{3}$ containing TMS as a suitable internal reference. Experiments were performed in two stages: 1) initially 1D-edited DOSY experiments were used to optimize the diffusion period $\Delta$ for each sample $(\Delta=100 \mathrm{~ms})$ and 2) the $2 \mathrm{D}$ dstebpgp35 sequence was then used, based on the optimized $\Delta$ from the previous procedure and with $\delta=4 \mathrm{~ms}$, with gradient amplitudes ranging from 2 to $85 \%$ using 16 increments (difflist). Diffusion constants were obtained directly employing the T1/T2 module in TOPSPIN 3.2 using the variable gradient function and plots were generated using the eddosy module.

\section{1. ${ }^{1} \mathrm{H}$ and ${ }^{13} \mathrm{C}$ NMR of PIDA}<smiles>CC(=O)OI(OC(C)=O)c1ccccc1</smiles>

2

Data for 2: ${ }^{1}$ H NMR (400 MHz) $\delta 8.08(2 \mathrm{H}, \mathrm{dd}, J=8.3$ and $1.6 \mathrm{~Hz}, 2-\mathrm{H}), 7.59(2 \mathrm{H}, \mathrm{tt}, J=7.4$ and $1.1 \mathrm{~Hz}, 3-\mathrm{H}), 7.49(1 \mathrm{H}, \mathrm{tt}, J=7.7$ and $1.5 \mathrm{~Hz}, 4-\mathrm{H}), 2.00\left(6 \mathrm{H}, \mathrm{s}, 6-\mathrm{H}_{3}\right) .{ }^{13} \mathbf{C}$ NMR (100 MHz) $\delta$ 176.5 (2 C, C-5), 135.1 (2 C, C-2), 131.8 (C-4), 131.1 (2 C, C-3), 121.8 (C-1), 20.5 (2 C, C-6). 

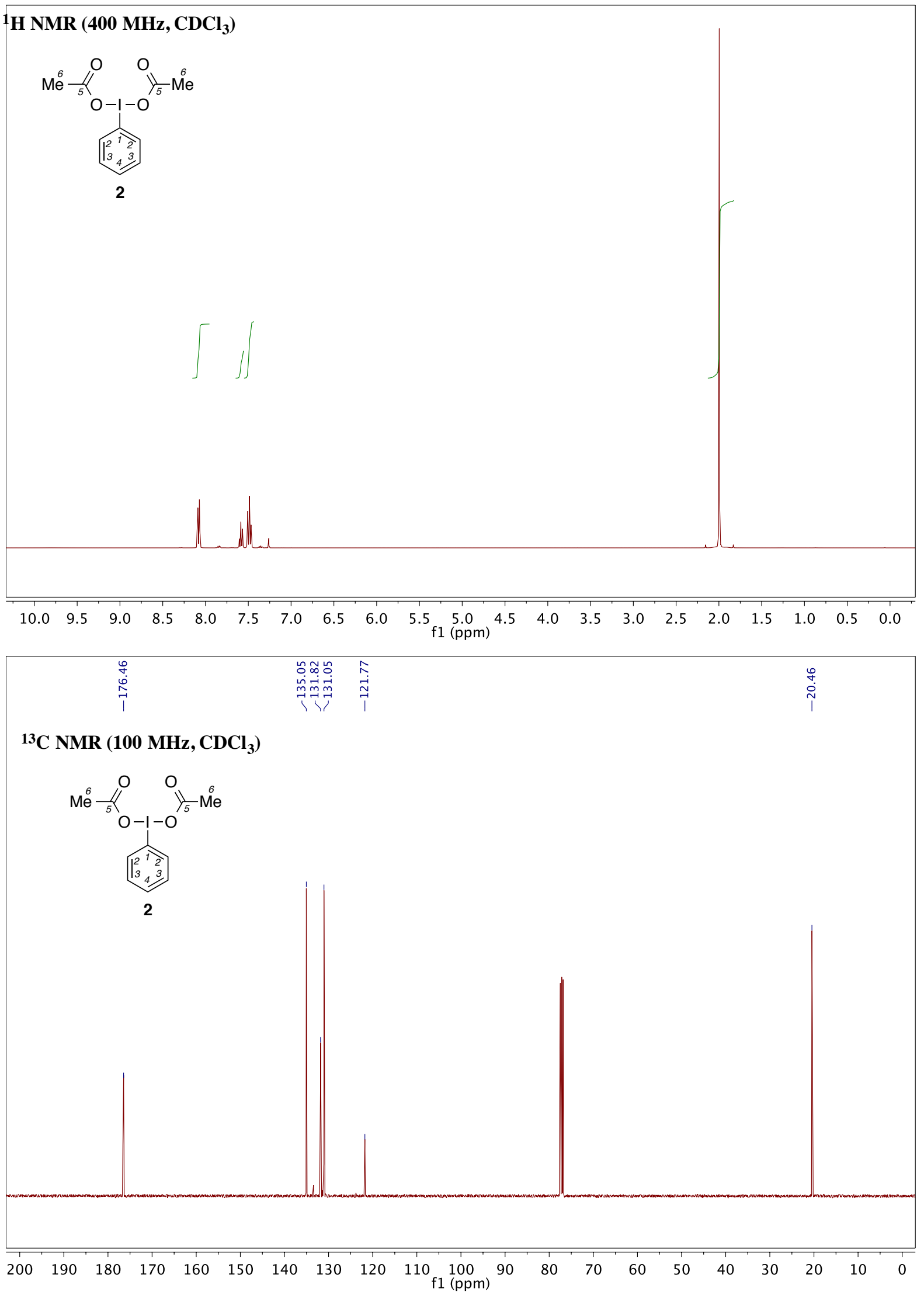


\section{2. ${ }^{1} \mathrm{H}$ and ${ }^{13} \mathrm{C}$ NMR of HFIP}<smiles>OC([C+](O)(F)F)[C+](F)(F)[18F]</smiles>

3

Data for 3: ${ }^{1} \mathbf{H}$ NMR (400 MHz) $\delta 4.41\left(1 \mathrm{H}\right.$, sept, $\left.J_{\mathrm{H}-\mathrm{F}}=5.9 \mathrm{~Hz}, 1{ }^{\prime}-\mathrm{H}\right), 2.88(1 \mathrm{H}, \mathrm{s}, \mathrm{OH}) .{ }^{13} \mathbf{C}$ NMR (100 MHz) $\delta 121.5\left(2 \mathrm{C}, \mathrm{q}, J_{\mathrm{C}-\mathrm{F}}=282.6 \mathrm{~Hz}, \mathrm{C}-2^{\prime}\right), 69.8\left(1 \mathrm{C}\right.$, sept, $\left.J_{\mathrm{C}-\mathrm{F}}=33.5 \mathrm{~Hz}, \mathrm{C}-1^{\prime}\right)$.

${ }^{1} \mathrm{H}$ NMR (400 MHz, $\left.\mathrm{CDCl}_{3}\right)$<smiles>OC(F)(F)C(F)(F)F</smiles>

3
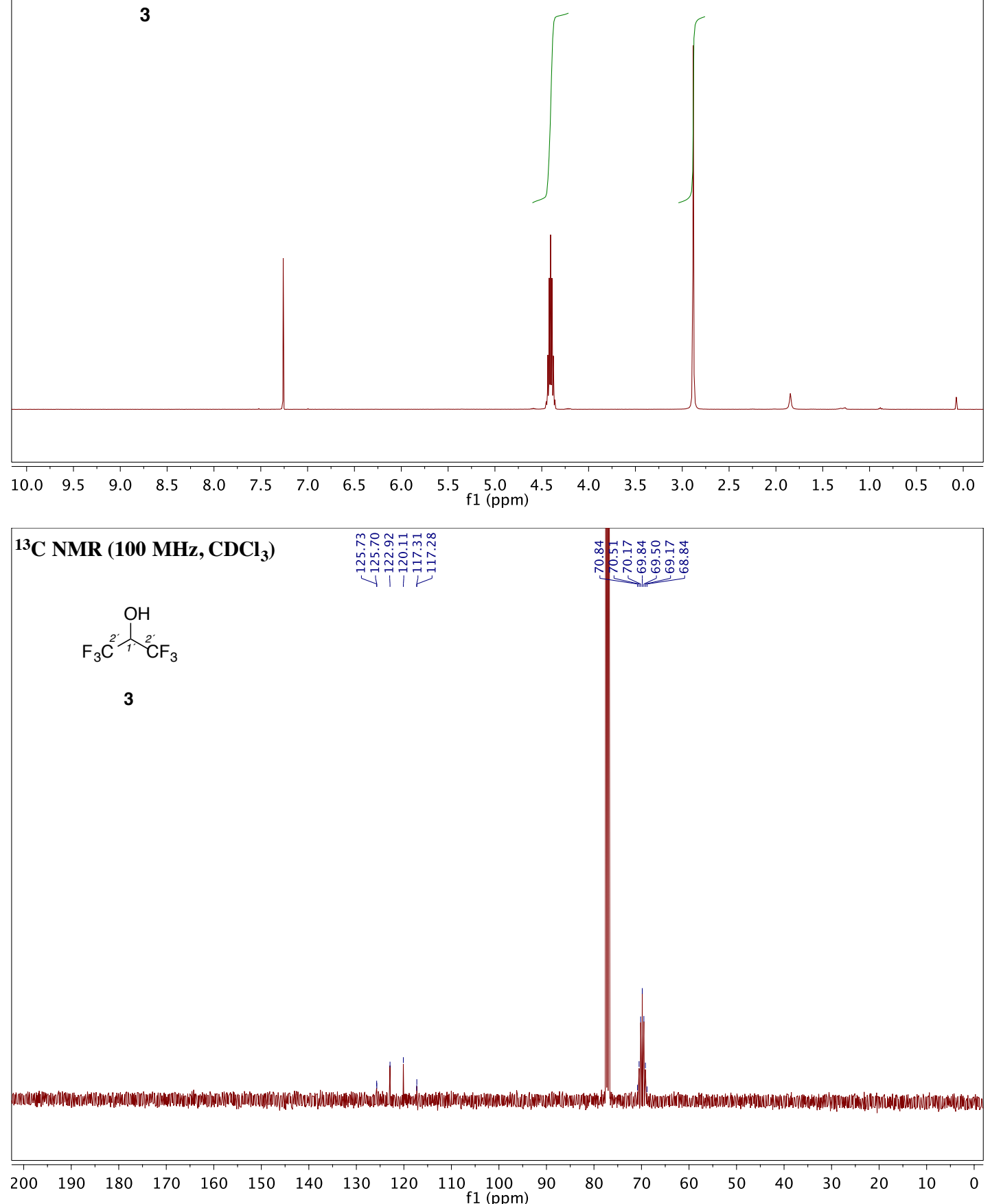
4.3. ${ }^{1} \mathrm{H},{ }^{13} \mathrm{C}$ NMR, NOESY-2D and nOe of a 1:1 mixture of HFIP:PIDA (5).

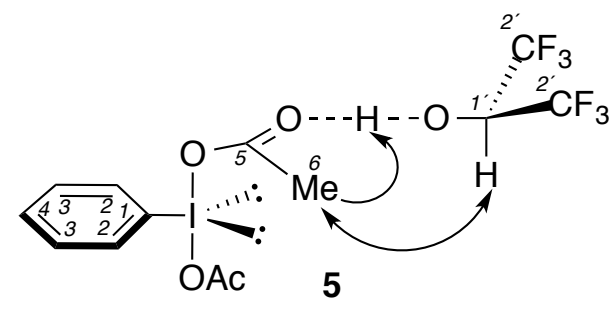

Data for 5: ${ }^{1}$ H NMR (400 MHz) $\delta 8.08(2 \mathrm{H}, \mathrm{dd}, J=8.3$ and $1.3 \mathrm{~Hz}, 2-\mathrm{H}), 7.61(2 \mathrm{H}, \mathrm{tt}, J=7.5$ and $1.1 \mathrm{~Hz}, 3-\mathrm{H}), 7.50(1 \mathrm{H}, \mathrm{tt}, J=7.7$ and $1.7 \mathrm{~Hz}, 4-\mathrm{H}), 5.88(1 \mathrm{H}, \mathrm{br} \mathrm{s}, \mathrm{OH}), 4.40\left(1 \mathrm{H}\right.$, sept, $J_{\mathrm{H}-\mathrm{F}}=6.2$ $\left.\mathrm{Hz}, 1^{\prime}-\mathrm{H}\right), 2.01$ (6 H, s, 6-H $) .{ }^{13} \mathbf{C}$ NMR (100 MHz) $\delta 177.2$ (2 C, C-5), 135.1 (2 C, C-2), 132.0 (C4), $131.2(2 \mathrm{C}, \mathrm{C}-3), 121.9\left(2 \mathrm{C}, \mathrm{q}, J_{\mathrm{C}-\mathrm{F}}=280.1 \mathrm{~Hz}, \mathrm{C}-2^{\prime}\right), 121.6(\mathrm{C}-1), 69.4\left(1 \mathrm{C}\right.$, sept, $J_{\mathrm{C}-\mathrm{F}}=33.2$ $\left.\mathrm{Hz}, \mathrm{C}-1^{\prime}\right), 20.4$ (2 C, C-6).
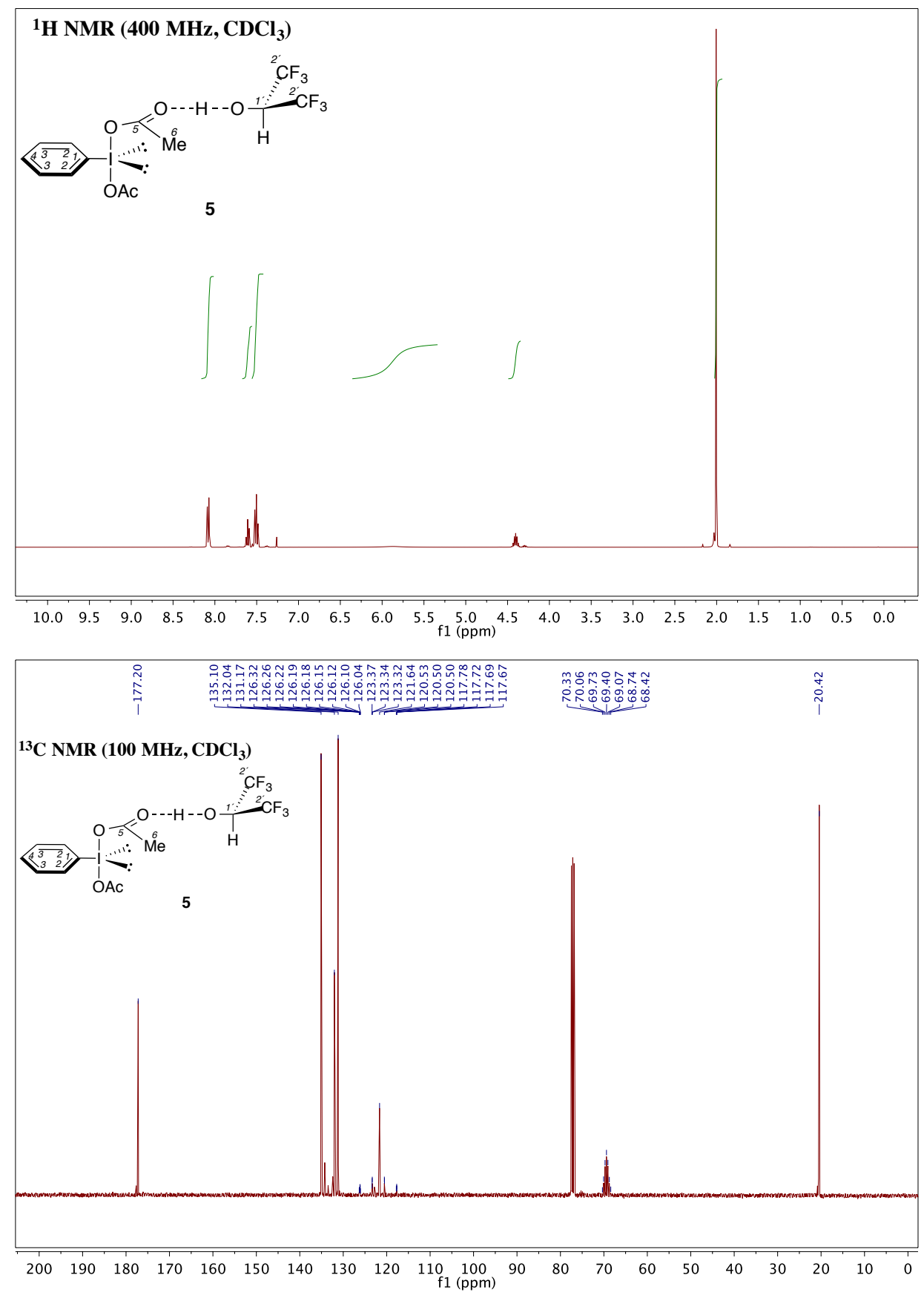
Additional support for the structure 5, presenting an intermolecular H-bond was found upon inspection of the NOESY 2D spectra of 5 , that showed interactions between $6-\mathrm{H}_{3}$ and $\mathrm{OH}$ and between $6-\mathrm{H}_{3}$ and $1^{\prime}-\mathrm{H}$, confirming the nature of a new bonded specie.
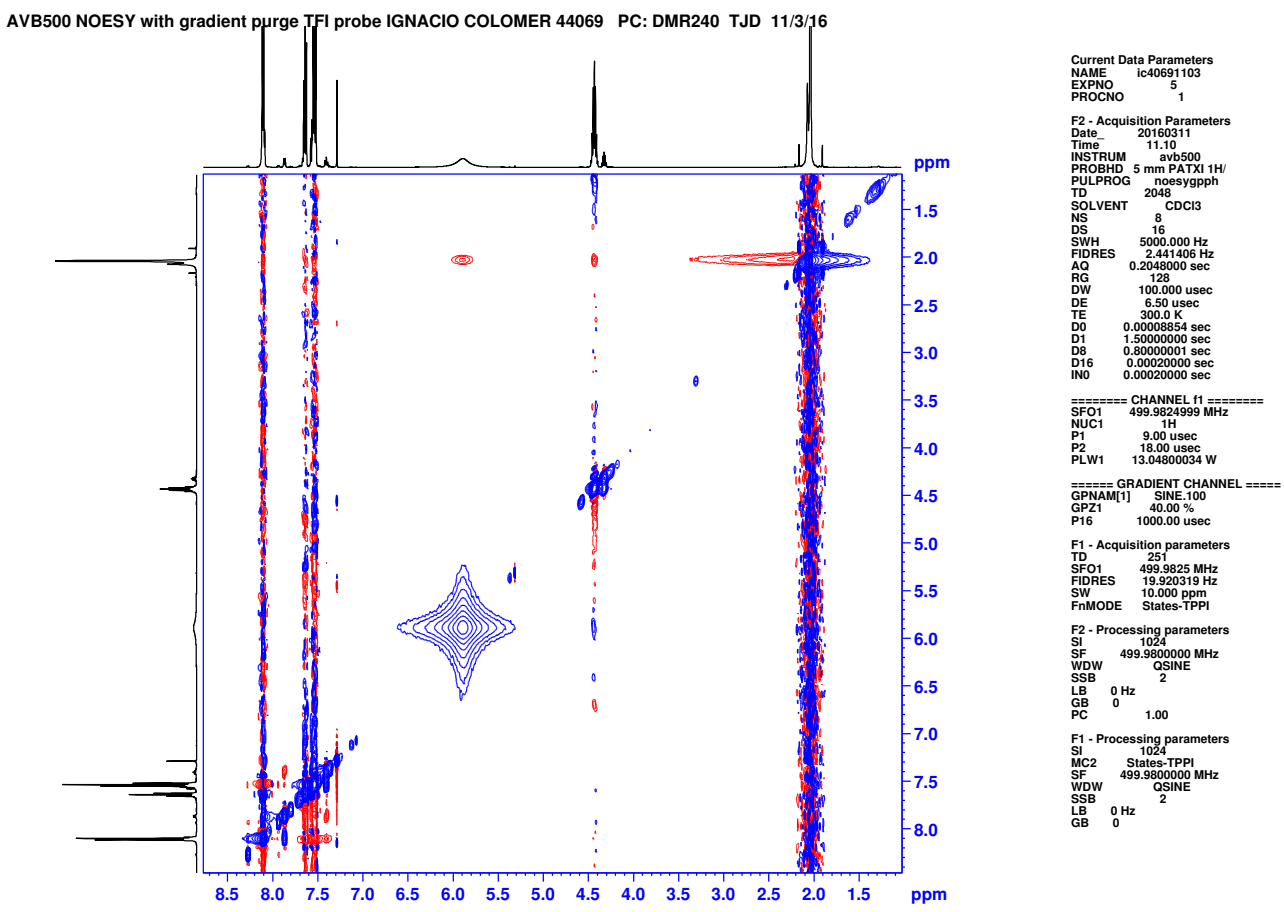

In the same manner, from the $1 \mathrm{D}$ nOe experiments, when irradiating the $6-\mathrm{H}_{3}$ nuclei we observed an nOe effect with $1^{\prime}-\mathrm{H}$ and with $\mathrm{OH}$. In the reverse way, when irradiating 1 '- $\mathrm{H}$ the same nOe effect is shown with $6-\mathrm{H}_{3}$.

AVB500 1H TFI probe IGNACIO COLOMER 44069 PC: DMR240 TJD 11/3/16
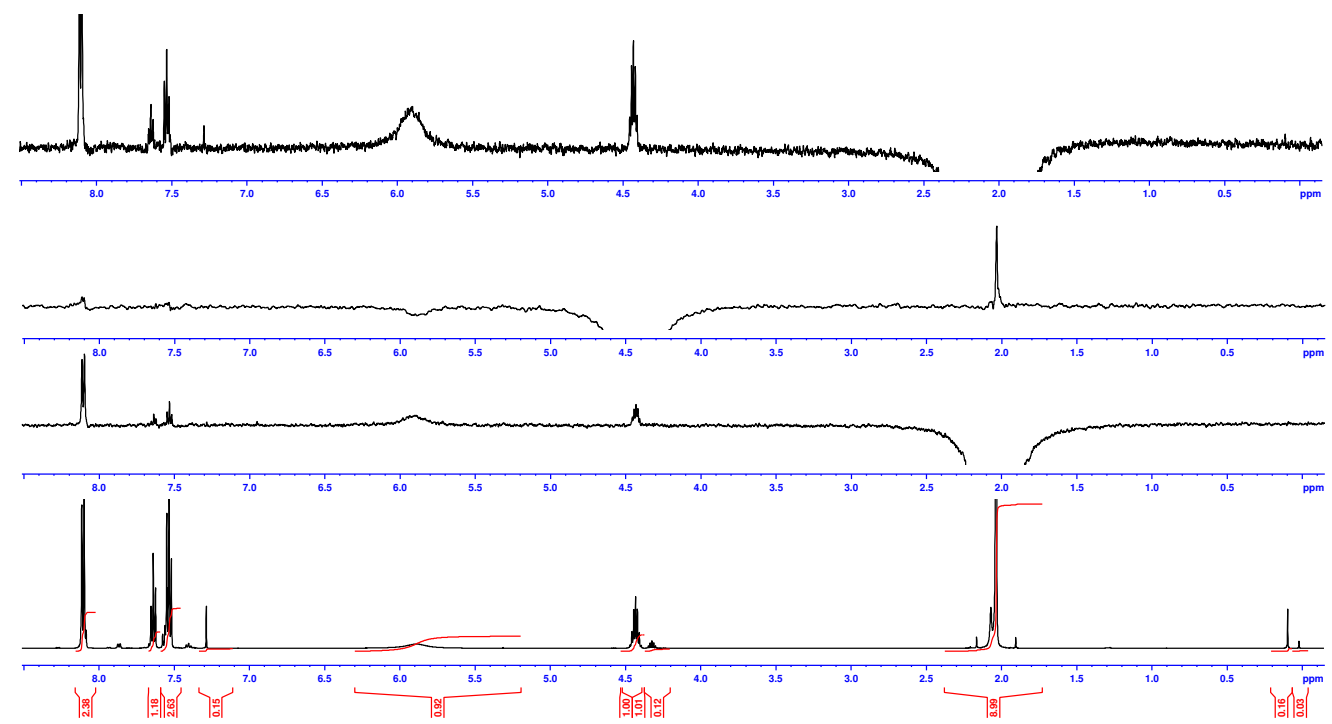

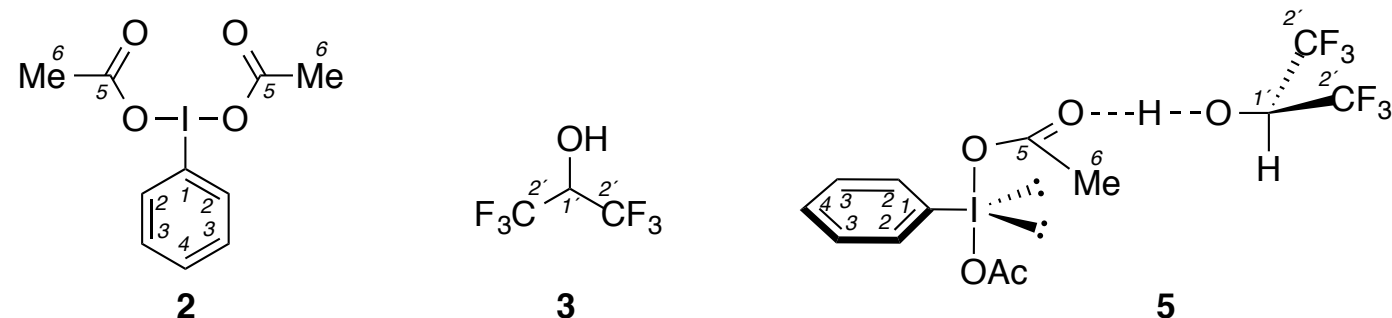

\begin{tabular}{|c|c|c|c|c|c|c|c|c|}
\hline & \multicolumn{2}{|c|}{ PIDA (2) } & \multicolumn{2}{|c|}{ HFIP (3) } & \multicolumn{2}{|c|}{ Adduct (5) } & \multicolumn{2}{|c|}{$\Delta \delta$} \\
\hline & ${ }^{1}$ H NMR & ${ }^{13} \mathrm{C}$ NMR & ${ }^{1} \mathrm{H}$ NMR & ${ }^{13} \mathrm{C}$ NMR & ${ }^{1}$ H NMR & ${ }^{13} \mathrm{C}$ NMR & ${ }^{1}$ H NMR & ${ }^{13} \mathrm{C}$ NMR \\
\hline 1 & - & 121.8 & - & - & - & 121.6 & - & -0.2 \\
\hline 2 & $\begin{array}{c}8.08 \mathrm{dd} \\
(8.3 \\
1.6)\end{array}$ & 135.1 & - & - & $\begin{array}{c}8.08 \mathrm{dd} \\
(8.3,1.3)\end{array}$ & 135.1 & 0.0 & 0.0 \\
\hline 3 & $\begin{array}{c}7.59 \mathrm{tt} \\
(7.4 \\
1.1)\end{array}$ & 131.1 & - & - & $\begin{array}{c}7.61 \mathrm{tt} \\
(7.5,1.1)\end{array}$ & 131.2 & 0.02 & 0.1 \\
\hline 4 & $\begin{array}{c}7,49 \mathrm{tt} \\
(7.7 \\
1.5)\end{array}$ & 131.8 & - & - & $\begin{array}{c}7,50 \mathrm{tt} \\
(7.7,1.7)\end{array}$ & 132.0 & 0.0 & 0.2 \\
\hline 5 & - & 176.5 & - & - & - & 177.2 & - & 0.7 \\
\hline 6 & $2.00 \mathrm{~s}$ & 20.5 & - & - & $2.01 \mathrm{~s}$ & 20.4 & 0.01 & -0.1 \\
\hline $1^{\prime}$ & - & - & $\begin{array}{c}4.41 \text { hept } \\
\text { (5.9) }\end{array}$ & $\begin{array}{c}69.8 \text { hept } \\
(33.5)\end{array}$ & $\begin{array}{c}4.40 \text { hept } \\
\text { (6.2) }\end{array}$ & $\begin{array}{c}\text { 69.4 hept } \\
(33.2)\end{array}$ & -0.01 & -0.4 \\
\hline $2^{\prime}$ & - & - & - & $\begin{array}{l}121.5 \mathrm{q} \\
(282.6)\end{array}$ & _ & $\begin{array}{l}121.9 \mathrm{q} \\
(280.1)\end{array}$ & - & 0.4 \\
\hline $\mathrm{OH}$ & - & - & $2.88 \mathrm{~s}$ & - & 5.88 br s & - & 3.0 & - \\
\hline
\end{tabular}

The most significant changes found in ${ }^{1} \mathrm{H}$ NMR are the down shielding shift of the $\mathrm{O}-\mathrm{H}$ proton, from a frequency of $2.88 \mathrm{ppm}$ to $5.88 \mathrm{ppm}$, as well as it shape, from a sharp singlet to a broad singlet. Minor changes are found in $3-\mathrm{H}, 6-\mathrm{H}$ and $1^{\prime}-\mathrm{H}$ with a smaller shifting of 0.01 or 0.02 ppm. Alternatively the most noteworthy changes found in ${ }^{13} \mathrm{C}$ NMR are the down shielding effect of $0.7 \mathrm{ppm}$ in the carbonyl moiety (C-5) from $176.5 \mathrm{ppm}$ to $177.2 \mathrm{ppm}$, as well as the $0.4 \mathrm{ppm}$ shifting observed in C-1'and C-2'. Minor changes of 0.1 and 0.2 ppm are also noticed in C-3, C-4 and C-6. 


\section{5. ${ }^{1} \mathrm{H}$ and ${ }^{13} \mathrm{C}$ NMR of PIFA}<smiles>O=C(OI(OC(=O)C(F)(F)F)c1ccccc1)C(F)(F)F</smiles>

Data for PIFA: ${ }^{1}$ H NMR (500 MHz) $\delta 8.20(2 \mathrm{H}, \mathrm{d}, J=7.4 \mathrm{~Hz}, 2-\mathrm{H}), 7.74(1 \mathrm{H}, \mathrm{t}, J=7.5 \mathrm{~Hz}, 4$ H), $7.62(2 \mathrm{H}, \mathrm{t}, J=7.9 \mathrm{~Hz}, 3-\mathrm{H}) .{ }^{13} \mathbf{C}$ NMR (125 MHz) $\delta 161.2\left(2 \mathrm{C}, \mathrm{q}, J_{\mathrm{C}-\mathrm{F}}=41.2 \mathrm{~Hz}, \mathrm{C}-5\right), 135.3$ (2 C, C-2), 133.8 (C-4), 132.2 (2 C, C-3), 122.9 (2 C, C-1), 113.0 (2C, q, $J_{\mathrm{C}-\mathrm{F}}=288.4$ Hz, C-6).

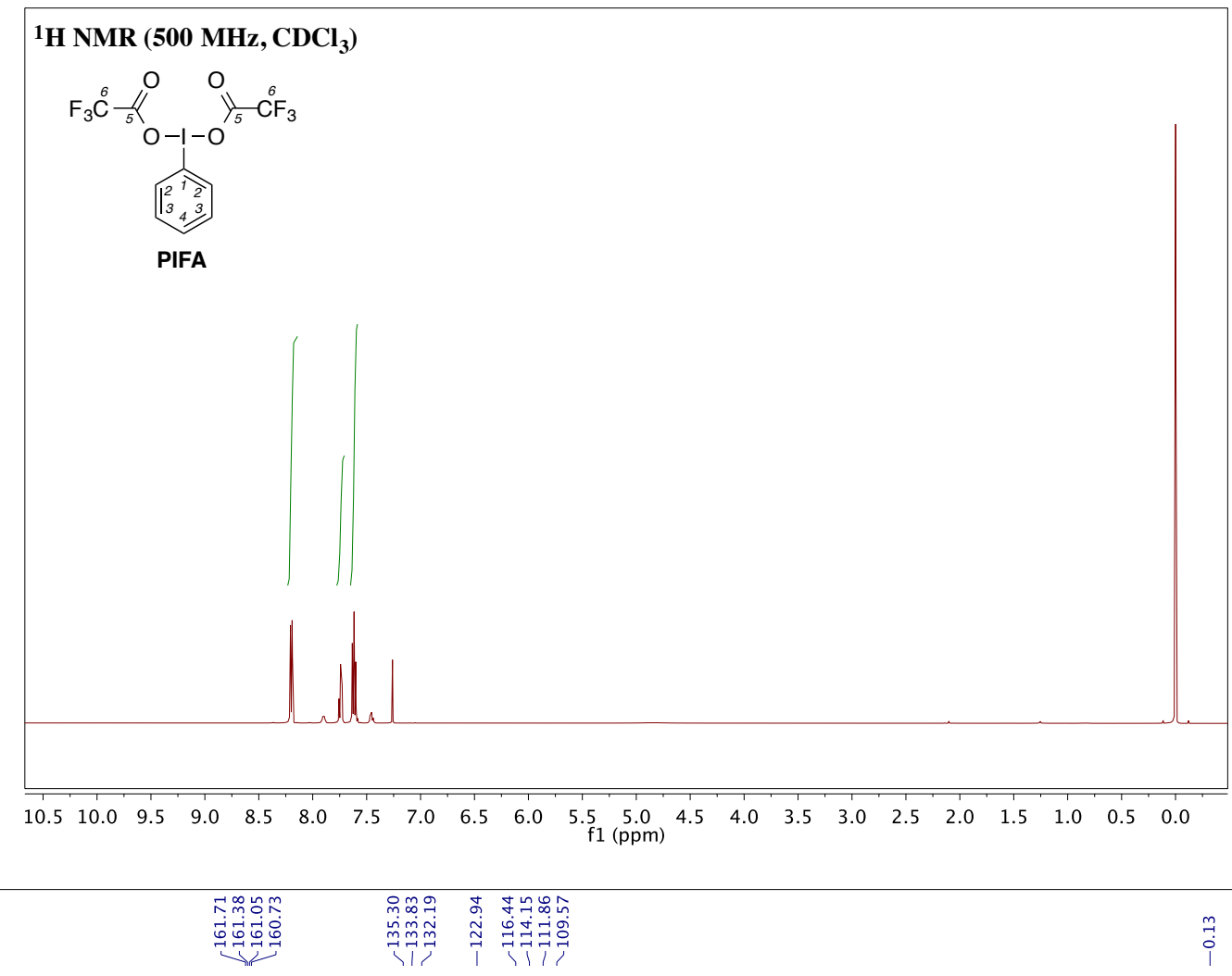

${ }^{13} \mathrm{C}$ NMR (125 MHz, $\left.\mathrm{CDCl}_{3}\right)$

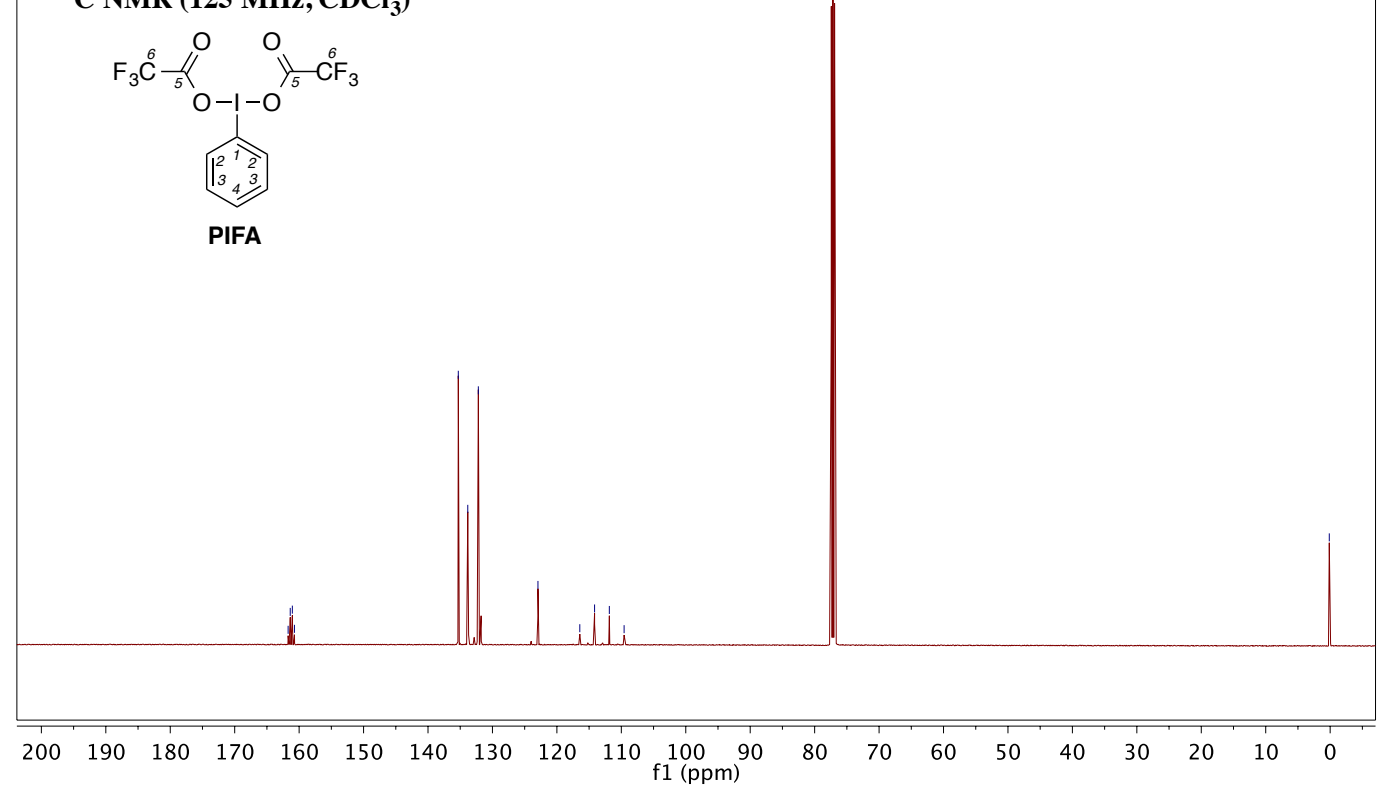


4.6. ${ }^{1} \mathrm{H},{ }^{13} \mathrm{C}$ NMR, ${ }^{19} \mathrm{~F}$ and HOESY of a 1:1 mixture of HFIP:PIFA (16).

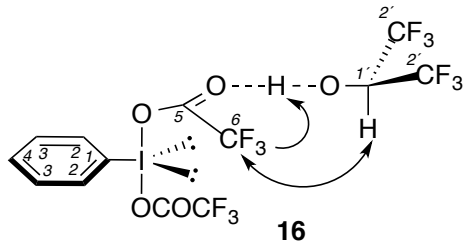

Data for 16: ${ }^{1}$ H NMR (500 MHz) $\delta 8.22(2 \mathrm{H}, \mathrm{d}, J=7.4 \mathrm{~Hz}, 2-\mathrm{H}), 7.77(1 \mathrm{H}, \mathrm{t}, J=7.5 \mathrm{~Hz}, 4-\mathrm{H})$, $7.65(1 \mathrm{H}, \mathrm{t}, J=7.9 \mathrm{~Hz}, 3-\mathrm{H}), 4.43\left(1 \mathrm{H}\right.$, sept, $\left.J_{\mathrm{H}-\mathrm{F}}=5.9 \mathrm{~Hz}, 1^{\prime}-\mathrm{H}\right), 3.55$ (1 H, br s, OH). ${ }^{13} \mathbf{C} \mathbf{~ N M R}$ (125 MHz) $\delta 161.2$ (2 C, q, J $\left.J_{\mathrm{C}-\mathrm{F}}=41.2 \mathrm{~Hz}, \mathrm{C}-5\right), 135.2$ (2 C, C-2), 133.7 (C-4), 132.1 (2 C, C-3), $122.8(\mathrm{C}-1), 121.4\left(1 \mathrm{C}, \mathrm{qq}, J_{\mathrm{C}-\mathrm{F}}=282.8\right.$ and $\left.3.0 \mathrm{~Hz}, \mathrm{C}-2^{\prime}\right), 112.9\left(2 \mathrm{C}, \mathrm{q}, J_{\mathrm{C}-\mathrm{F}}=288.3 \mathrm{~Hz}, \mathrm{C}-6\right), 69.6$ $\left(1 \mathrm{C}\right.$, sept, $\left.J_{\mathrm{C}-\mathrm{F}}=33.6 \mathrm{~Hz}, \mathrm{C}-1^{\prime}\right) .{ }^{19}$ F NMR (470 MHz) $\delta-73.5\left(\mathrm{CF}_{3}, \mathrm{PIFA}\right),-75.7\left(\mathrm{CF}_{3}, \mathrm{HFIP}\right)$.
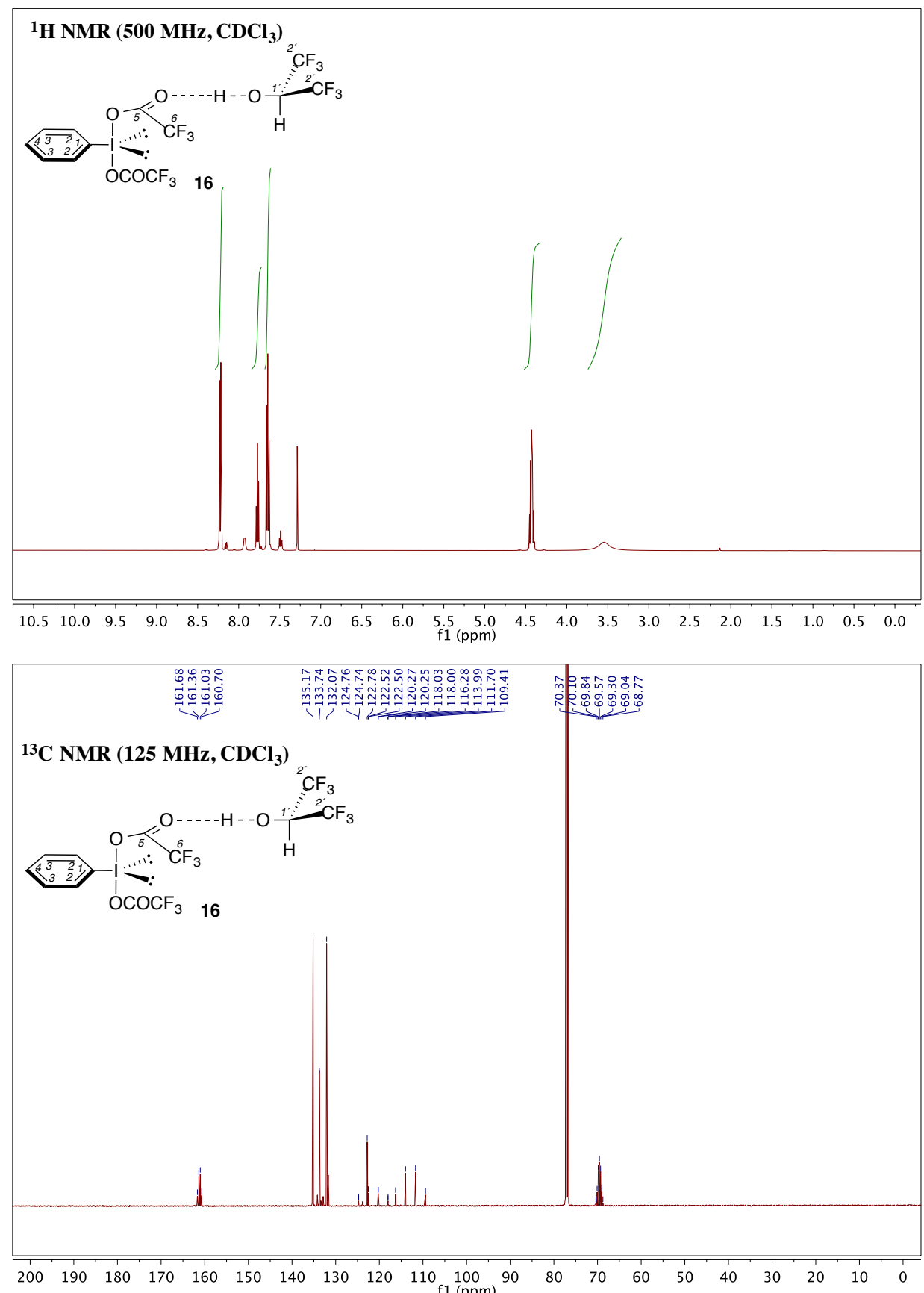


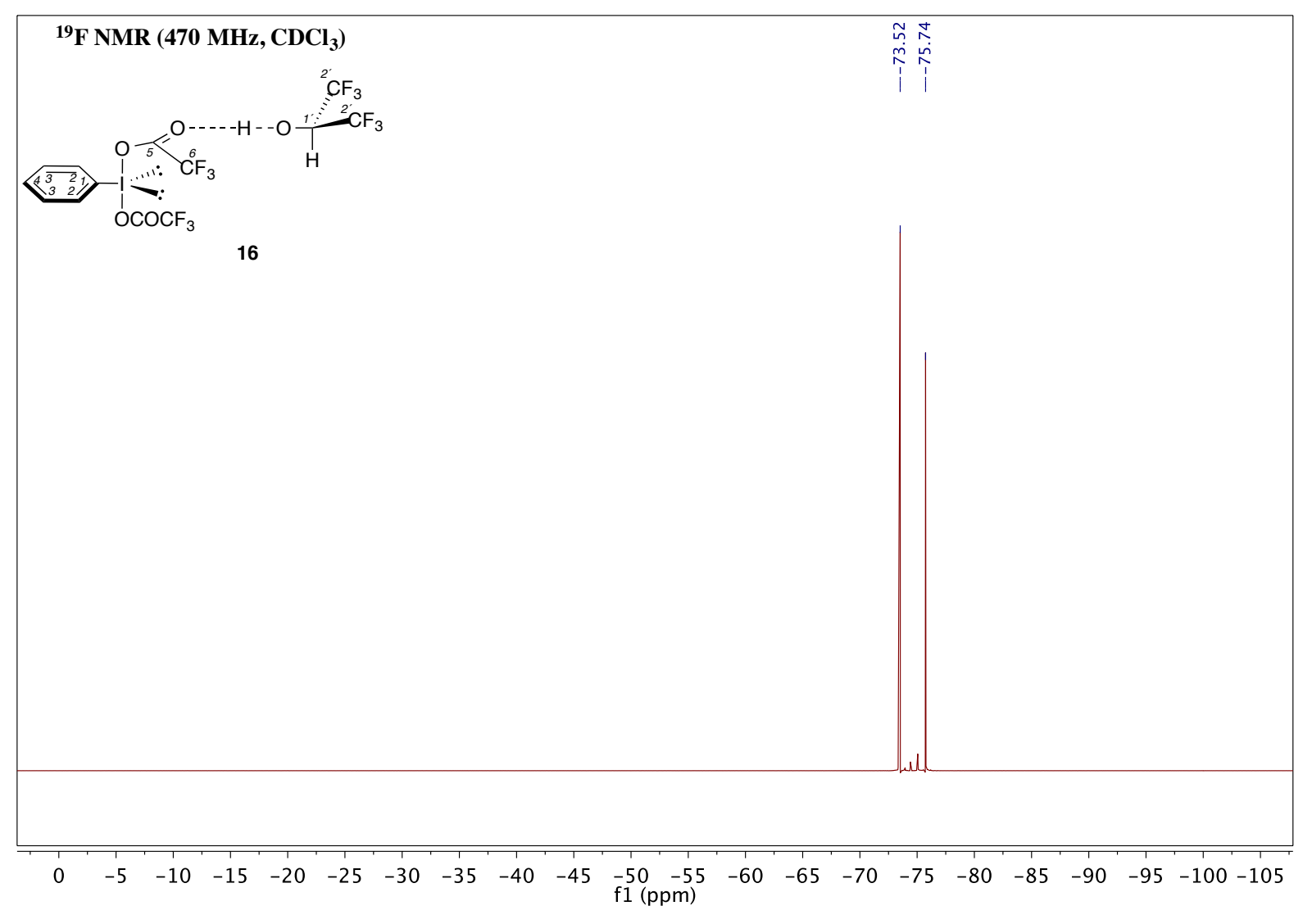

AVB500 1H TFI probe IGNACIO COLOMER 44673 PC: DMR00240 TJD 17/5/16 1-D SELECTIVE HOESY Tmix = 500msec

blank irradiation at -78ppm

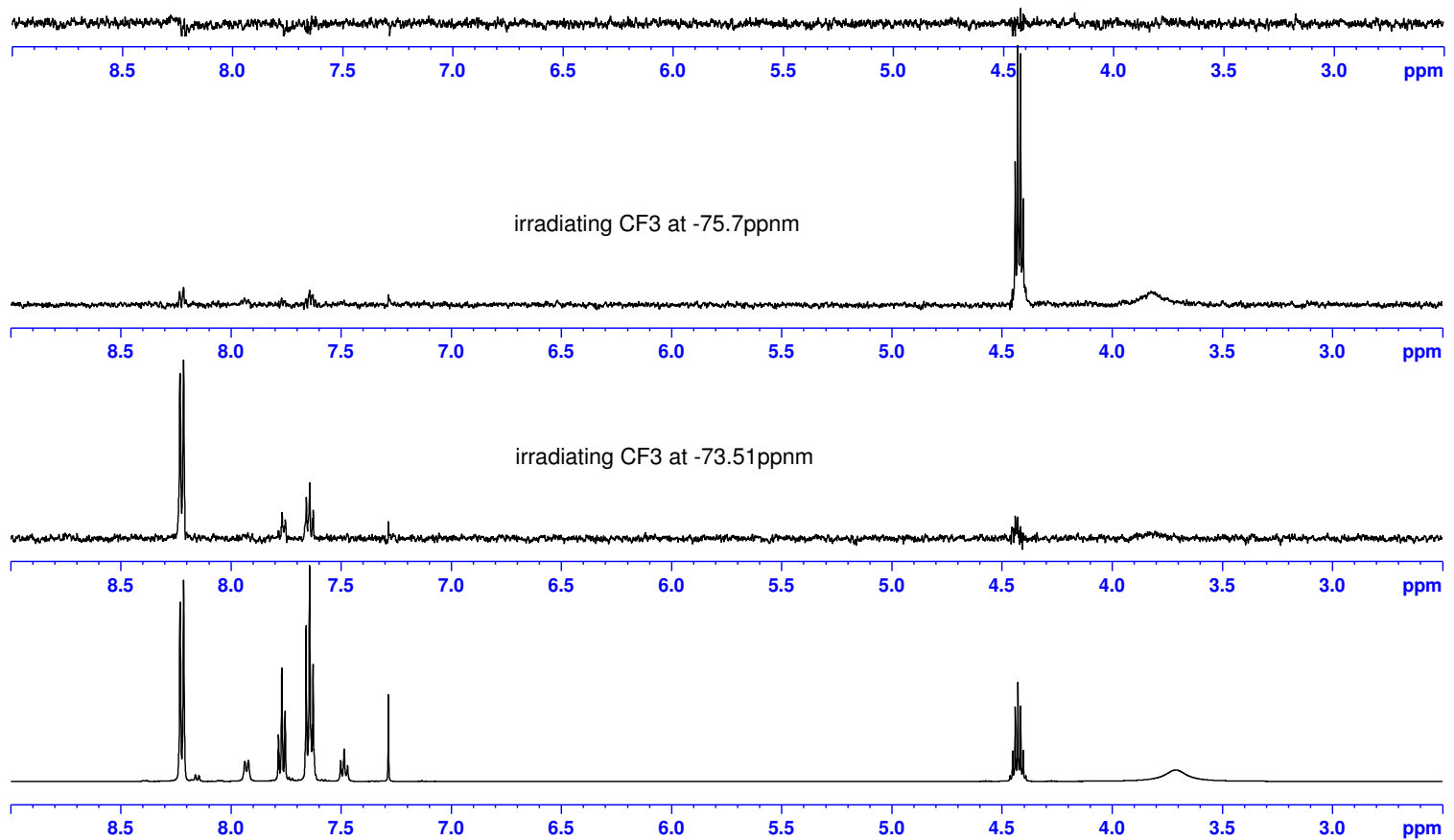




\section{7. ${ }^{1} \mathrm{H}$ and ${ }^{13} \mathrm{C}$ NMR of HTIB}

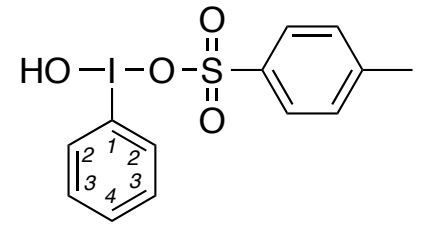

Data for HTIB: ${ }^{1}$ H NMR (400 MHz) $\delta$ 8.03-8.23 (2 H, m, 2-H), 7.82-7.97 (1 H, m, 4-H), 7.37-7.50 (2 H, m, 3-H), 7.55 (2 H, d, J=7.5 Hz, 2 x CH Ts), $7.14(1 \mathrm{H}, \mathrm{d}, J=7.9 \mathrm{~Hz}, 2$ x CH Ts), 2.36 (3 H, s, Me Ts), 1.55 (6 H, s, OH). ${ }^{13}$ C NMR (100 MHz) $\delta 141.7$ (C Ts), 138.8 (C Ts), 133.7 (C-2), 132.4 (C-4), 131.3 (C-3), 129.1 (2 x CH Ts), 126.1 (2 x CH Ts), 123.5 (C-1), 21.4 (Me Ts).
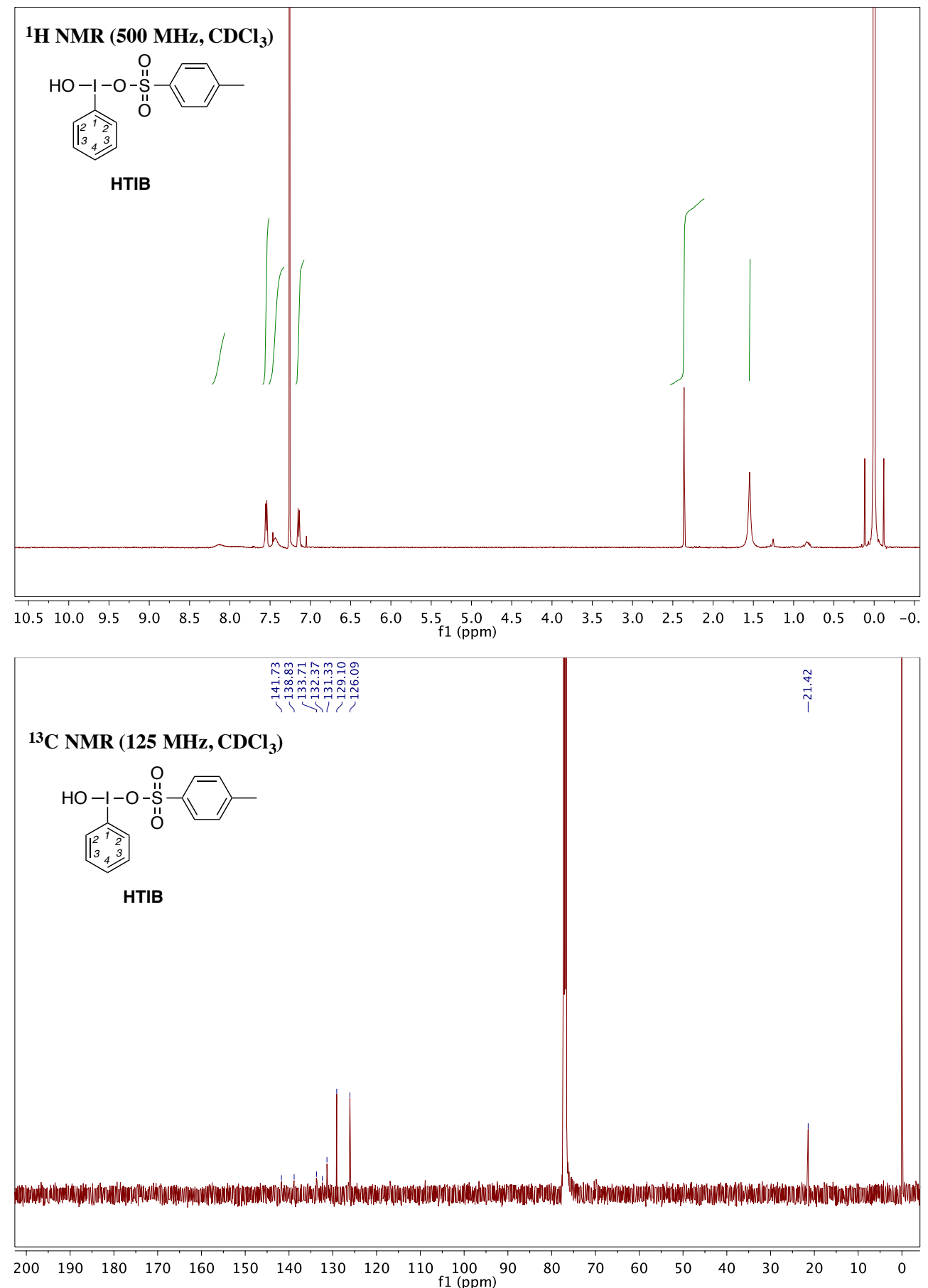
4.8. ${ }^{1} \mathrm{H}$ and ${ }^{13} \mathrm{C}$ NMR of a 1:1 mixture of HFIP:HTIB (17).

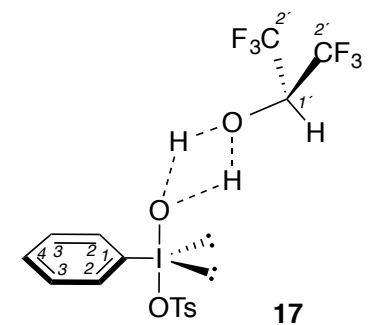

Data for 17: ${ }^{1} \mathbf{H}$ NMR (500 MHz) $8.00(2 \mathrm{H}, \mathrm{d}, J=7.8 \mathrm{~Hz}, 2-\mathrm{H}), 7.58(1 \mathrm{H}, \mathrm{t}, J=7.5 \mathrm{~Hz}, 4-\mathrm{H})$, $7.48(1 \mathrm{H}, \mathrm{d}, J=8.2 \mathrm{~Hz}, 2$ x CH Ts), $7.41(2 \mathrm{H}, \mathrm{t}, J=7.8 \mathrm{~Hz}, 3-\mathrm{H}), 7.14(2 \mathrm{H}, \mathrm{d}, J=8.0 \mathrm{~Hz}, 2 \times \mathrm{CH}$ Ts), $4.40\left(1 \mathrm{H}\right.$, sept, $J_{\mathrm{H}-\mathrm{F}}=6.0 \mathrm{~Hz}, 1$ '-H), 3.91 (1 H, br s, OH), 2.38 (3 H, s, Me Ts). ${ }^{13}$ C NMR (125 MHz) $\delta 142.3$ (C Ts), 138.1 (C Ts), 134.3 (C-2), 132.9 (C-4), 131.4 (C-3), 129.2 (2 x CH Ts), 125.9 (2 x CH Ts), 123.5 (C-1), 121.5 (1C, qq, $J_{\mathrm{C}-\mathrm{F}}=283.1$ and $\left.3.3 \mathrm{~Hz}, \mathrm{C}-6\right), 69.4$ ( $1 \mathrm{C}$, sept, $J_{\mathrm{C}-\mathrm{F}}=$ $33.3 \mathrm{~Hz}, \mathrm{C}-1^{\prime}$ ), 21.4 (Me Ts).

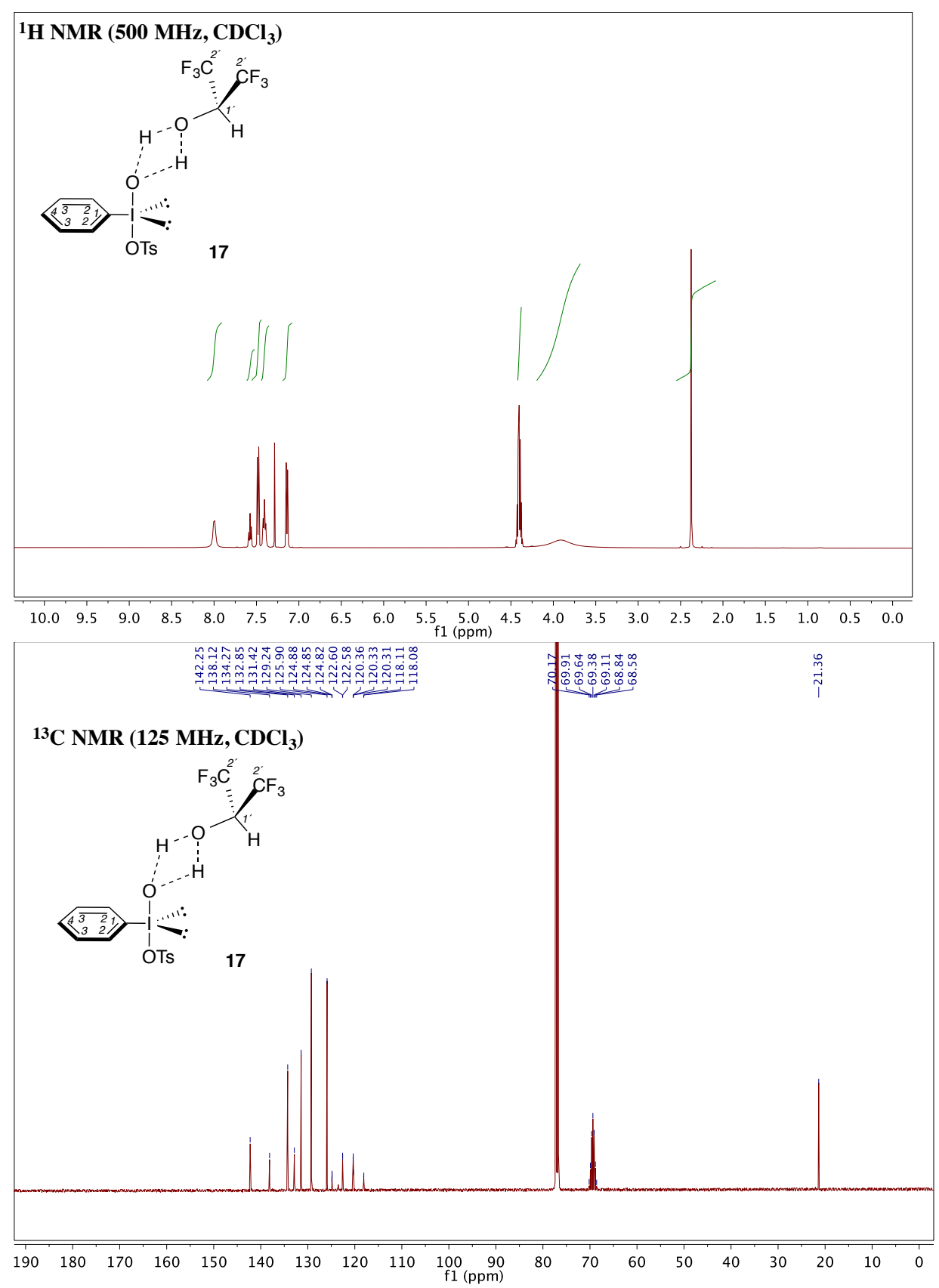




\section{9. ${ }^{1} \mathrm{H}$ DOSY and Diffusion coefficient of PIDA (2).}

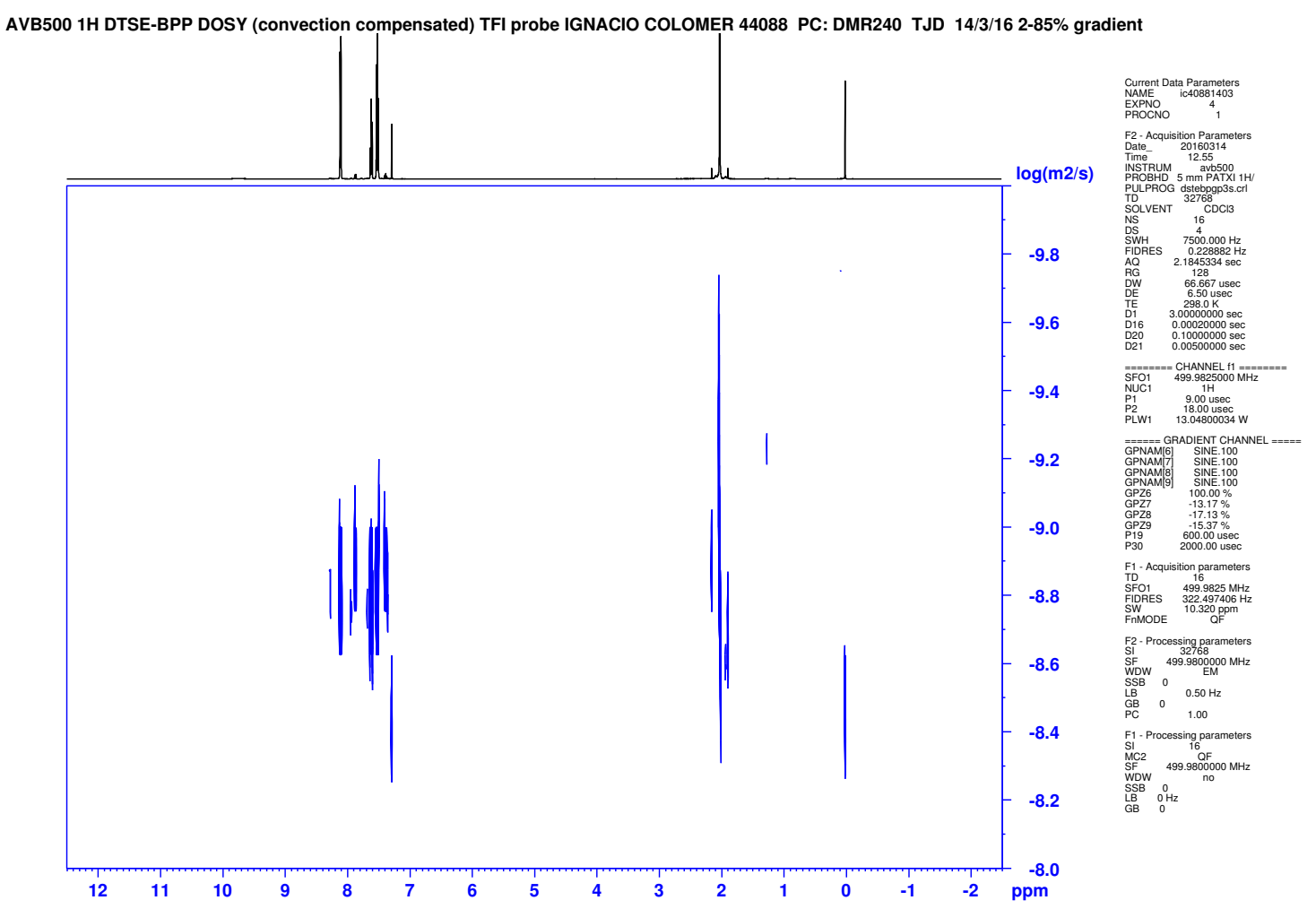

AVB500 1H DTSE-BPP DOSY (convection compensated) TFI probe IGNACIO COLOMER 44088 PC: DMR240 TJD 14/3/16 2-85\% gradient
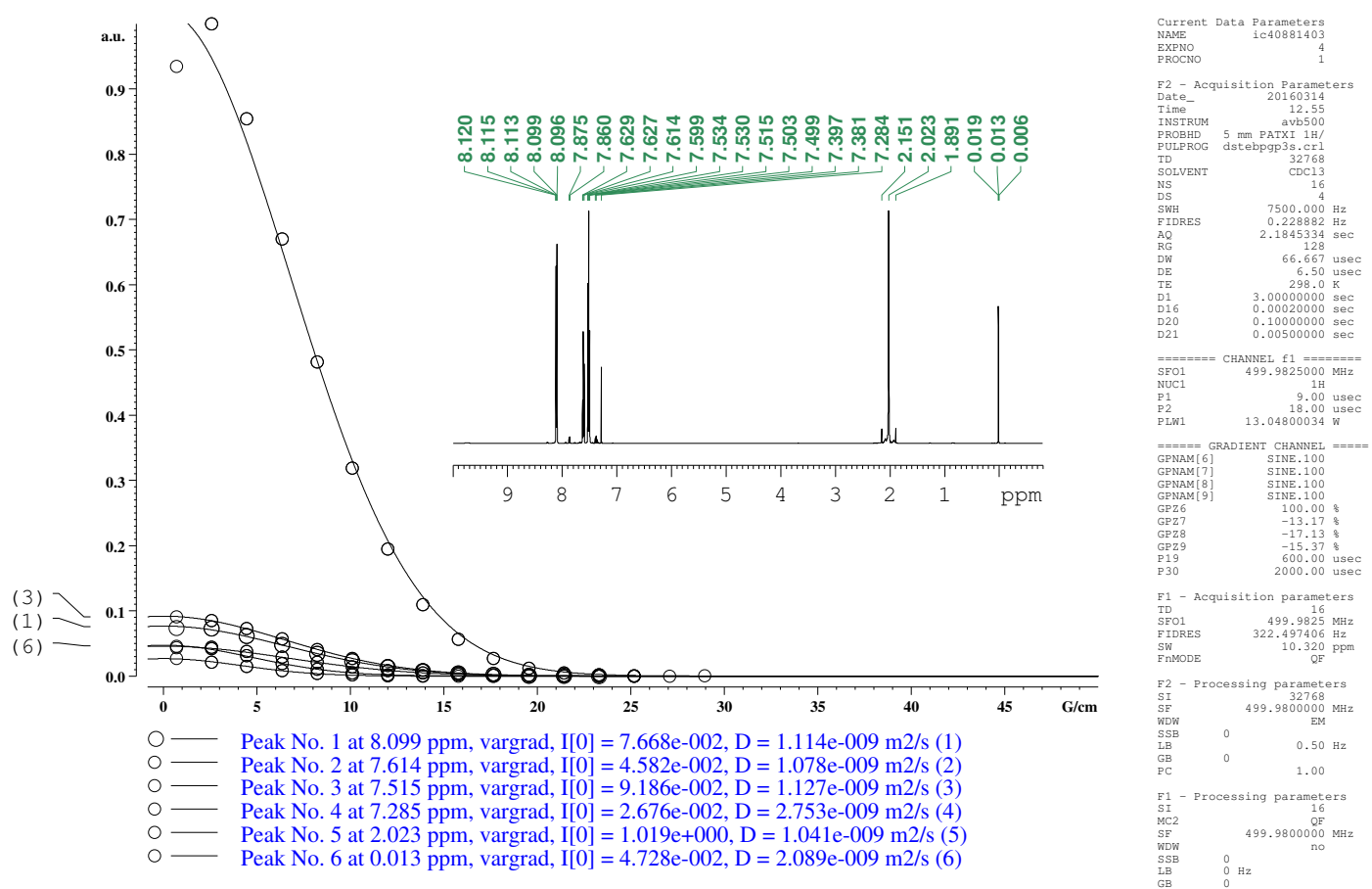
4.10. $\quad{ }^{1} \mathrm{H}$ DOSY and Diffusion coefficient of HFIP (3).

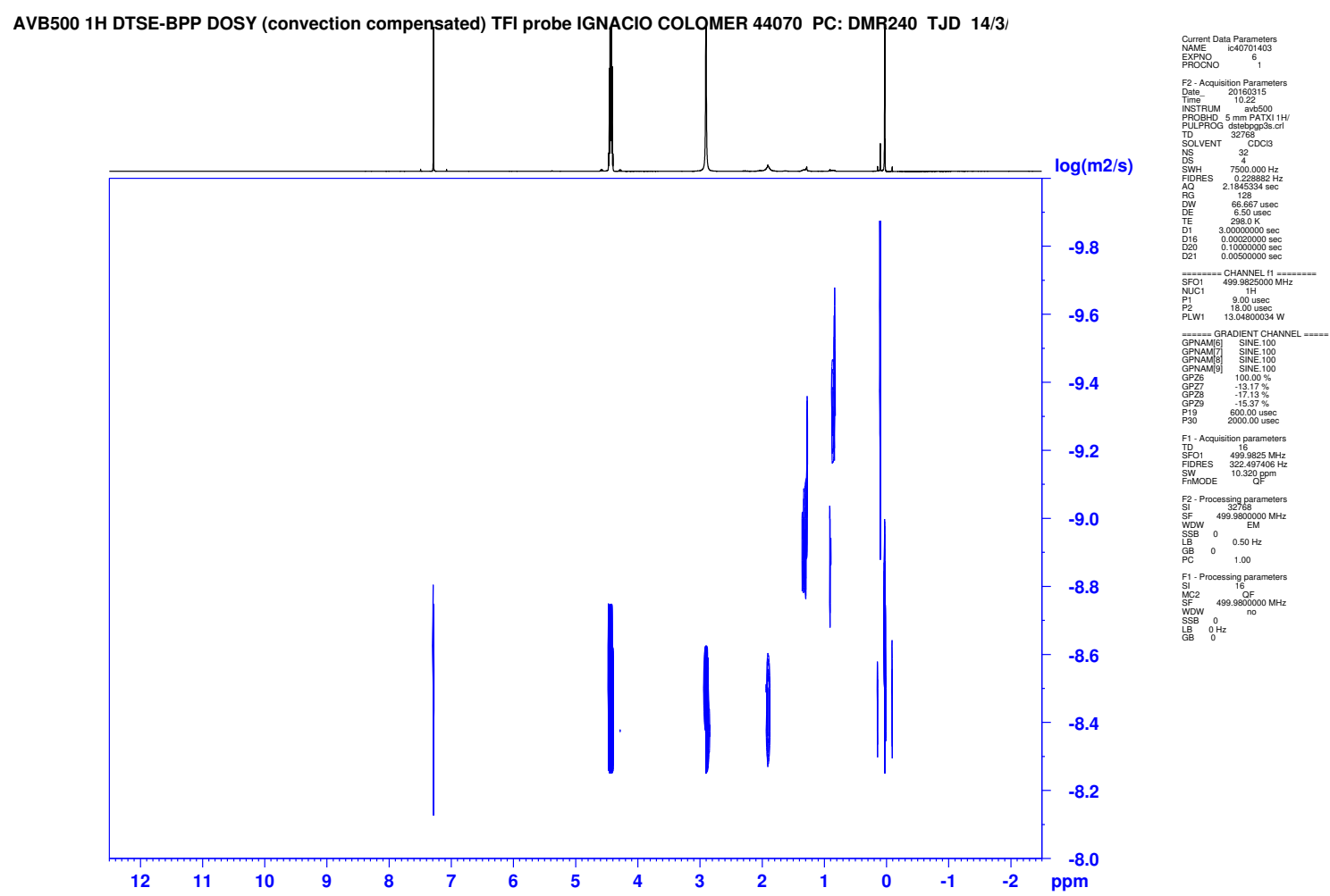

AVB500 1H DTSE-BPP DOSY (convection compensated) TFI probe IGNACIO COLOMER 44070 PC: DMR240 TJD 14/3/16 2-85\% gradient

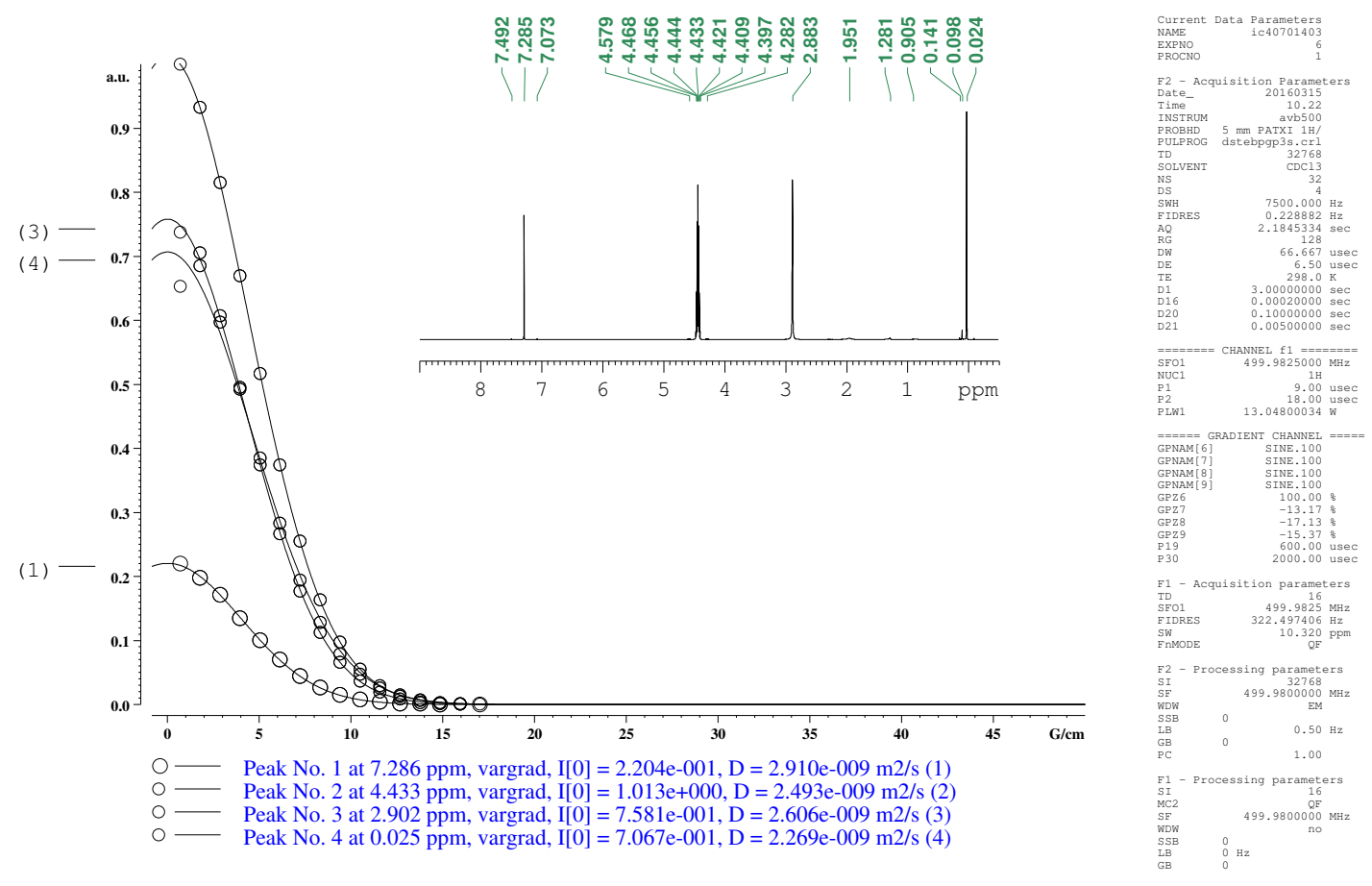


4.11. ${ }^{1} \mathrm{H}$ DOSY and Diffusion coefficient of a 1:1 mixture of HFIP:PIDA (5).

AVB500 1H DTSE-BPP DOSY (convection compensated) TFI probe IGNACIO COLOMER 44069 PC: DMR240 TJD 11/3/16
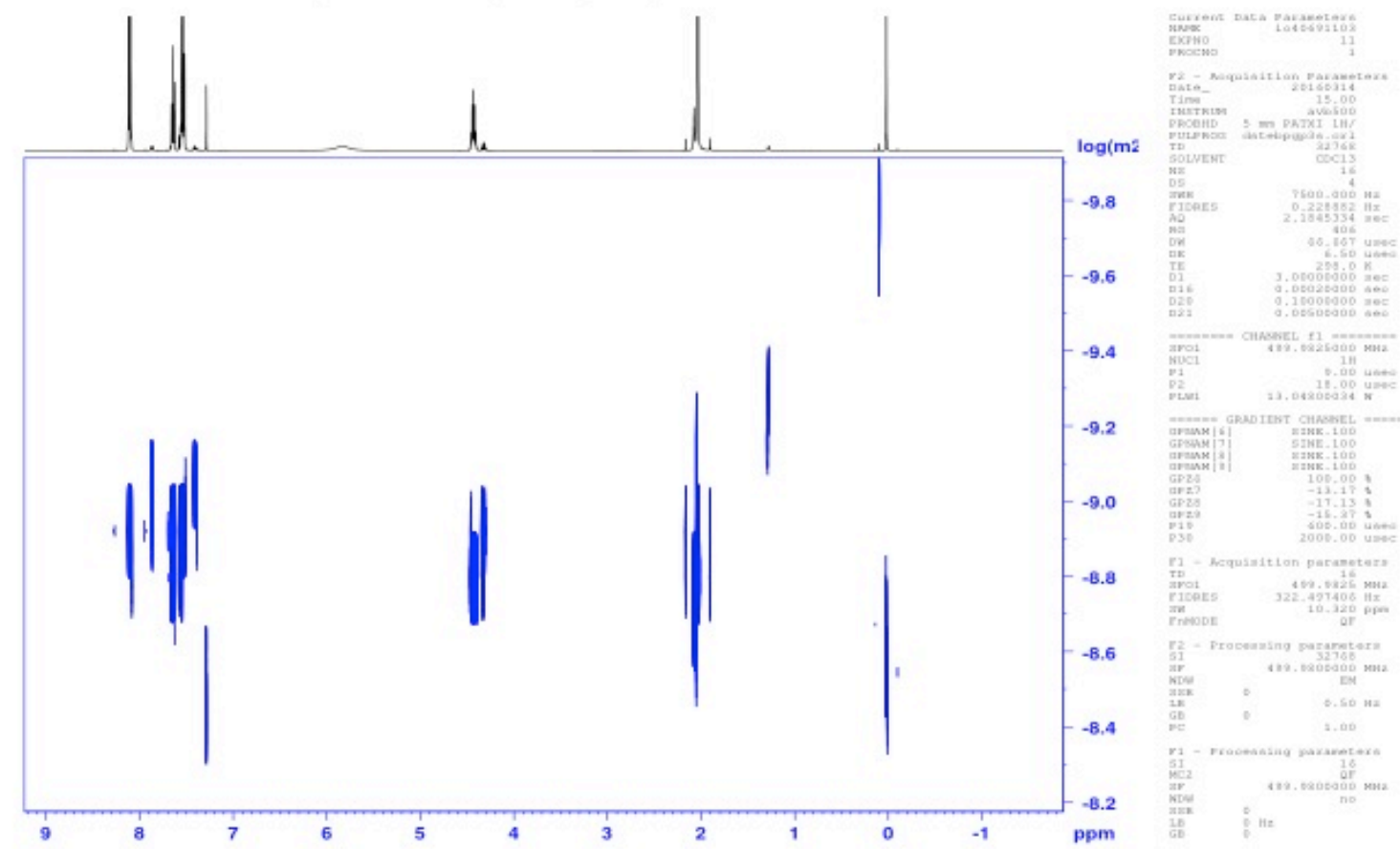

AVB500 1H DTSE-BPP DOSY (convection compensated) TFI probe IGNACIO COLOMER 44069 PC: DMR240 TJD 11/3/16
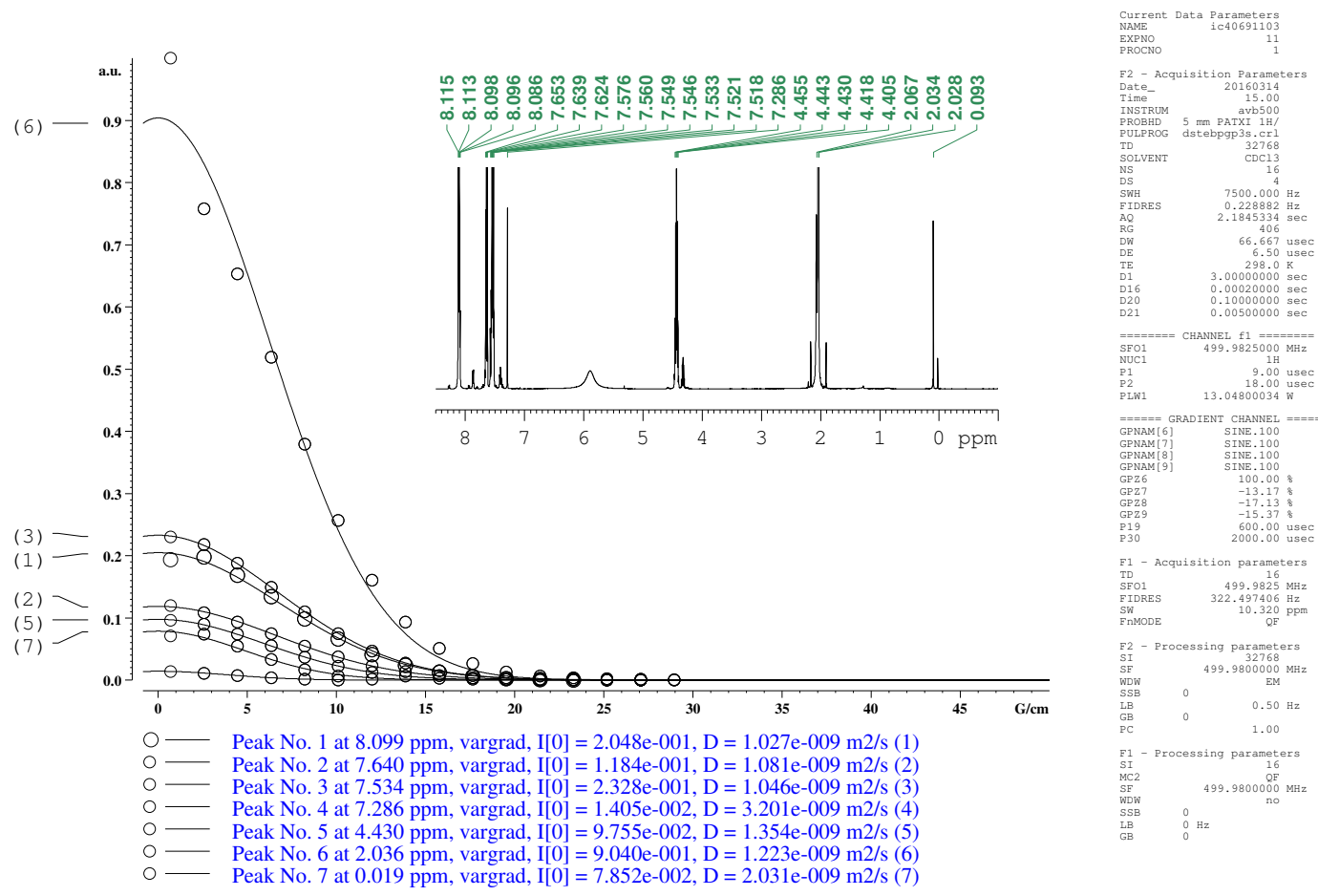


\subsection{DOSY and Diffusion coefficient of $i$-PrOH}

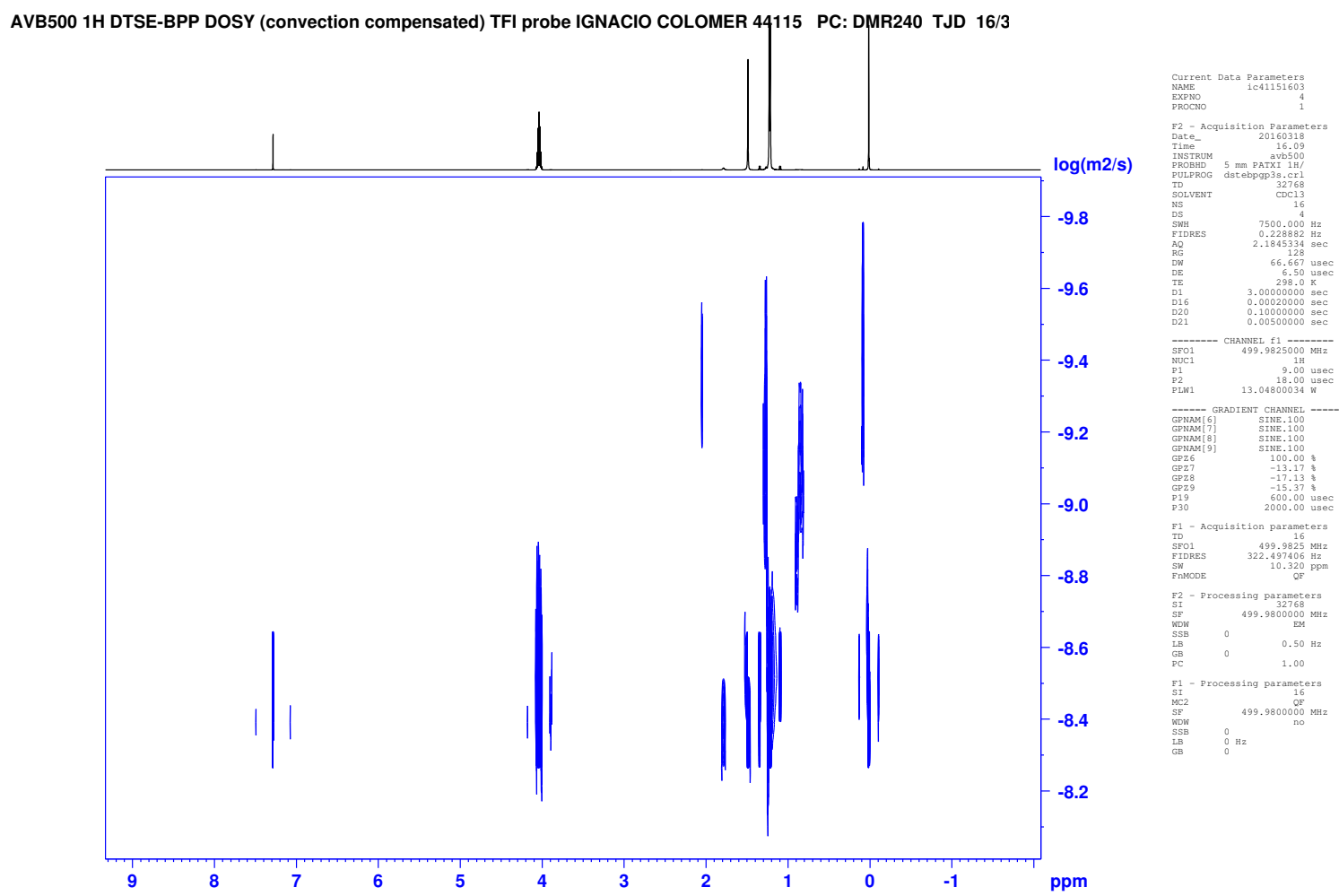

AVB500 1H DTSE-BPP DOSY (convection compensated) TFI probe IGNACIO COLOMER 44115 PC: DMR240 TJD 16/3/16

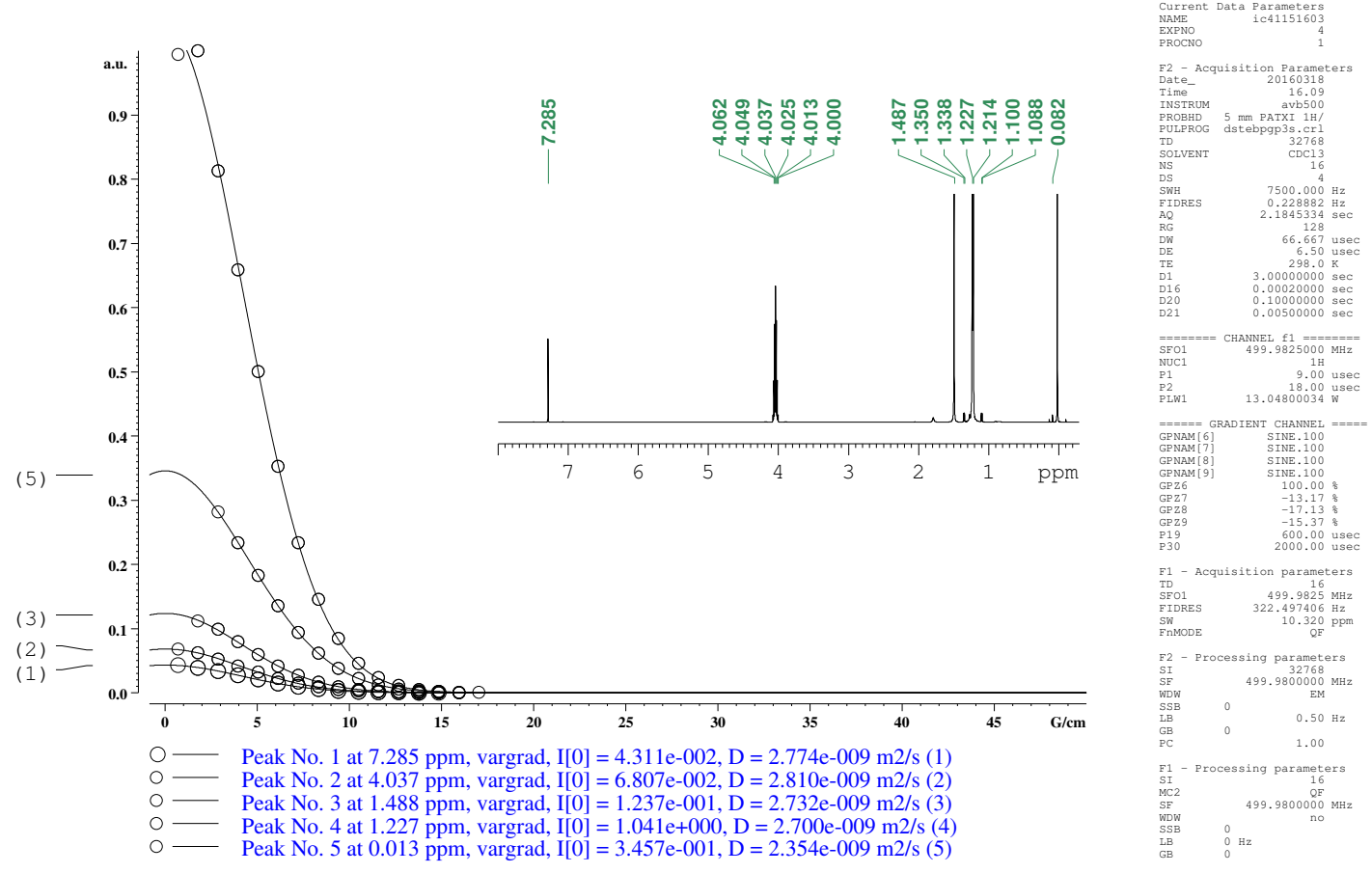


4.13. ${ }^{1} \mathrm{H}$ DOSY and Diffusion coefficient of a 1:1 mixture of $i$-PrOH:PIDA (18).
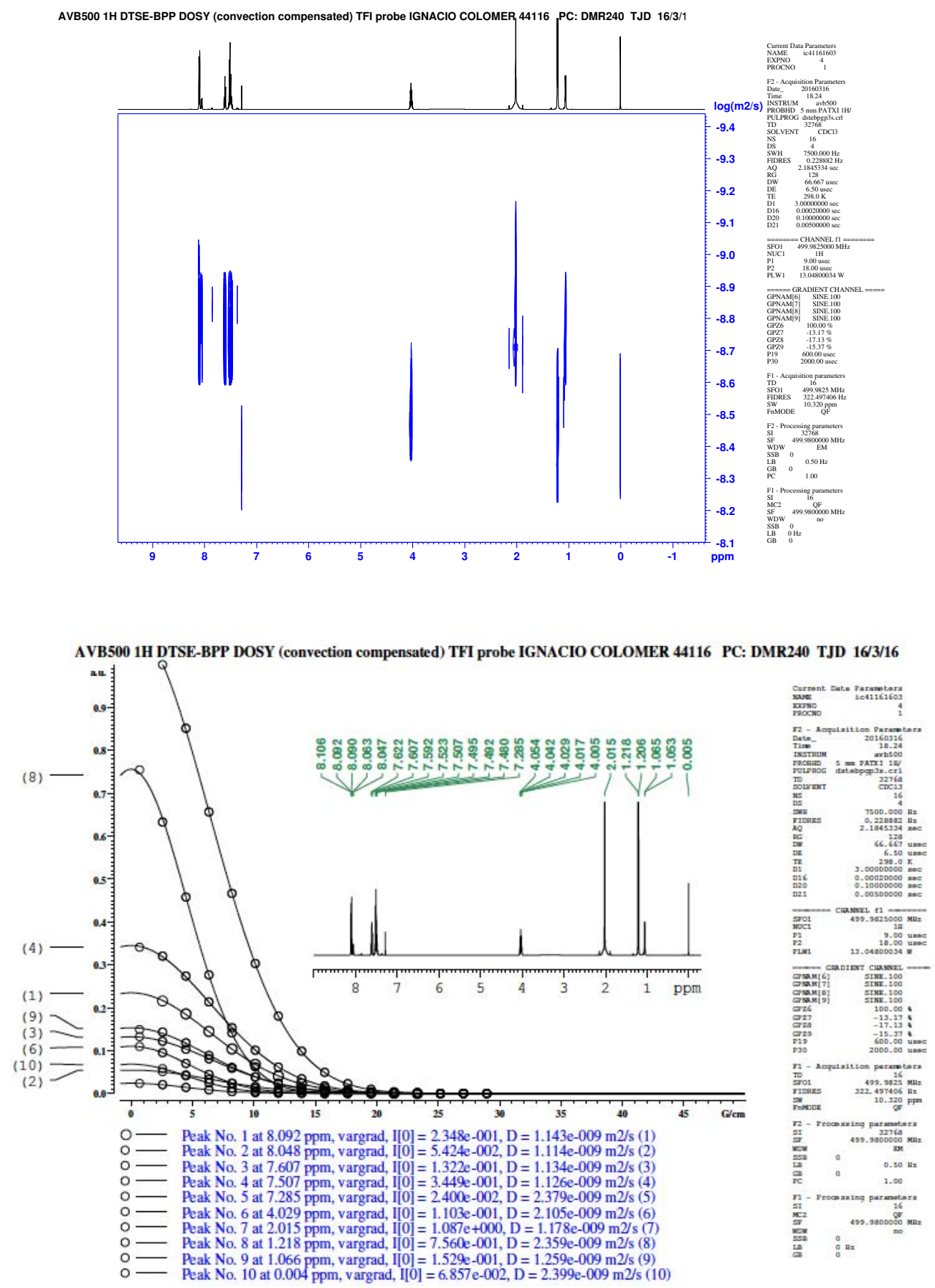

4.14. Table 1: Diffusion coefficients of PIDA (2), $i$-PrOH and the 1:1 mixture of PIDA: $i$ PrOH (18) in $\mathrm{CDCl}_{3}$ as measured via DOSY

\begin{tabular}{c|c|c} 
Compound & $D\left(10^{-9} \mathrm{~m}^{2} \mathrm{~s}^{-1}\right)$ & $D / D^{\mathrm{TMS}}$ \\
\hline TMS & 2.13 & 1.00 \\
$\mathbf{2}$ & 1.09 & 0.52 \\
$\boldsymbol{i}$-PrOH & 2.49 & 1.10 \\
$\mathbf{1 8}$ (PIDA) & 1.15 & 0.54 \\
$\mathbf{1 8}$ (i-PrOH) & 2.23 & 1.05
\end{tabular}




\subsection{5. ${ }^{1} \mathrm{H}$ DOSY and Diffusion coefficient of PIFA}

AVB500 1H DTSE-BPP DOSY (convection compensated) TFI probe IGNACIO COLOMER 44756 PC: DMR240 TJD 23/5
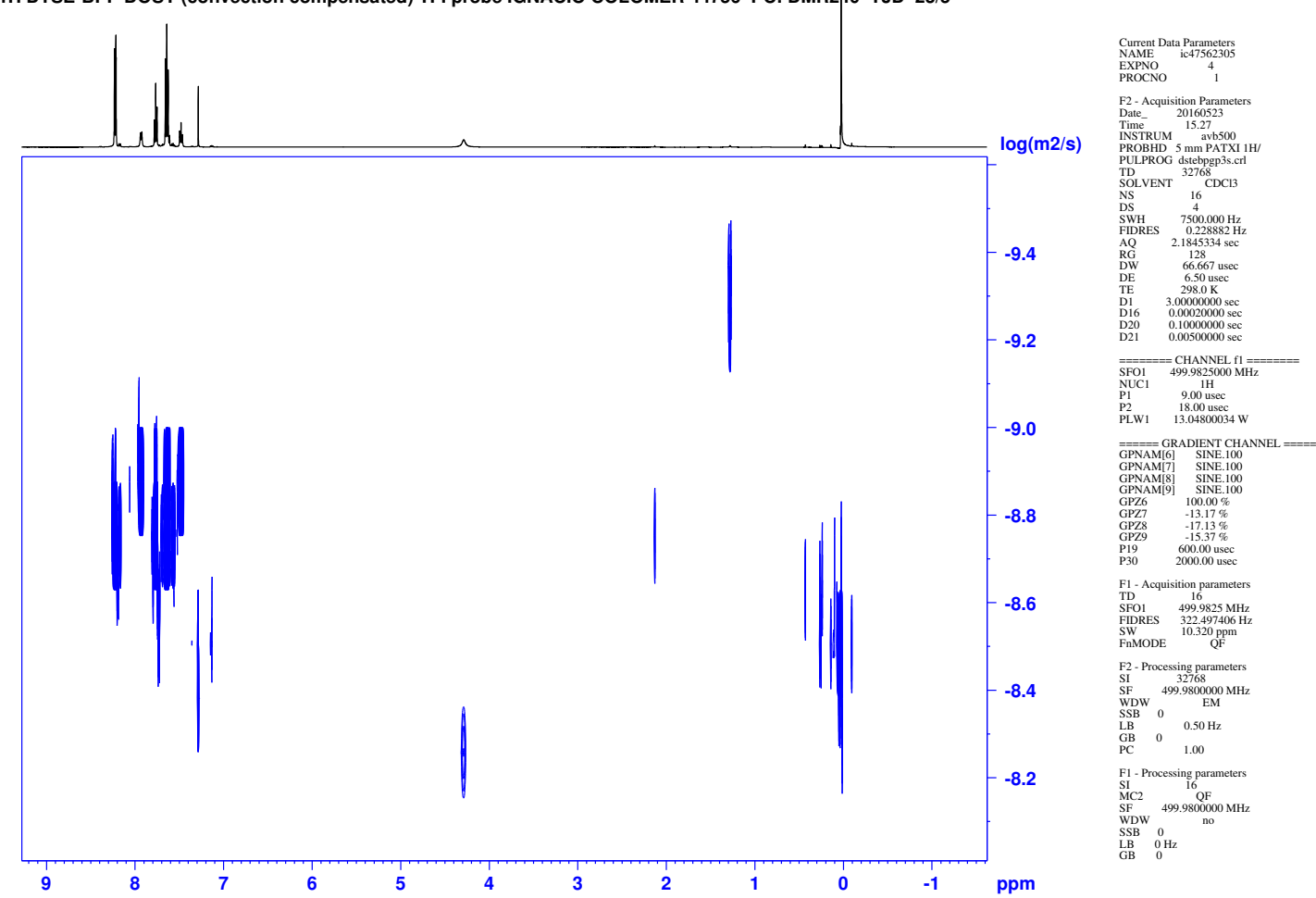

AVB500 1H DTSE-BPP DOSY (convection compensated) TFI probe IGNACIO COLOMER 44756 PC: DMR240 TJD 23/516
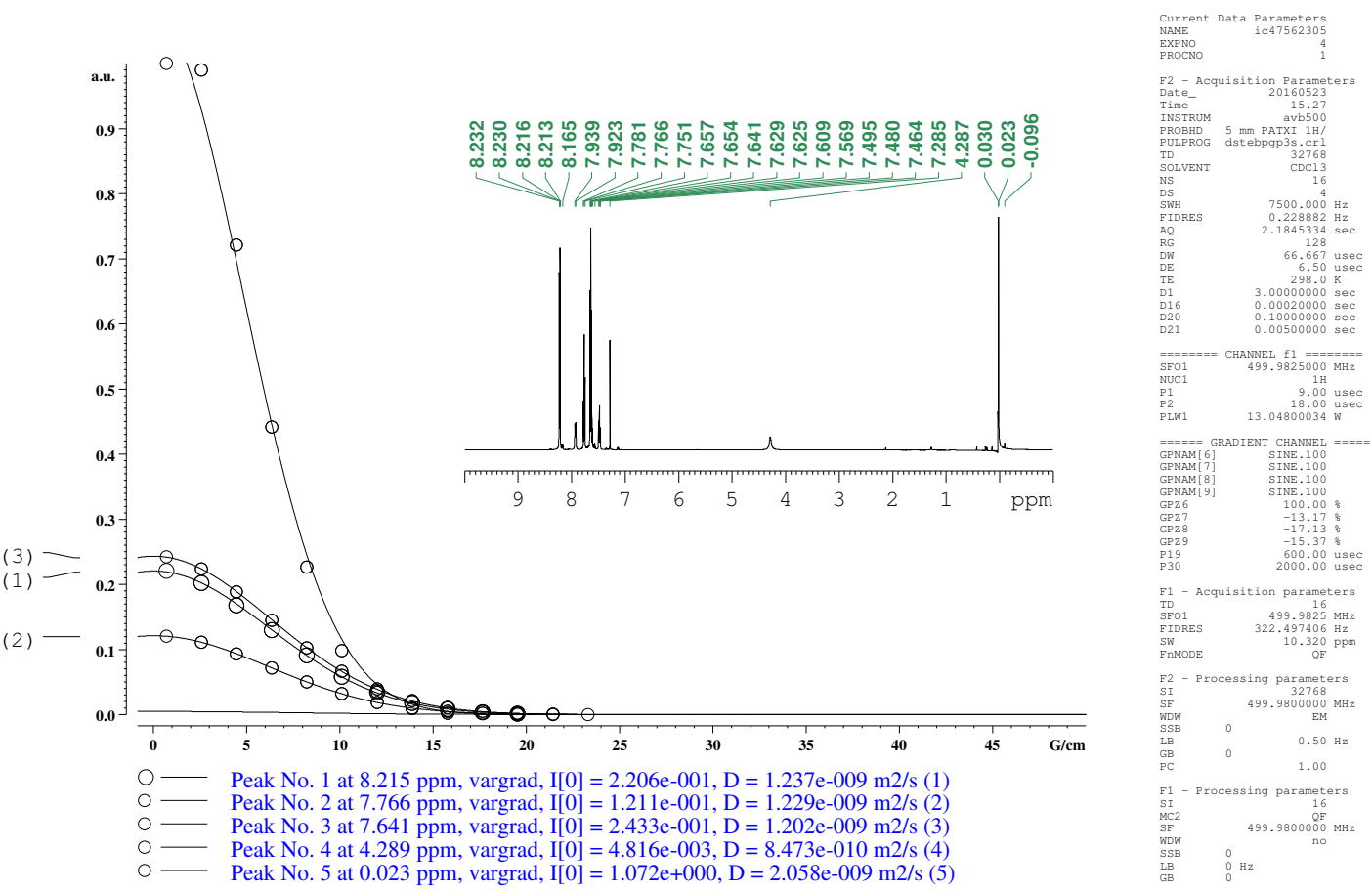
4.16. $\quad{ }^{1} H$ DOSY and Diffusion coefficient of a 1:1 mixture of HFIP:PIFA (16).

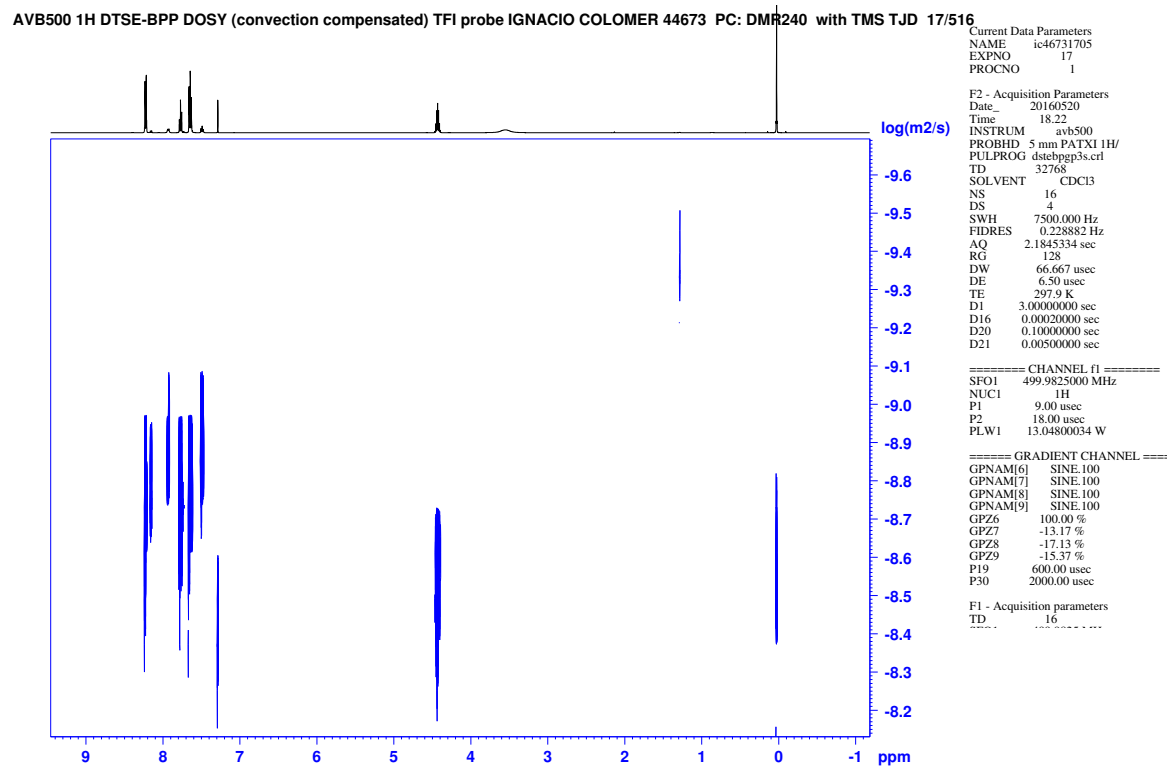

AVB500 1H DTSE-BPP DOSY (convection compensated) TFI probe IGNACIO COLOMER 44673 PC: DMR240 with TMS TJD $17 / 516$
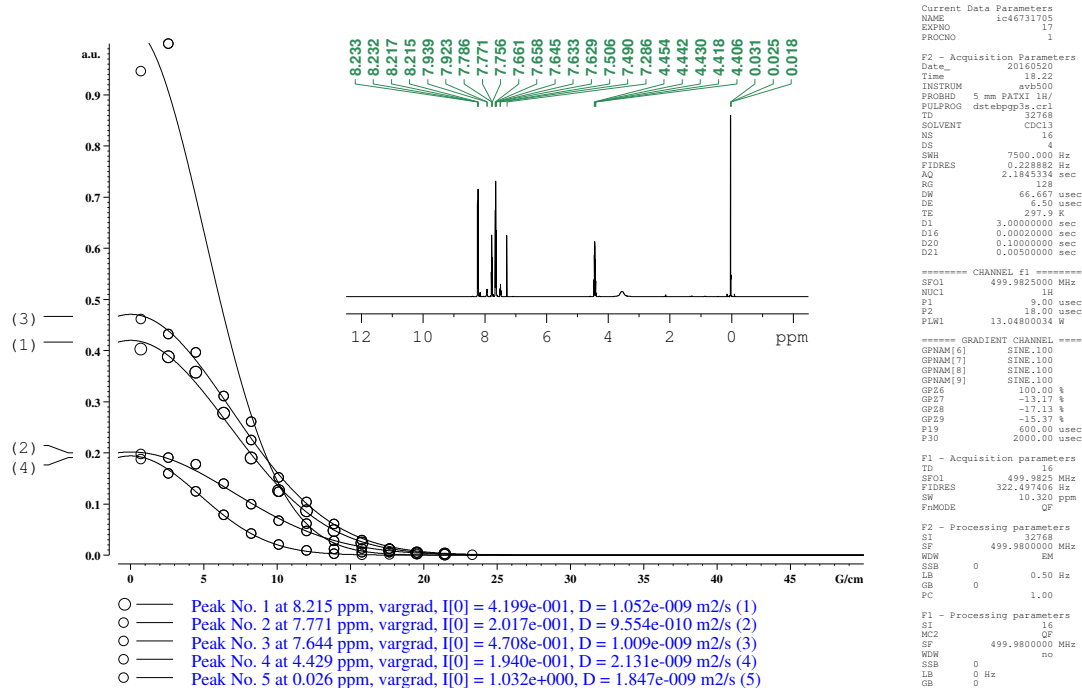

4.17. Table 2: Diffusion coefficients of PIFA, HFIP and the 1:1 mixture of PIFA:HFIP (16) in $\mathrm{CDCl}_{3}$ as measured via DOSY

\begin{tabular}{c|c|c} 
Compound & $D\left(10^{-9} \mathrm{~m}^{2} \mathrm{~s}^{-1}\right)$ & $D / D^{\mathrm{TMS}}$ \\
\hline TMS & 2.06 & 1.00 \\
HFIP & 2.49 & 1.10 \\
PIFA & 1.22 & 0.59 \\
16 (HFIP) & 2.10 & 1.05 \\
16 (PIFA) & 1.05 & 0.63
\end{tabular}




\subsection{8. ${ }^{1} \mathrm{H}$ DOSY and Diffusion coefficient of HTIB}

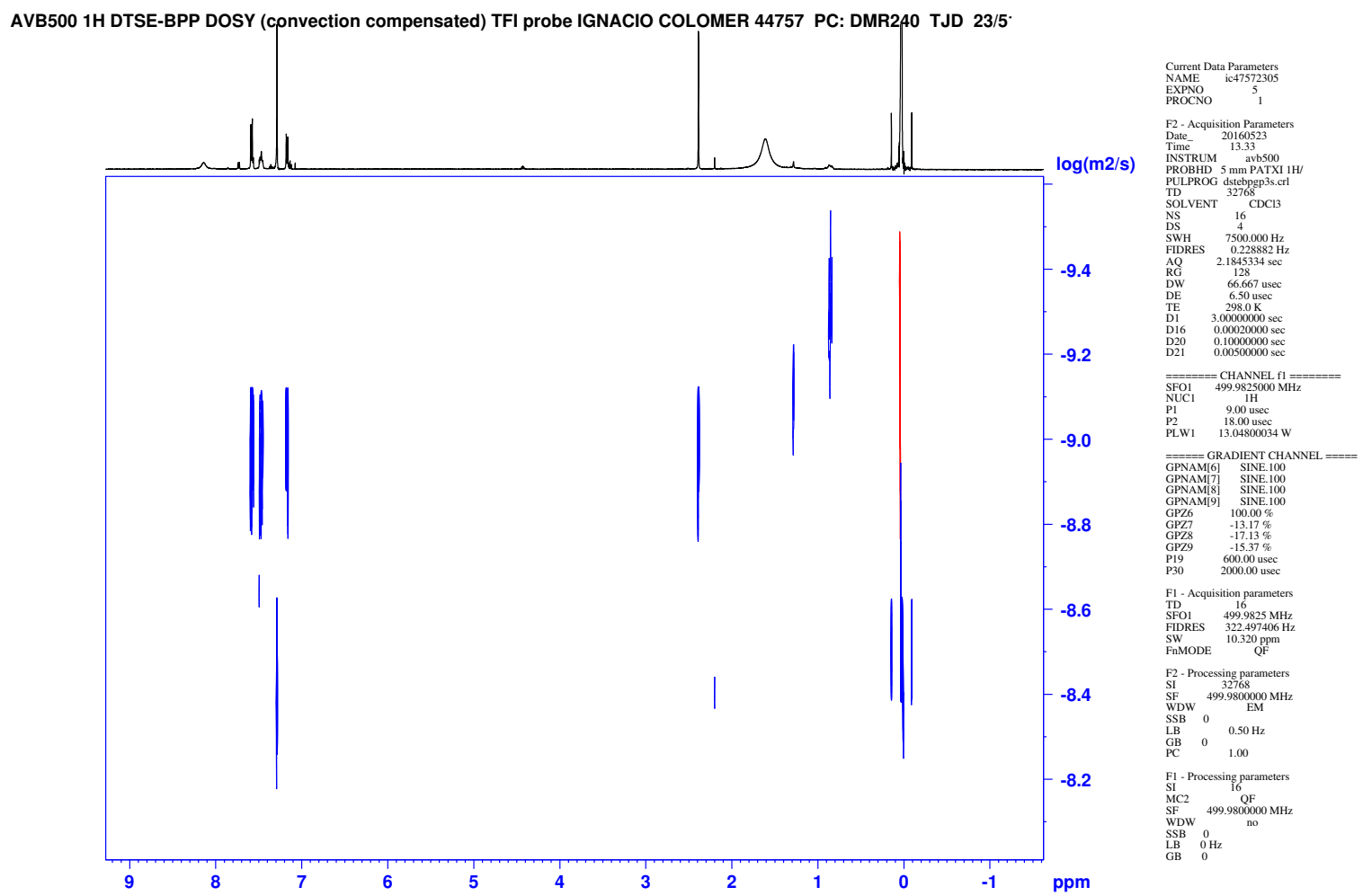

AVB500 1H DTSE-BPP DOSY (convection compensated) TFI probe IGNACIO COLOMER 44757 PC: DMR240 TJD 23/516
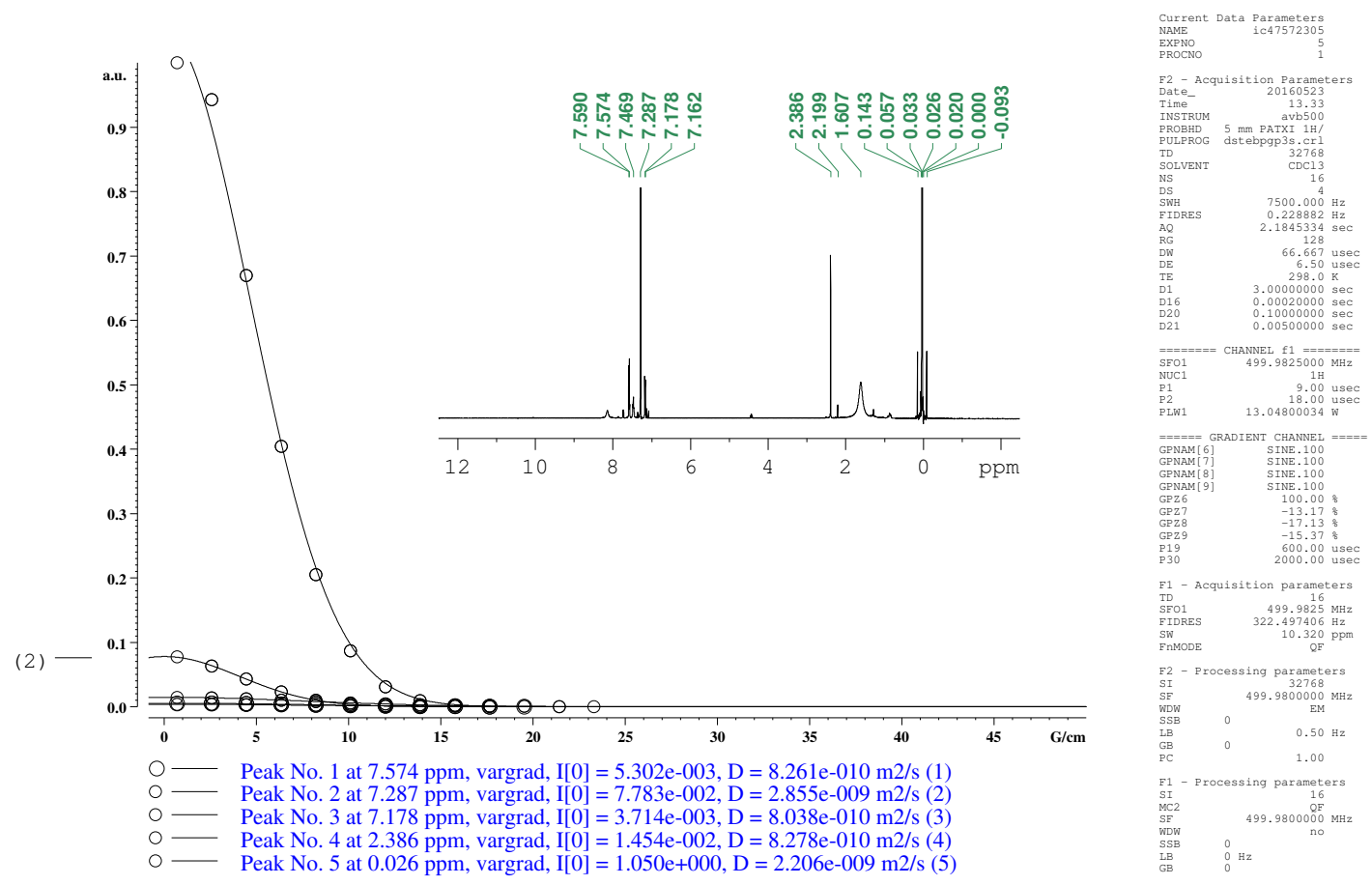
4.19. ${ }^{1} \mathrm{H}$ DOSY and Diffusion coefficient of a 1:1 mixture of HFIP:HTIB (17).

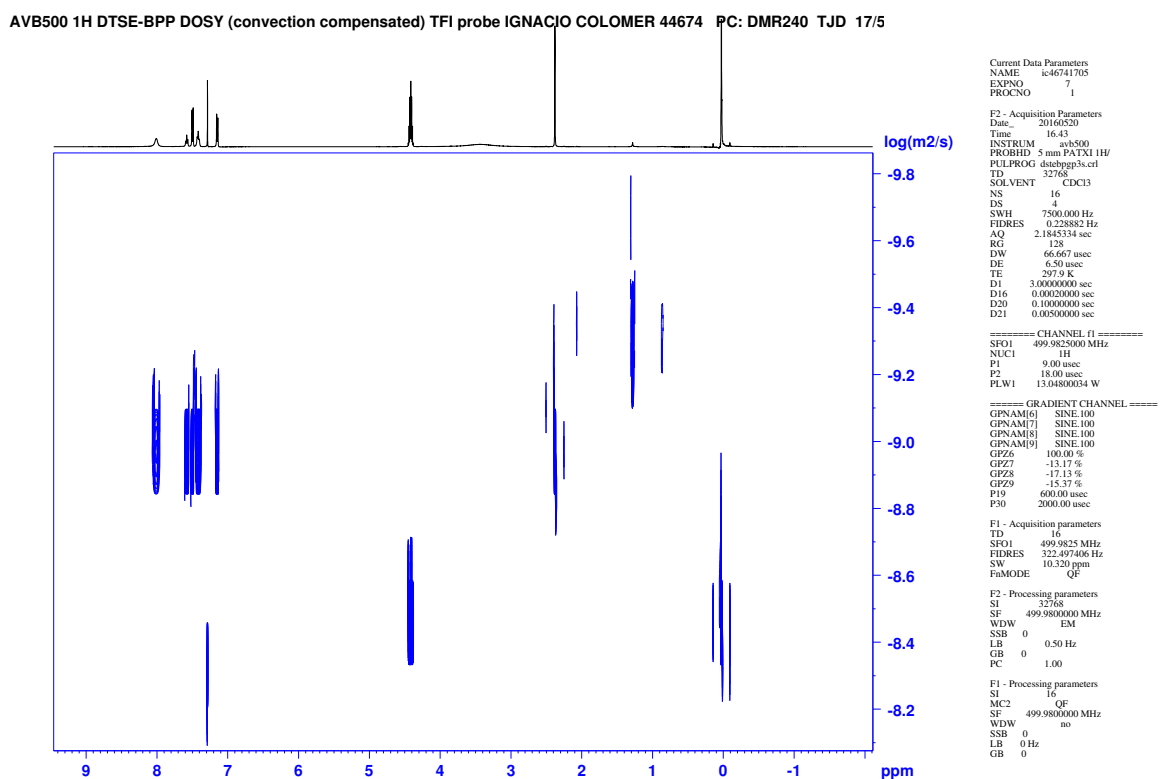

AVB500 1H DTSE-BPP DOSY (convection compensated) TFI probe IGNACIO COLOMER 44674 PC: DMR240 TJD 17/516

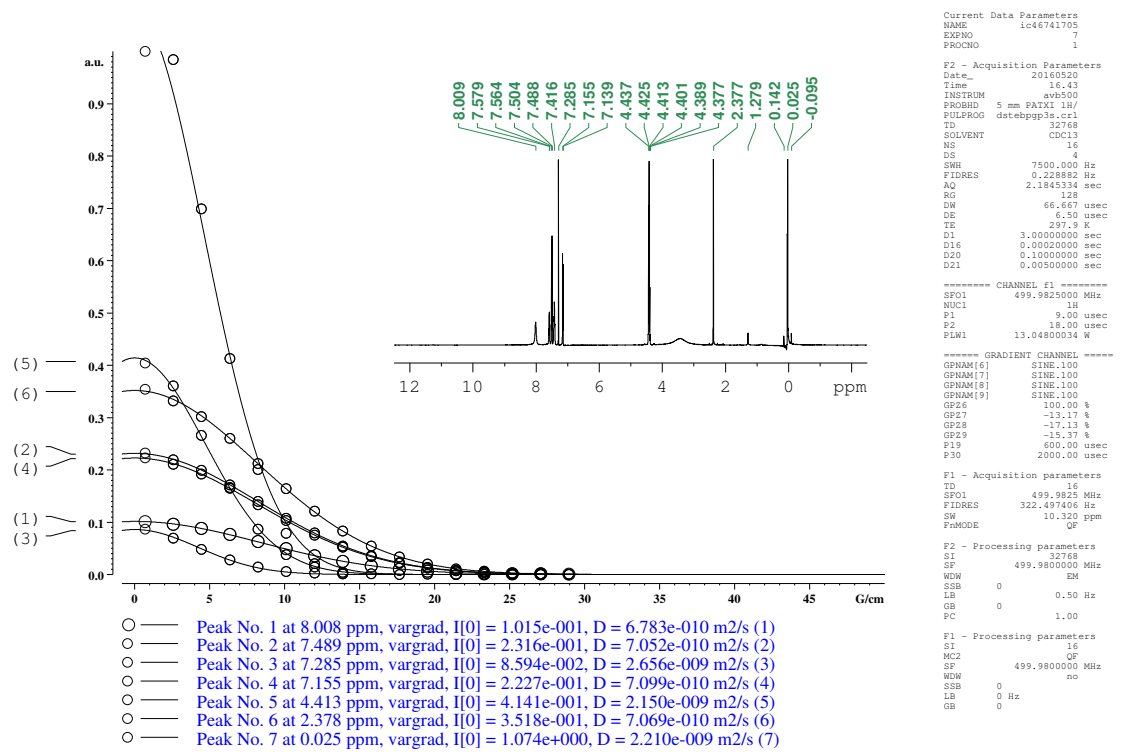

4.20. Table 3: Diffusion coefficients of HFIP, HTIB and the 1:1 mixture of HFIP: HTIB (17) in $\mathrm{CDCl}_{3}$ as measured via DOSY

\begin{tabular}{c|c|c} 
Compound & $D\left(10^{-9} \mathrm{~m}^{2} \mathrm{~s}^{-1}\right)$ & $D / D^{\mathrm{TMS}}$ \\
\hline TMS & 2.21 & 1.00 \\
HFIP & 2.49 & 1.10 \\
HTIB & 0.82 & 0.37 \\
$\mathbf{1 7}$ (HFIP) & 2.15 & 0.97 \\
$\mathbf{1 7}$ (HTIB) & 0.71 & 0.32
\end{tabular}




\section{References}

${ }^{1}$ Colomer, I.; Coura Barcelos, R.; Donohoe, T. J. Angew. Chem. Int. Ed. 2016, 55, 4748-4752. ${ }^{2} \mathrm{Yu}$, J.; Gaunt, M. J.; Spencer, J. B. J. Org. Chem. 2002, 67, 4627.

3 (a) Banks, C. E.; Compton, R. G. Understanding Voltammetry $2^{\text {nd }}$ Ed. 2010 World Scientific.

${ }^{4}$ (a) Guidelli, R.; Compton, R.G.; Feliu, J. M.; Gileadi, E.; Lipkowski, J.; Schmickler, W.; Trasatti, S. Pure Appl. Chem. 2014, 86, 245-258. (b) Guidelli, R.; Compton, R.G.; Feliu, J. M.; Gileadi, E.; Lipkowski, J.; Schmickler, W.; Trasatti, S. Pure Appl. Chem. 2014, 86, 259-262.

${ }^{5}$ Demaille, C.; Bard, A. J. Acta Chem. Scand. 1999, 53, 842-848. 